UNIVERSIDADE DE SÃO PAULO

INSTITUTO DE GEOCIÊNCIAS

\title{
ANÁLISE DA DISTRIBUIÇÃO ESTRATIGRÁFICA DE Corumbella werneri HAHN ET AL. 1982 (FORMAÇÃO TAMENGO, EDIACARANO): IMPLICAÇÕES TAFONÔMICAS E PALEOAMBIENTAIS
}

Cleber Quidute Clemente Diniz

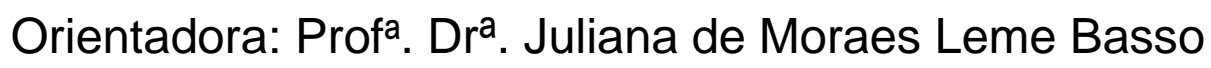

DISSERTAÇÃO DE MESTRADO

Programa de Pós-Graduação em Geoquímica e Geotectônica

São Paulo 
ANÁLISE DA DISTRIBUIÇÃO ESTRATIGRÁFICA DE Corumbella werneri HAHN ET AL. 1982 (FORMAÇÃO TAMENGO, EDIACARANO): IMPLICAÇÕES TAFONÔMICAS E PALEOAMBIENTAIS

Dissertação apresentada ao Instituto de Geociências da Universidade de são Paulo, como parte dos requisitos para obtenção do grau de Mestre em Geociências.

Área de concentração: Geotectônica

Orientadora: Profa. Dra. Juliana de Moraes Leme Basso.

São Paulo 
Autorizo a reprodução e divulgação total ou parcial deste trabalho, por qualquer meio convencional ou eletrônico, para fins de estudo e pesquisa, desde que citada a fonte.

Ficha catalográfica preparada pelo Serviço de Biblioteca e Documentação do Instituto de Geociências da Universidade de São Paulo

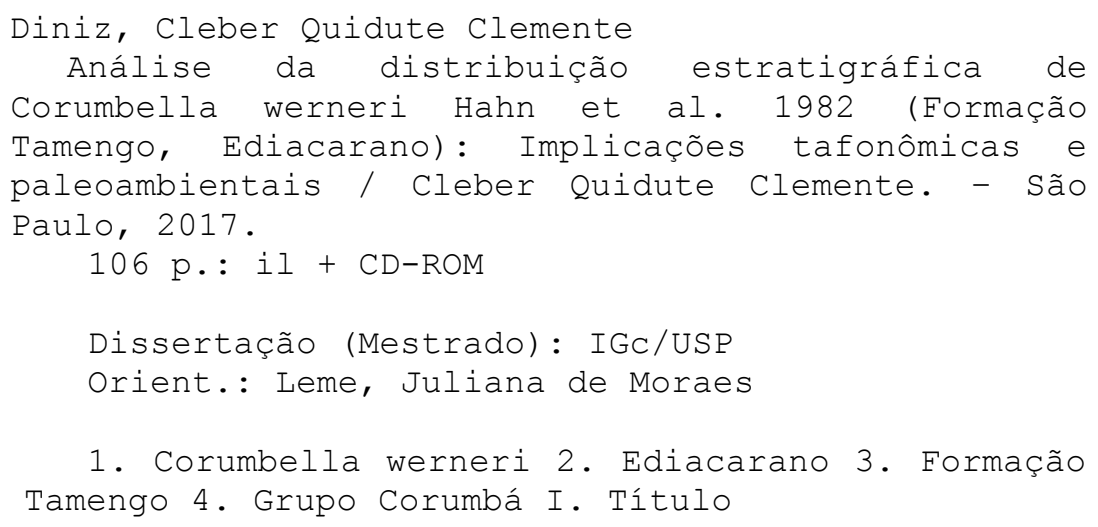




\section{AGRADECIMENTOS}

Agradeço,

A Prof ${ }^{\mathrm{a}}$ Juliana de Moraes Leme, pelos ensinamentos, pela orientação, pelo exemplo de que um grande profissional é capaz de ter uma vida pessoal e principalmente por ter dado oportunidade a alguém sem histórico, obrigado por ter acreditado em mim.

Aos órgãos de fomento CAPES e FAPESP e ao Programa de Pós-graduação em Geoquímica e Geotectônica IGc/Usp, pela bolsa de mestrado e ter auxiliado nos projetos que fizeram parte do desenvolvimento dessa pesquisa.

Ao Profo Paulo César Bogianni, pelas aulas particulares em campo, discussões e que sem o auxílio essa pesquisa não teria se completado.

Ao Profo ${ }^{\circ}$ Thomas Fairchild, por me dar um rumo através de sua vasta referência.

Ao Prof ${ }^{\circ}$ Paulo Eduardo de Oliveira por me direcionar as discussões deste trabalho.

Ao Prof ${ }^{\circ}$ Carlos Bicudo por ter me cedido seu tempo e atenção

A Profa Nair Sumie Yokoya do Instituto de Botânica por elucidar questões que fizeram crescer e implementar este trabalho.

A Ivone Cardoso, por me direcionar enquanto estagiário no laboratório de coleção cientifica de Paleontologia, dicas, auxilio e por sempre torcer por mim.

Ao $\mathrm{Dr}^{\circ}$ Isaac Jamil Sayeg, por me proporcionar imagens de excelente qualidade para que meu trabalho estivesse em ótimas condições e pelas discussões que abriram minha mente.

A Dr ${ }^{a}$ Cibele Voltani Poioiovsk, pelo empréstimo do equipamento para preparação do material.

Aos funcionários do IGc/USP, que me auxiliariam com toda atenção e foram prestativos a resolverem minhas questões pertinentes durante meu processo de trabalho. 


\section{DEDICATÓRIA}

Dedico,

Aos orixás, mentores espirituais e a espiritualidade, por sempre cuidarem de mim e me tornarem apto a superar as provações da vida.

A minha Família de sangue, alma e coração, minha mãe Claudia que me inspira em força e superação, meu pai Clélio que me mostra que nunca é tarde para mudar e minha irmã Caren que me instrui sobre o que é ter coragem.

Ao meu namorado Carlos, por me ensinar que a generosidade é uma dádiva, me dar muito amor e me presentear com um relacionamento no qual existe um desenvolvimento mútuo.

Aos meus amigos de longa data Giulianna, por me mostrar as diversas formas de amor e despertar os melhores sentimentos que há em mim. A Nathalia, por me demonstrar que se arrepender e reconhecer te faz uma pessoa iluminada. Ao Peu, por me dizer que não é errado ser quem você é. A Ivone por me orientar a ter algo pelo que lutar e tentar fazer um mundo melhor. A Bruna por me ajudar a perseguir os meus sonhos. A Mônica por me educar que com amor a profissão você se torna o maior especialista. A Marta por me mostrar que mudanças sempre são para melhores. Tenho orgulho do que nos tornamos.

As novas amizades que fiz no decorrer dessa jornada, ao Andrés por me mostrar que amizade franca e verdadeira não são as mais longas. A Maria por me mostrar um mundo novo. A Dory por transbordar de carinho e me dar um pouquinho. A Fernanda por aguentar meus desabafos e acalmar meu coração. A Aline pelo suporte e amor que me enviou nos momentos desesperadores.

Obrigado. 
"Aprenda com o passado, que assim entenderá o presente"

Vô Camilo de Aruanda 


\section{RESUMO}

Fósseis de Corumbella werneri, cnidário Ediacarano com carapaça biomineralizada são encontrados em pelitos da Formação Tamengo, Grupo Corumbá (MS). Este trabalho teve como objetivos analisar a distribuição estratigráfica de detalhe de Corumbella werneri nessa formação, correlacionar a distribuição estratigráfica às características tafonômicas desses fósseis e estabelecer condições paleoecológicas e paleoambientais, a partir das análises estratigráficas e tafonômicas. Foram analisadas 160 amostras de mão. Para realização da descrição e identificação dos fósseis foram realizadas imagens digitais e em Microscopia Eletrônica de Varredura, medições de características morfológicas e análises químicas através da Espectroscopia de Energia Dispersiva. Para a realização da análise tafonômica básica, foram utilizadas algumas assinaturas tafonômicas como fragmentação, grau de empacotamento e preservação da carapaça. Foi realizada a medição centímetrica das seções pelíticas estudadas e efetuou-se a descrição de fácies sedimentares, estruturas sedimentares, granulometria e conteúdo fossilífero. Foi observado que as ocorrências de Corumbella werneri são na parte pelítica e mais concentradas na base da Formação Tamengo. A ocorrência em determinados níveis estratigráficos onde apresentam abundância de carapaças de $C$. werneri, pode ser provavelmente, explicada por variações ambientais, como a variação na taxa de sedimentação que eventualmente, proporcionava condições para a preservação das carapaças. A análise estratigráfica de detalhe também permitiu observar as associações de $C$. werneri com outros organismos e com icnofósseis que também aparecem de forma isolada como estruturas sedimentares circulares de provável origem bioinduzida, estruturas fragmentadas, possível estrutura basal, além de macroalgas, vendotaenídeos e icnofósseis. Com esses registros pode-se dizer que a paleodiversidade da Formação Tamengo é maior do que se pensava anteriormente. Essas associações podem evidenciar correlações paleoecológicas e paleoambientais. Dois grupos tafonômicos distintos de C. werneri foram interpretados. O grupo 1, representado por indivíduos incompletos, apresentariam um ambiente deposicional com aumento da taxa de sedimentação, capaz de preservar o corpo em uma forma mais completa e, em alguns casos, preservar a carapaça de forma tridimensional. $\mathrm{O}$ grupo 2, caracterizado por indivíduos fragmentados, apresentam um ambiente com baixa energia e baixa taxa de sedimentação, resultando em um maior tempo de 
exposição do organismo no substrato, causando a fragmentação das carapaças. Amostras apresentando os dois grupos tafonômicos podem indicar mistura temporal resultando em uma registro intra-habitat no qual várias gerações de uma espécie se preservam em uma mesmo registro fossilífero devido à baixa taxa de sedimentação. A ocorrência de $C$. werneri exclusivamente nos pelitos, enquanto, Cloudina lucianoi apenas nas camadas de calcário, indica que provavelmente habitaram ambientes diferentes, ou pelo menos o modo e a capacidade de preservação das carapaças deveriam ser distintos. A associação de $C$. werneri juntamente com macroalgas e a presença de Paraconularia $s p$. podem indicar condições de águas mais rasas, ainda em zona fótica. Esses novos dados mostram que, talvez, mesmo ocorrendo em pelitos, indicando deposição em águas calmas, seria possível que $C$. werneri tivesse condições paleoecológicas de habitat desde águas mais rasas, acima do nível de base de ondas de tempestades até mesmo, mais profundas. No entanto, os níveis de ocorrência e de maior abundância de $C$.werneri devem estar associados a momentos de aumento na taxa de sedimentação e deposição de partículas finas, em substrato abaixo do nível de base de ondas de tempestades.

Palavras chave: Corumbella werneri, Cnidaria, Ediacarano, Formação Tamengo, Grupo Corumbá, tafonomia, paleoecologia, paleoambiente, macroalgas, icnofósseis. 


\begin{abstract}
\end{abstract}
Analysis of the stratigrahphic distribution of Corumbella werneri Hahn et al. 1982 (Tamengo Formation, Ediacarano): Tafonomic and paleo-environmental implications.

Fossils of Corumbella werneri, Ediacaran cnidarian with biomineralized carapace are found in pelite of the Tamengo Formation, Corumbá Group (MS). The objective of this work was to analyze a stratigraphic distribution of Corumbella werneri in this Formation, to correlate the stratigraphic distribution to the taphonomic characteristics of fossils and to establish paleoecological and paleoenvironmental conditions, based on the stratigraphic and taphonomic analyzes. A total of 160 hand samples were analyzed. For the description and identification of fossils, digital images and scanning electron microscopy, measurements of morphological characteristics and chemical analyzes using Dispersive Energy Spectroscopy were performed. To perform the basic taphonomic analysis, taphonomic signatures was adopted, such as fragmentation, degree of packing and carapace preservation. A centimeter measurement of the pelitie sections was done and a description of sedimentary facies, sedimentary structures, granulometry and fossiliferous content was made. It was observed that the occurrences of Corumbella werneri are in the pelite part and more concentrated in the base of the Tamengo Formation. The occurrence at certain stratigraphic levels where an abundance of $C$. werneri carapaces can be explained by environmental variations as a change in the sedimentation rate that eventually, provides conditions for a preservation of the carapaces. The stratigraphic analysis of detail also allowed to observe a correlation of $C$. werneri with other organisms and with icnofósseis that also appear isolated, like a sedimentary structures in circular form of probable bio-induced origin, fragmented structures, possible basal structure, macroalgae, vendotaenídeos and icnofósseis. With these records, it can be said that the paleodiversity of the Tamengo Formation is greater than previously thought. These associations can show paleoecological and paleoenvironmental correlations. Two distinct taphonomic groups of $C$. werneri were interpreted. Group 1, represented by incomplete individuals, interpreted a deposited environment with increased sedimentation rate, capable of preserving the body in a more complete form and, in some cases, preserving a threedimensional shape carapace. Group 2, characterized by having fragmented individuals, presents in an environment with low energy and low sedimentation rate, resulting in a longer exposure time of the organism in the substrate, causing 
fragmentation of the carapaces. Samples showing the two taphonomic groups results an intra-habitat record when multiple genarations of species preserved in a single fossil record due to the low sedimentation rate. The occurrence of $C$. werneri exclusively in the pelitics, while, Cloudina lucianoi only in the layers of limestone, indicates that they inhabited different environments, or at least the way and capacity of preservation of the carapaces should be different. An association of $C$. werneri with macroalgae and a presence of Paraconularia sp. may indicate shallower water conditions, still in the photic zone. These new data show that even $C$. werneri occurring in pelitcs, indicating deposition in calm waters, it would be possible to have paleoecological conditions of habitat from shallower waters, above the base level of waves of thunderstorms or even deeper. However, C. werneri occurrence levels and greater abundance are associated with growth times in sedimentation rate and fine particle deposition in substrate below the storm level.

Key-words: Corumbella werneri, Cnidaria, Ediacaran, Tamengo Formation, Corumbá Group, taphonomy, paleoecology, paleoenvironment, macroalgae, ichnofossils. 


\section{LISTA DE FIGURAS}

Figura 1.1: Diorama do conjunto de Avalon com alguns de seus representantes, imagem meramente ilustrativa. (A) Charnia masoni, (B) Espécime com fronde, (C) Fractofus misrai, (D) Aspidella terranovica, (E) Bradgatia linfordensis. Modificado de (Clapham \& Narbonne, 2002; Clapham et al., 2003). 20

Figura 1.2: Diorama do conjunto de White Sea com alguns de seus representantes, imagem meramente ilustrativa. (A) Tribachidium heraldicum, (B) Charniodiscus concentricus, (C) Dickinsonia sp., (D) Kimberella waggoneri. Modificado de (Clapham \& Narbonne, 2002; Clapham et al., 2003).

Figura 1.3: Diorama do conjunto de Nama com alguns de seus representantes, imagem meramente ilustrativa. (A) Ernietta plateauensis, (B) Swartpuntia germsi. Modificado de (Clapham \& Narbonne, 2002; Clapham et al., 2003).

Figura 1.4: Reconstituição de Corumbella werneri, segundo Hahn et al., 1982, apresentando as duas regiões, a proximal unisseriada com pólipos primários, e a distal bisseriada com pólipos secundários.

Figura 1.5: Reconstituição de Corumbella werneri como organismos bentônicos coloniais, fixados em uma "massa orgânica", conforme sugerido por Babcock et al. (2005).

Figura 1.6: Reconstituição de estruturas morfológicas em Corumbella werneri. (A) reconstituição da região oral e (B) com o respectivo fóssil. (C) detalhe para o septo. (D) Modelo geral tridimensional para uma porção em seção transversal, $(E)$ detalhe da borda lateral e linha mediana. (F) Região aboral unisseriada, $(G)$ representação dessa região. $(H)$ Inserção incerta da região aboral. Escala: $1 \mathrm{~mm}$. Retirado de Pacheco (2012). 26

Figura 2.1: Mapa geológico de Mato Grosso do Sul com enfoque ao Grupo Corumbá, retirado de Van inte et al. (2016) e Parry et al. (submetido). .30

Figura 2.2: Coluna estratigráfica do Grupo Corumbá 1: formações do Grupo Corumbá, 2: detalhe da Fm. Tamengo, 3: correlação do topo da Fm. Tamengo na Mina Corcal. Modificada de Van Iten et al. (2016) e Parry et al. (submetido).

Figura 2.3: Mapa geográfico da cidade de Corumbá e Ladário com os respectivos pontos aflorantes da Fm. Tamengo. Marcados da direita para esquerda P1, P2, P3, P4, Pontos no Porto Sobramil e Pontos da Mina Corcal. .34

Figura 2.1: Relação das fácies encontradas na Formação Tamengo. Retirado de Boggiani (1998). .35

Figura 4.1: Seção P1 da base da Formação Tamengo. A: Imagem completa da seção. B: Detalhe da Seção apresentando calcário e ritmitos. 
Figura 4.2 Seção estratigráfica do pacote de pelito - P1 da base da exposição da Formação Tamengo. Unidade de medida da Seção em $\mathrm{cm}$.

Figura 4.3: Seção estratigráfica P2, parte inferior da Formação Tamengo. A: Imagem completa da seção. B: Detalhe da Seção apresentando o calcário e estrutura sedimentar estilo hummocky.

Figura 4.4: Seção do pacote de pelito - P2 exposto em Ladário subsequente a P1 da Formação Tamengo. Unidade de medida da Seção em $\mathrm{cm}$.

Figura 4.5: Seção P3, parte inferior da Formação Tamengo. A: Imagem completa da seção. B: Detalhe da Seção apresentando ritmitos.

Figura 4.6: Seção estratigráfica do pacote de pelito - P3 em Ladário subsequente a P2 da Formação Tamengo. Unidade de medida da Seção em $\mathrm{cm}$.

Figura 4.7: Seção P4, parte intermediária da Formação Tamengo. A: Imagem ampla da seção. B: Detalhe da Seção apresentando siltito. .50

Figura 4.8: Seção estratigráfica do pacote de pelito - P4, exposto no Hotel Gold Fish em Corumbá subsequente a P3 da Formação Tamengo. Unidade de medida da Seção em $\mathrm{cm}$.

Figura 4.9: Seção P5S, parte superior da Formação Tamengo. A: Imagem ampla da seção, Escala: 1,4 m. B: Detalhe da seção apresentando siltito e ritmitos. .53

Figura 4.10: Seção estratigráfica do pacote de pelito - P5S exposto no Porto Sobramil em Corumbá, subsequente a P4 da Formação Tamengo. Unidade de medida da Seção em cm. .54

Figura 4.11: Seção P6S, parte superior da Formação Tamengo. A: Imagem ampla da seção. B: Detalhe da seção apresentando folhelho. .55

Figura 4.12: Seção estratigráfica do pacote de pelito P6S exposto na parte inferior do Porto Sobramil em Corumbá, subsequente a P5S da Formação Tamengo. Unidade de medida da Seção em cm.

Figura 4.13: Seção P7S, parte superior da Formação Tamengo. A: Imagem ampla da seção. B: Detalhe da seção apresentando siltito e ritmitos.

Figura 4.14: Seção estratigráfica do pacote de pelito - P7S exposto na parte inferior do Porto Sobramil em Corumbá, subsequente a P6S da Formação Tamengo . Unidade de medida da Seção em $\mathrm{cm}$. .58

Figura 4.15: Seção P5C, parte superior da Formação Tamengo. Imagem ampla da seção apresentando calcários e siltitos. Escala $1 \mathrm{~m}$. 
Figura 4.16: Seção estratigráfica do pacote de pelito P5C, exposto na parte superior da Pedreira Corcal em Corumbá, correspondente a seção P5S da Formação Tamengo. Unidade de medida da Seção em $\mathrm{cm}$.

Figura 4.17: Seção P6C, parte superior da Formação Tamengo. Imagem ampla da seção. Apresentando calcários e ritmito.

Figura 4.18: Seção estratigráfica do pacote de pelito - P6C, exposto na parte intermediária da Pedreira Corcal em Corumbá, correspondente a seção P6S e subsequente a seção P5C da Formação Tamengo. Unidade de medida da Seção em $\mathrm{cm}$.

Figura 4.19: Seção P6C, parte superior da Formação Tamengo. A: Imagem ampla da seção Escala 1,4 m. B: detalhe da formação apresentando siltito

Figura 4.20: Seção estratigráfica do pacote de pelito P7C exposto na parte inferior da Pedreira Corcal em Corumbá, correspondente a seção P7S da Formação Tamengo . Unidade de medida da Seção em cm.

Figura 4.21: Primeiro grupo tafonômico representado por espécimes de $C$. werneri incompletas com dois tipos de preservação distintos de carapaça. A: preservada tridimensionalmente. B: carapaça parcialmente preservada

Figura 4.22: Segundo grupo tafonômicos representado por espécimes de $C$. werneri fragmentadas com dois tipos de preservação distintos $\mathbf{A}$ : carapaça preservada e $\mathbf{B}$ : carapaça parcialmente preservada.

Figura 4.23: Amostra GP/1E - 10989 macroalga pseudo-parenquimatosa com provável estrutura de crescimento em seu ápice. A: visão geral do espécime. B: estriamento longitudinal ao longo do talo. C: Talo apresentando dicotomia (SETAS). D: parte basal com estruturas circulares (SETAS) E: parte apical com provável estrutura de crescimento, (SETAS). F: imagem retirada em MEV demonstrando parte da película na parte apical (SETAS). G: imagem em EDS marcando a presença de carbono no fóssil. H: imagem em EDS marcando a presença de sílica na rocha. ....74

Figura 4.24: Amostra GP/1E - 10990 macroalga pseudo-parenquimatosa. A: visão geral da espécime. B: Presença de dicotomia (SETAS). C e D: talos com estruturas similares a espinhos (SETAS). E: Membrana interligando os talos (SETAS). F: imagem geral do espécime em MEV. G: imagem em EDS marcando a presença de carbono no fóssil. $\mathbf{H}$ : imagem em EDS marcando a presença de sílica na rocha, escala $1 \mathrm{~mm}$. .76

Figura 4.25: Amostra GP/1E - 11187, possível alga com talos estriados e dicotômicos. A: visão geral da alga. B: detalhe do talo estriado, com estrutura longitudinal espessa central (SETAS). 
Figura 4.26: Amostra GP/1E - 11005. Icnofósseis de Multina minima encontrados na Formação Tamengo em P1, representados por: A e B: pequenos tubos curtos subhorinzontais sinuosos com preenchimento diferente da matriz rochosa. C e D: estruturas circulares associadas com o mesmo tipo de preservação.

Figura 4.27: Filamentos encontrados na Formação Tamengo. A: Filamentos agrupados, B: Filamento isolado. C: Detalhe do estriamento no filamento (SETA). D: Filamento com película escura E: Filamento com a borda demarcada (SETAS)......82

Figura 4.28: Vendotaenídeos descritos por Zaine (1991). A e B: fitas cobertas por mineral (SETAS). C e D: amostras de filamentos com película escura (SETAS). ....83

Figura 4.29: Amostra GP/1E - 11197 retirada da seção P4 a $30 \mathrm{~cm}$ da base da seção, representando possível estrutura sedimentar induzida por esteira microbiana (MISS).

Figura 4.30: Amostra GP/1E - 9971. A: estrutura circular concêntrica, com círculo externo e central. Notar os espécimes incompletos de Corumbella werneri, setas. B: detalhe da estrutura circular. .86

Figura 4.31: A: disco basal Charniodiscus sp. retirado de (Ford, 1958). B: Parte basal de Sphenotallus sp. na qual se conectaria ao disco retirado de (Li et al., 2004).......86

Figura 4.32: Imagens de possível fragmentos . A e B amostra GP/1E - 11124, representando fragmentos ramificados e uniformes. C e D amostra GP/1E - 11125, representado fragmentos de estruturas disformes.

Figura 5.1: Amostra com distintos padrões tafonômicos (espécimes incompletas e fragmentadas) indicando efeito de mistura temporal.

Figura 5.2: Representação paleoeambiental de C. werneri e outros fósseis da Fm. Tamengo. Modificado de Rodrigues et al. (2003) e Matos et al. (2017). .96 


\section{LISTA DE TABELAS}

Tabela 4.1: Informações do Fóssil de C. werneri encontrados na Seção P1 65

Tabela 4.2: Informações do Fóssil de $C$. werneri encontrados na Seção P2. .66

Tabela 4.3: Informações do Fóssil de C. werneri encontrados na Seção P3. .67

Tabela 4.4: Informações do Fóssil de C. werneri encontrados na Seção P5S. 69

Tabela 4.5: Informações do Fóssil de C. werneri encontrados na Seção P7S. .70

Tabela 4.6: Informações do Fóssil de $C$. werneri encontrados na Seção P7C..........70 


\section{SUMÁRIO}

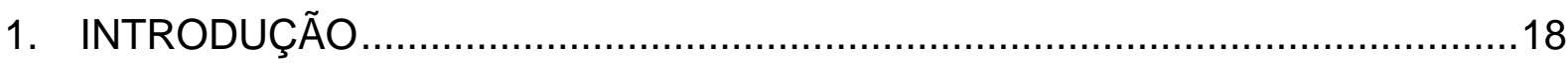

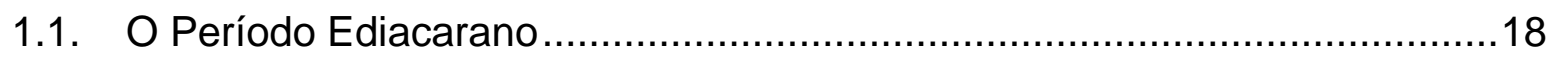

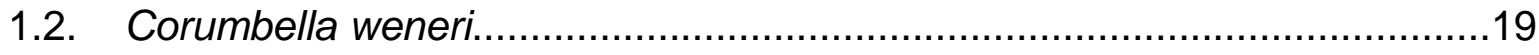

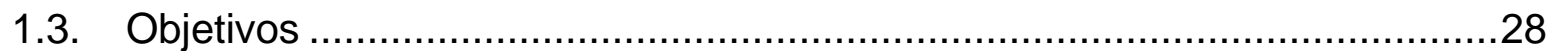

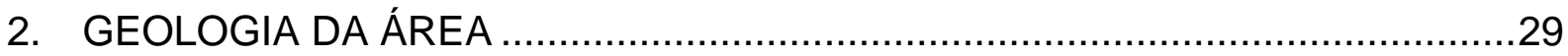

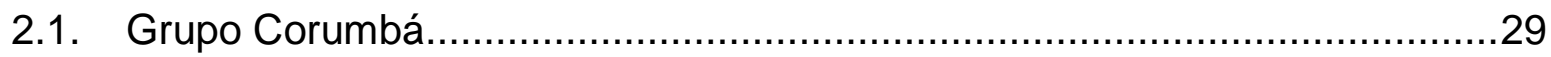

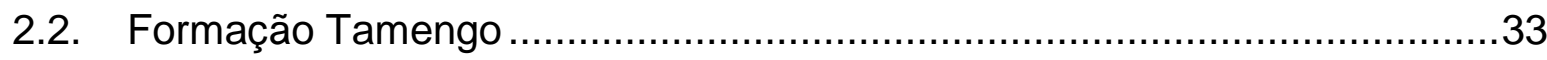

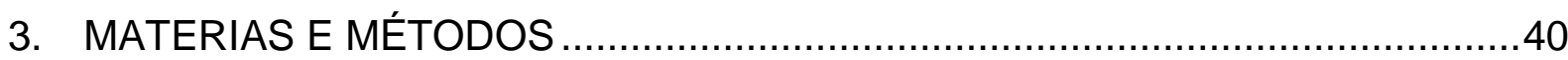

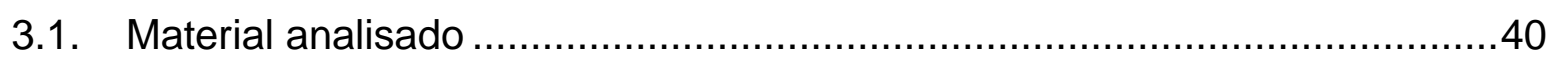

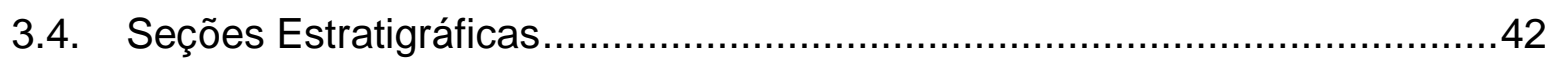

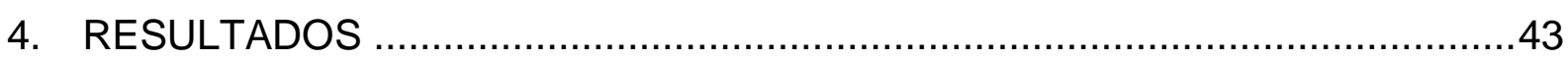

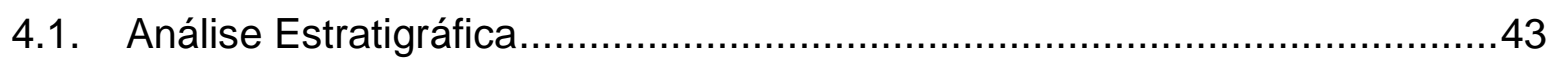

4.1.1. Seção Estratigráfica - P1 ........................................................... 43

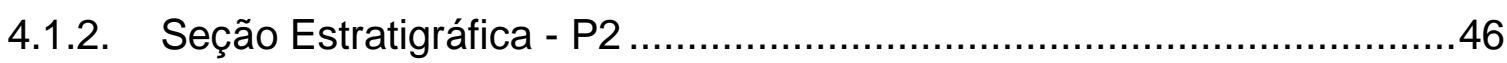

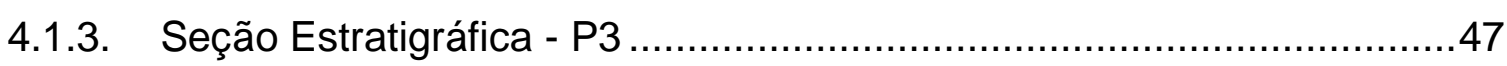

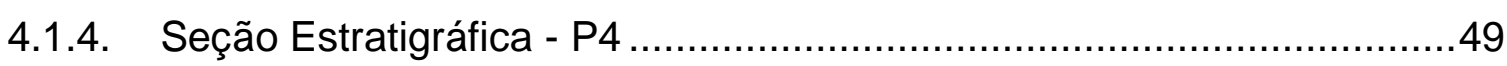

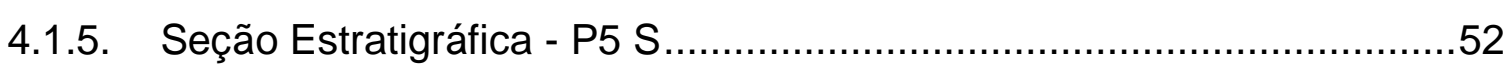

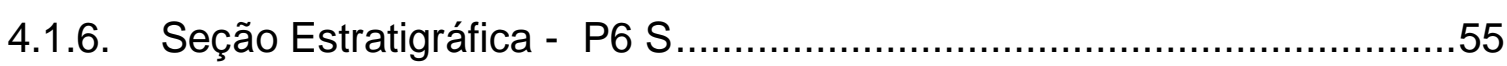

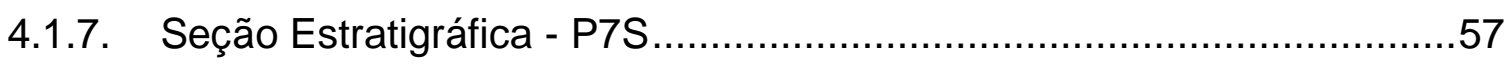

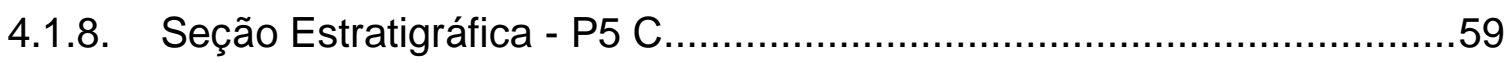

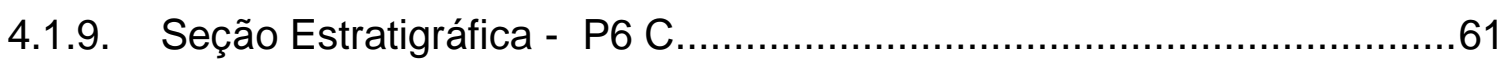

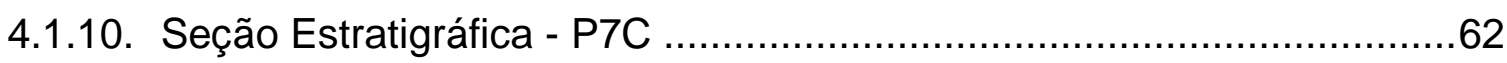

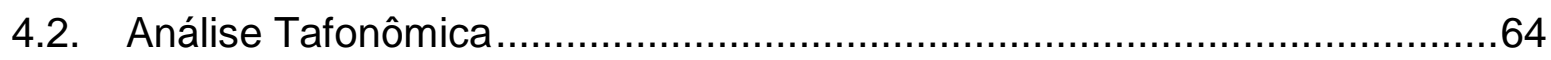

4.3. Novas ocorrências de Fósseis na Formação Tamengo ..............................72

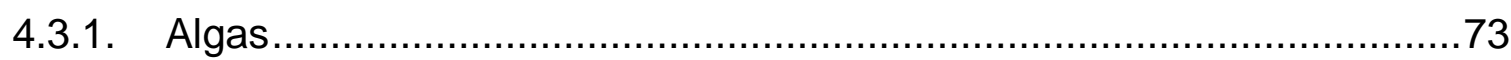

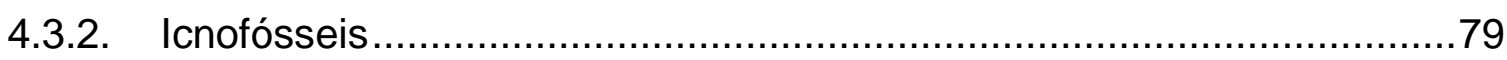

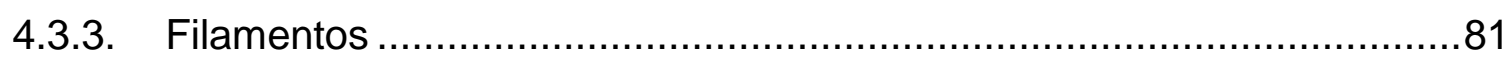

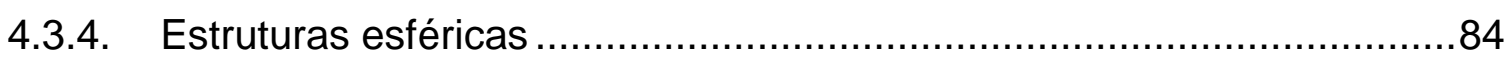

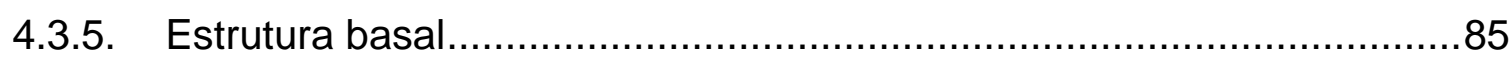

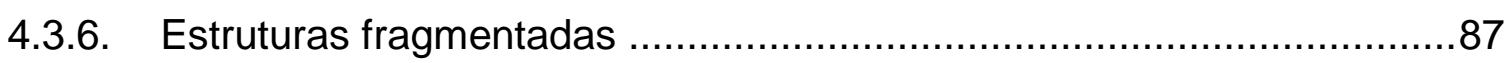

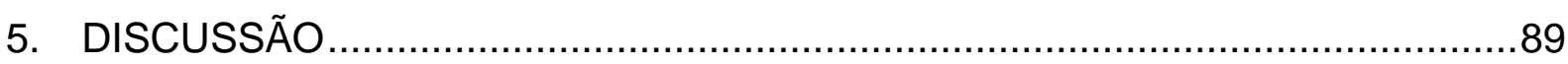

5.1. Distribuição Estratigráfica de Corumbella werneri e relações paleoecológicas

5.2. Implicações tafonômicas de Corumbella werneri 
5.3. Implicações paleoambientais de Corumbella werneri ..................................93

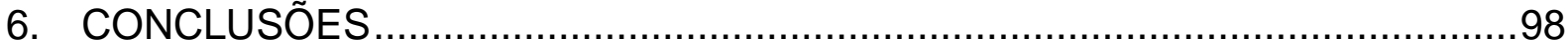

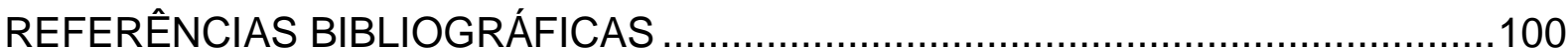




\section{INTRODUÇÃO}

\subsection{O Período Ediacarano}

O Período Ediacarano (Neoproterozoico) foi importante para a diversificação da vida no oceano. Através do registro fossilífero, percebe-se essa mudança a partir do aparecimento de formas macroscópicas mais complexas, evidências de metazoários e a expansão de grupos distintos como os vendobiontes (Narbonne, 2005). Um dos primeiros autores a utilizar a Fauna da Ediacara para caracterizar organismos invertebrados de corpo mole foi Sprigg $(1947,1949)$ que descreveu o que acreditava ser formas medusoides nas colinas de Ediacara, no Sul da Austrália, posicionando os fósseis encontrados no Cambriano Inferior. Glaessner \& Daily (1959) confirmaram o corpo mole dos organismos e perceberam que não existiam só formas medusoides, mas uma fauna marinha que tinham característica bentônicas. Constataram através da relação biostratigráfica dos fósseis de Rangea junto com Pteridinium que as formas medusoides estavam abaixo das rochas ditas cambrianas e atribuíram a biota de Ediacara para o Pré-Cambriano.

Seilacher (1992), atribuiu a esse grupo de seres de corpo mole o nome de Vendobiontes, grupo de organismos imóveis com aspecto folheado, corpo acolchoado com larga superfície para interação com o ambiente como respiração e absorção de nutrientes. Os Vendobiontes foram caracterizados a partir de sua morfologia, sendo rangeomorfos, isso é, com estruturas fractais repetitivas formando um auto-padrão, construindo frondes que facilitavam a sua elevação no substrato, e ernietomorfomos, que representavam organismos com estruturas seriais alternadas em volta de uma linha mediana, mas que não o tornam simetricamente bilaterais (Narbonne, 2004; Seilacher, 2007; Xiao \& Laflamme, 2009). Estudos posteriores como os de Seilacher et al. (2003) e Seilacher (2007) interpretam vendobiontes como um grupo semelhante aos protistas rizópodes atuais denominados xenophyophora.

O registro fossilífero da fauna de Ediacara está ao redor do mundo, em diversos países como Rússia, Inglaterra, Austrália, China, África, Brasil entre outros que conciliavam ao período Ediacarano (Waggoner, 2003; Narbonne, 2005; Hall et al., 2015) com tipos de preservação distintos, desde impressões e moldes de fósseis de 
corpo mole (Narbonne et al., 1997), embriões de metazoários (Xiao et al., 1998b), algas multicelulares fosfatizadas (Xiao et al., 2004), moldes externos de texturas orgânicas (Gehling \& Droser, 2009), eucariontes macroscópicos (Yuan et al., 2011), fósseis com carapaça biomineralizada (Cortijo et al., 2015) e icnofósseis (Jensen et al., 2005) sendo que as afinidades biológicas dos organismos ainda eram incertas pois acreditam que desenvolveram grupos que não condizem com os atuais portanto de difícil classificação.

A biota de Ediacara possui uma diversidade que são difíceis de realizar relações filogenéticas e atribuir a determinados táxons, portanto criou-se uma maneira de unilos em conjuntos ou assemblagens de acordo com os padrões de ocorrência das espécies ao longo do tempo espaço, como ela responde a história tectônica da Terra, além de sua especiação e extinção (Waggoner, 2003). Cada conjunto, apresenta caráter evolutivo importante para a história de vida tais como, evidências de locomoção (Narbonne, 2005), características de predação (Bengtson \& Zhao, 1992) e presença de esqueletogênese (Warren et al., 2012).

O conjunto de Avalon (Figura 1.1) possui a idade mais antiga entre 579 - 559 milhões de anos com biotas que viviam em localidades muito próximas umas às outras (Waggoner, 2003). Encontra-se em determinadas zonas da Inglaterra central e em Newfoundland, Canadá, com presença de rangeomorfos como Bradgatia linfordensis Boynton \& Ford 1995 e Fractofusus misrai Gehling \& Narbonne 2007, táxons cosmopolitas como Charnia masoni Ford 1958 e Aspidella terranovica Billings 1872, ou endêmicos como os da área da Floresta Charnwood sendo sua maioria frondes. Em alguns lugares como na Formação Mistaken Point, os fósseis são preservados em depósitos de turbidito abaixo de cinzas vulcânicas podendo caracterizar ambientes de água profunda (Narbonne \& Gehling, 2003). 


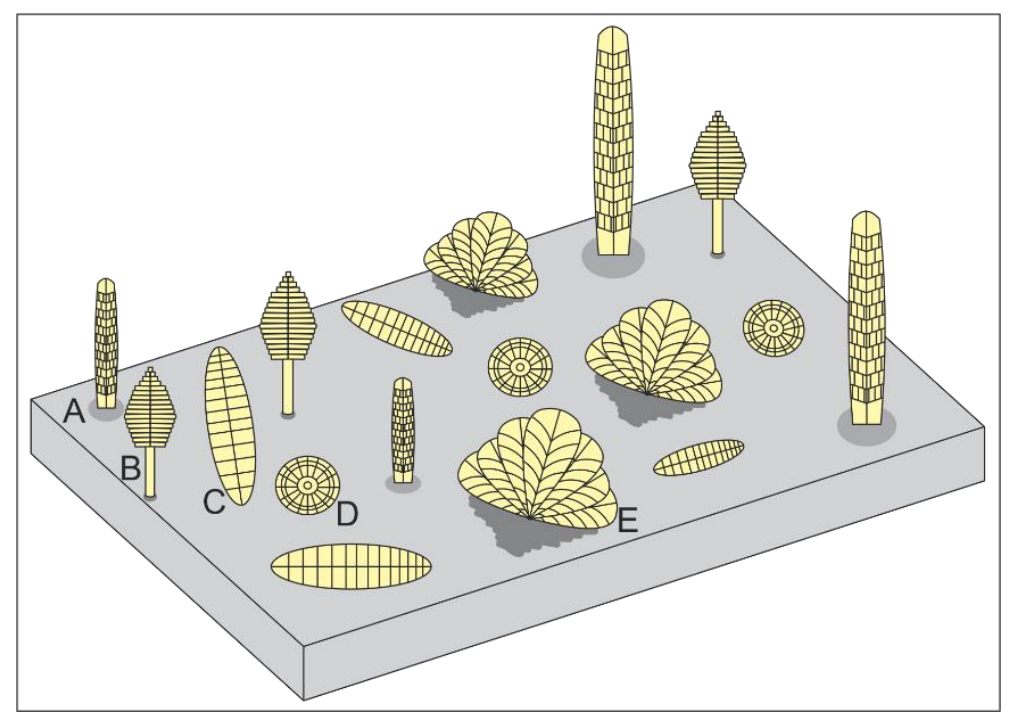

Figura 1.1: Diorama do conjunto de Avalon com alguns de seus representantes, imagem meramente ilustrativa. (A) Charnia masoni, (B) Espécime com fronde, (C) Fractofus misrai, (D) Aspidella terranovica, (E) Bradgatia linfordensis. Modificado de (Clapham \& Narbonne, 2002; Clapham et al., 2003).

O conjunto de White Sea (Figura 1.2) possui idade intermediária em relação aos outros conjuntos entre 558 - 550 milhões de anos, com biotas distribuídas descontinuamente ao longo do globo em paleolatitudes temperadas (Waggoner, 2003). É encontrada no Sul da Rússia em White Sea e preservada em arenitos de granulação fina ou depósitos de argilitos, onde ocorrem fósseis de organismos bilaterais como Kimberella quadrata Glaessner \& Daily 1959, Yorgia waggoneri Ivantsovi 1999 e Dickinsonia Sprigg 1947, discoidais como Tribachidium heraldicum Glaessner \& Daily 1959 e com frondes como Charniodiscus concentricus Ford 1958, que podem ter existido em ambiente de águas marinhas rasas com influência de um sistema deltaico (Fedonkin et al., 2007). 


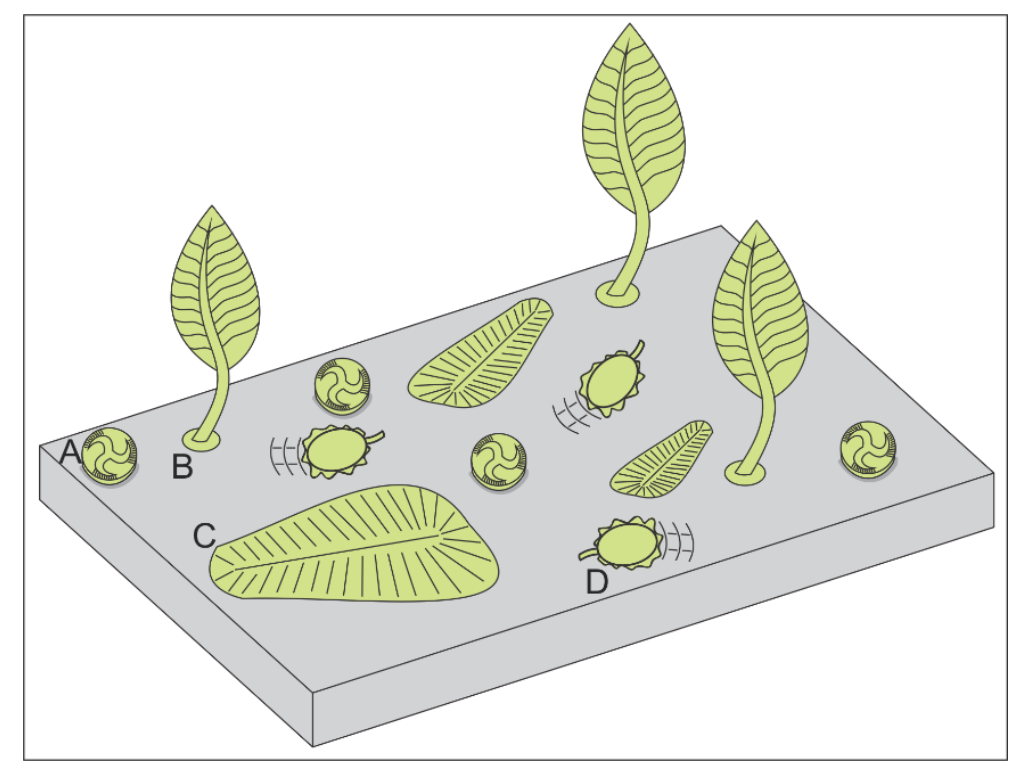

Figura 1.2: Diorama do conjunto de White Sea com alguns de seus representantes, imagem meramente ilustrativa. (A) Tribachidium heraldicum, (B) Charniodiscus concentricus, (C) Dickinsonia, (D) Kimberella waggoneri. Modificado de (Clapham \& Narbonne, 2002; Clapham et al., 2003).

O conjunto de Nama (Figura 1.3) é o mais novo dentre os conjuntos citados com idade de 549 - 541 milhões de anos, nesse conjunto temos a presença de Cloudina sp. (Beurlen \& Sommer) Germs, 1972 um dos mais antigos representantes animais biocalcificados (Zaine \& Fairchild, 1985; Hahn \& Pflug, 1985; Grant, 1990). Esse conjunto pode ser preservado em depósitos de arenitos formados por tempestade, no qual ocorrem fósseis ernietomorfos ou com frondes como Swartpuntia germsi Narbonne et al. 1997 e Ernietta plateauensis Pflug 1966 que possivelmente viveram em ambiente marinho em zona fótica (Narbonne et al., 1997).

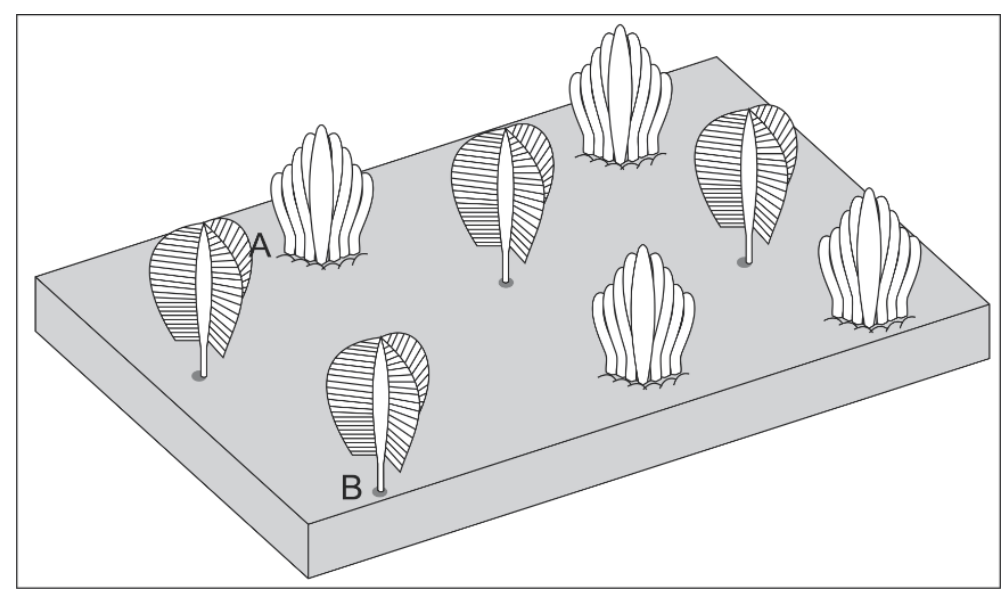

Figura 1.3: Diorama do conjunto de Nama com alguns de seus representantes, imagem meramente ilustrativa. (A) Ernietta plateauensis, (B) Swartpuntia germsi. Modificado de (Clapham \& Narbonne, 2002; Clapham et al., 2003). 


\subsection{Corumbella werneri}

Corumbella werneri foi identificada primeramente por Hahn et al. (1982), que descreveu a espécie contendo duas regiões, a região proximal na qual consistia o pólipo primário e a região distal, contendo pólipos secundários (Figura 1.4). O pólipo primário presente na região proximal, era representado por um tubo peridérmico espesso, curvo e extenso que não possuía ramificação e era constituído por anéis quitinosos isolados, que em seu interior possuíam quatro pequenos relevos denominados esclerosseptos que refletiam à tetrametria. Os pólipos secundários presentes na região distal eram formados por tubos peridérmicos quitinosos menores e individuais sem a formação de anéis e sem esclerosseptos visíveis. Os autores não encontraram nenhuma estrutura de fixação no pólipo primário de $C$. werneri, o que permitiu a comparação com o gênero Stephanoscyphus Allman 1874, atribuindo C.werneri a Classe Scyphozoa (Filo Cnidaria). Adicionalmente, segundo Hahn et al. (1982), a composição estrutural de C.werneri que dividia-se em unisseriada na região proximal e bisseriada na região distal era exclusiva dessa espécie, sendo atribuída a nova Subclasse Corumbellata, abrangendo a Ordem Corumbeliida e a Família Corumbellidae. 

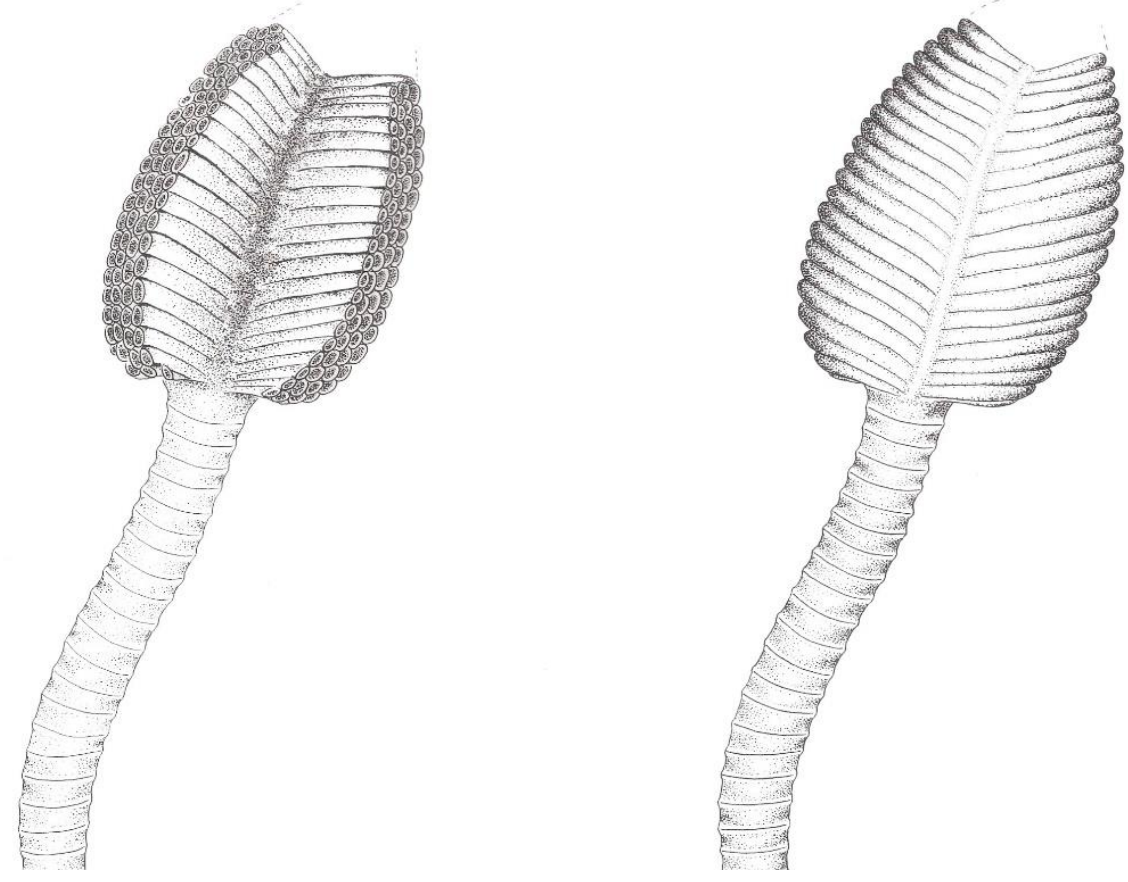

Figura 1.4: Reconstituição de Corumbella werneri, segundo Hahn et al., 1982, apresentando as duas regiões, a proximal unisseriada com pólipos primários, e a distal bisseriada com pólipos secundários.

Zaine \& Fairchild (1987) e Zaine (1991) retomaram o estudo sobre C. werneri através de uma maior quantidade de coletas na Formação Tamengo na antiga Pedreira Itaú atualmente Porto Sobramil, em Ladário e na Mina Laginha em Corumbá, ambos no Mato Grosso do Sul. Foram encontrados fósseis tridimensionais, preservados por conservação parcial, moldes e até mesmo incarbonização. $C$. werneri foi definida como tubos flexíveis unisseriados ou que apresentam formas de duas a quatro séries longitudinais subdivididas em segmentos ou compartimentos sem preenchimento, ordenados de formas alternadas opostas ou de modo imbricado (Zaine \& Fairchild 1987; Zaine, 1991). Não foi encontrada pelos autores nenhuma estrutura para comunicação com o meio, modo de reprodução, estruturas de fixação, esclerosseptos, natureza quitinosa ou alguma evidência relacionada a conexões entre as partes unisseriadas e bisseriadas (proximal e distal) e até mesmo organização antero-posterior. Zaine (1991) não confirmou o trabalho realizado por Hahn et al. (1982) de que C. werneri seria um organismo com uma porção proximal unisseriada e uma porção distal bisseriada, mas que mesmo assim fazia parte da fauna de Ediacara atribuída então a organismos de corpo mole e achatados capazes de fazer trocas com o meio através da difusão os vendobiontes (Seilacher, 1989; Buss \& Seilacher, 1994) devido ao tipo de preservação do qual o fóssil foi encontrado. 
Hagadorn \& Waggoner (2000) encontraram dois exemplares que atribuíram ao gênero Corumbella n. sp. na Formação Wood Canyon, nos Estados Unidos. Descreveram como fóssil tubular quadrangular de cantos arredondados com uma nítida separação entre a parte interior e exterior e sulcos longitudinais por toda a linha mediana de cada face, sendo que a espécie que tivera a melhor preservação obtinha uma torção helicoidal ao longo do eixo principal. Não encontraram nenhum indício de pólipos secundários e utilizaram as características de simetria e a ornamentação similares a de conularídios do Paleozoico para justificar a afinidade com a classe Scyphozoa (Filo Cnidaria).

Babcock et al. (2005) realizaram uma nova interpretação morfológica e atribuíram relações filogenéticas de $C$. werneri com cnidários. Da mesma forma que Hahn et al. (1982) foi interpretado duas partes distintas na espécie, sendo que a parte apical era uma região fixadora acoplada a outra parte, um tubo alongado com estruturas anelares transversais, flexível, capaz de se torcer e com simetria tetrarradial. Babcock et al. (2005) também descreveram uma massa orgânica ao redor da parte apical que poderia estar entrelaçada entre indivíduos de uma mesma colônia ou a outras estruturas orgânicas como bactérias (Figura 1.5).

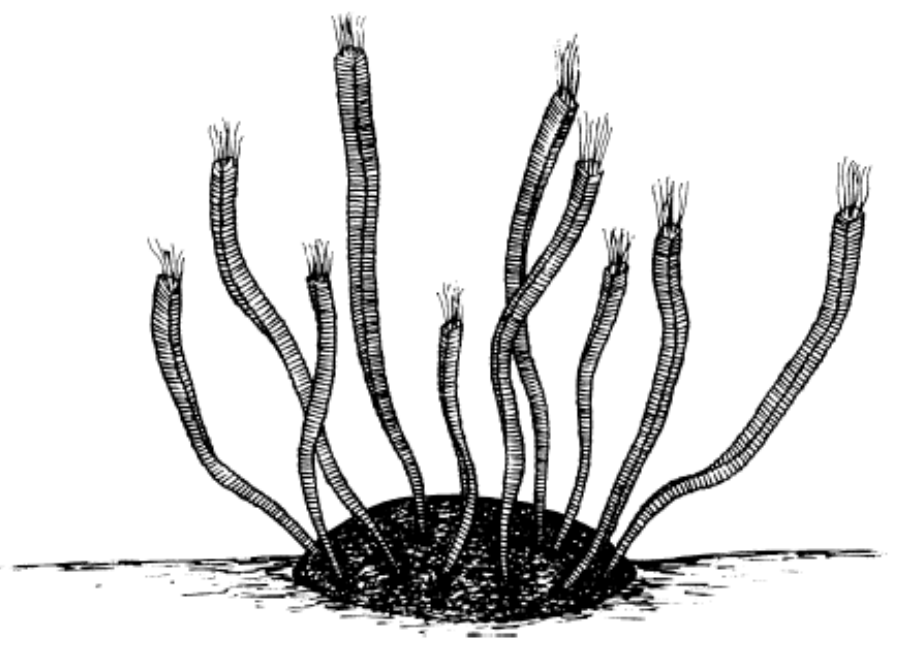

Figura 1.5: Reconstituição de Corumbella werneri como organismos bentônicos coloniais, fixados em uma "massa orgânica", conforme sugerido por Babcock et al. (2005).

Não foram solucionadas questões da composição da carapaça e nem identificaram os polipários, que segundo Hahn et al. (1982) seria a característica necessária para reconhecer a Subclasse Corumbellata e a Ordem Corumbellida. Entretanto, através de características morfológicas, como a aparente simetria radial, 
o corte transversal quadrangular e sulcos longitudinais externos que apareceram tanto na espécie estudada como nos conularídios, Babcock et al. (2005) sugeriram que esse fosse um grupo irmão, corroborando a afinidade com a Classe Scyphozoa já proposto anteriormente.

Pacheco (2012) analisou os aspectos morfológicos, tafonômicos, paleoecológicos e de afinidade taxonômica através da comparação de materiais citados nos estudos anteriores com novos materiais coletados e trabalhos relacionados a $C$ werneri. Em relação aos aspectos tafonômicos Pacheco et al. (2011) e Pacheco (2012) realizaram uma análise tafonômica básica para $C$. werneri afim de eliminar qualquer tipo de confusão ou interpretação errônea das características morfológicas devido a processos tafonômicos suscetíveis a alterações da carapaça, uma vez que a presença de natureza biomineralizada é propensa a fragmentação e/ou compressão.

Os aspectos tafonômicos propostos por esses autores foi dirigido para auxiliar a identificação taxonômica, dessa forma, foram dividas as classes tafonômicas em espécies tridimensionais que podem possuir geometria cilíndrica classificados com tubos anelados, unisseriados preenchidos por sedimentos de maioria fragmentada ou possuir geometria poliédrica, classificados como amostras aproximadamente piramidais com anéis poligonais sobrepostos e presença de sulcos interpretado como apótemas laterais na linha mediana, septos definidos e bordas laterais. Outra classe tafonômica apresentada foram das espécies bidimensionais produto da compactação, que possuíam preservação da carapaça por incarbonização, podendo ser uni, bi, tri e tetrasseriados, tendo um espécime com clara região oral (Pacheco et al., 2011; Pacheco, 2012).

Segundo Pacheco et al. (2011), Pacheco (2012) e Pacheco et al. (2015) C. werneri não possui diferenciação bipartite proposta por Hahn et al. (1982) como pólipo primário e polipário, mas possui polaridade de crescimento com organização oralaboral, um tubo poliédrico com geometria aproximadamente quadrangular, sendo as seriações uma parte do organismo seccionada ou demarcada por fendas medianas. O corpo é composto pela parte aboral unisseriada com estrutura cônica de fixação, composta de anéis que possuem um formato circular e transitam para anéis poligonais que se tornam mais largos, se sobrepõe uns aos outros e se tornam contínuos nas 
bordas laterais, convergindo para uma linha mediana na face da região boral (Figura 1.6).

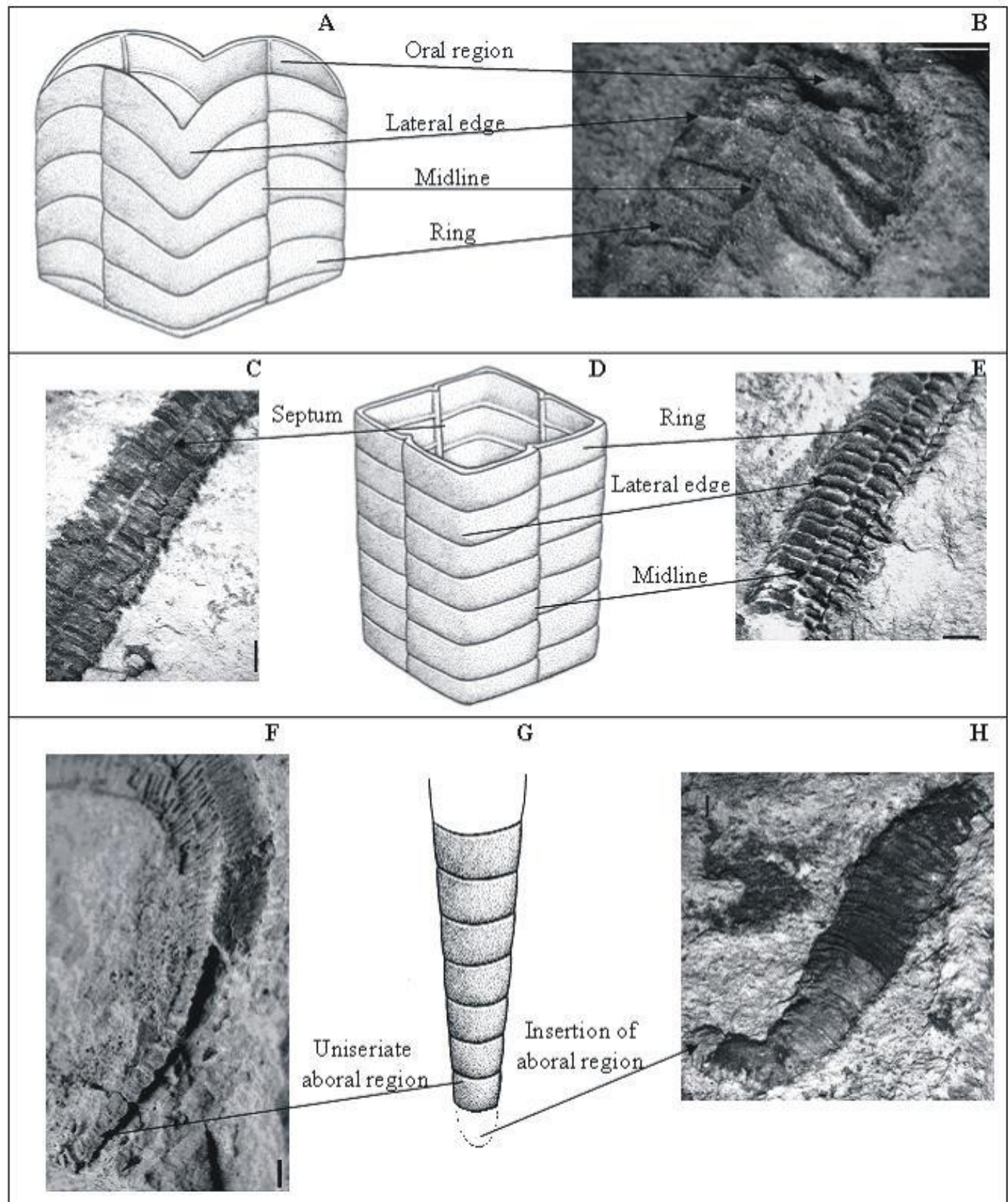

Figura 1.6: Reconstituição de estruturas morfológicas em Corumbella werneri. (A) reconstituição da região oral e $(B)$ com o respectivo fóssil. (C) detalhe para o septo. (D) Modelo geral tridimensional para uma porção em seção transversal, (E) detalhe da borda lateral e linha mediana. (F) Região aboral unisseriada, (G) representação dessa região. (H) Inserção incerta da região aboral. Escala: $1 \mathrm{~mm}$. Retirado de Pacheco (2012).

C. werneri apresenta diversas formas de preservação, tais como dobradas, comprimidas, fragmentadas, achatadas, inteiras, torcidas e tridimensionais. Através 
de ultraestrutura comparada com organismos cifozoários, espectroscopia Raman, EDS e FRX Pacheco (2012) e Pacheco et al. (2015) apresentaram novas características em sua carapaça, como estriações longitudinais, placas poligonais com poros e papilas, presença de carbonato na forma de calcita e cálcio, sugerindo que a carapaça de $C$. werneri seria orgânica mas fracamente mineralizada podendo ser flexível a ponto de ocorrer torções helicoidais devido a processos mecânicos, mas com possibilidade de se partir.

Pacheco (2012), Van Iten et al. (2014) e Pacheco et al. (2015) revisaram a sistemática de $C$. werneri e a atribuíram ao Filo Cnidaria, Classe Scyphozoa e Família Corumbellidae, com relações filogenéticas com os Conulariida Miller \& Gurley 1896, devido as características morfológicas tais quais geometria piramidal, seção transversal quadrangular, linhas medianas e disposição dos anéis. Entretanto, outros estudos divergem dessas afirmações, como Walde et al. (2015) que não corroboram essa relação filogenética, pois não confirmam a seção transversal tetragonal, mas uma seção transversal circular original (pré-compressão) e Walde et al. (2016) reinterpretam C. werneri ao grupo dos cloudinidas, Família Cloudinidae, possuindo simetria radial e relações filogenéticas com os poliquetas.

Diante do exposto, embora tenha ocorrido enorme avanço nas interpretações sistemáticas e paleoecológicas sobre $C$. werneri não houve atenção e nem o objetivo de demarcar a posição exata de ocorrências de $C$. werneri e de outros fósseis, ao longo da Formação Tamengo. Tal detalhamento da distribuição estratigráfica é fundamental para que muitas questões, ainda sem conclusões, como por exemplo, o modo de vida, o habitat deste táxon, bem como os processos e as condições paleoambientais e tafonômicas de preservação, possam ser entendidas com mais clareza. Dessa forma, este trabalho possui a proposta de identificar a distribuição estratigráfica de detalhe de $C$. werneri e classificar os aspectos tafonômicos básicos que aparecerem, possibilitando, inferir as condições paleombientais e paleoecológicas de preservação. 


\subsection{Objetivos}

Este trabalho está fundamentado nos estudos recentes sobre a anatomia, sistemática e paleobiologia de $C$. werneri e, diante disso, tem por objetivos:

a) Identificar a distribuição estratigráfica de detalhe de $C$. werneri, da Formação Tamengo, Grupo Corumbá, a partir de amostras provenientes dos afloramentos presentes na Cidade de Ladário e Corumbá, na Mina Corcal e no Porto Sobramil em Mato Grosso do Sul;

b) Determinar diferentes grupos tafonômicos a partir da análise de características tafonômicas presentes nos fósseis de $C$. werneri;

c) Descrever morfologicamente novos fósseis e estruturas encontradas na Formação Tamengo;

d) Estabelecer condições paleoecológicas e paleoambientais de $C$. werneri, tais como o habitat, a partir das análises estratigráficas e tafonômicas. 


\section{GEOLOGIA DA ÁREA}

\subsection{Grupo Corumbá}

O mapa geológico do Estado do Mato Grosso do Sul, pode ser dividido em três grandes províncias, o Cráton Amazônico, a Província Tocantins e as bacias sedimentares do Fanerozoico (Figura 2.1).

A Faixa Paraguai, que se encontra na Província Tocantins, representa uma unidade composta em sua maioria por rochas sedimentares depositadas em um ambiente de margem passiva durante o Neoproterozoico que posteriormente foram dobradas pela orogênese Brasiliana/Pan-Africana com aproximadamente $1200 \mathrm{~km}$ de comprimento que prolonga-se desde o Mato Grosso na região do Rio das Mortes, segue por Cuiabá e estende-se pela região de Corumbá até a Serra da Bodoquena em Mato Grosso do Sul. A faixa dobrada subdivide-se em duas, onde o Grupo Corumbá está presente na parte meridional e o Grupo Araras e Grupo Alto Paraguai na parte setentrional, sendo que os grupos Corumbá e Araras são predominantemente carbonáticos (Boggiani \& Alvarenga, 2004; Lacerda Filho et al., 2006).

A Faixa Paraguai possui 3 estágios estruturais em sua evolução sendo separadas de acordo com a mudança em sua litologia. As rochas metamorfisadas e intensamente dobradas como o xisto verde, turbiditos e até mesmo cinza vulcânica fazem parte do Grupo Cuiabá o estágio mais antigo, os diamictitos da Formação Puga juntamente com as sucessões carbonáticas com calcários e dolomitos e estruturas de estromatólitos do Grupo Corumbá fazem parte do estágio médio e a sedimentação detrítica de caráter molássico do Grupo Alto Paraguai define o estágio superior (Almeida, 1968). 


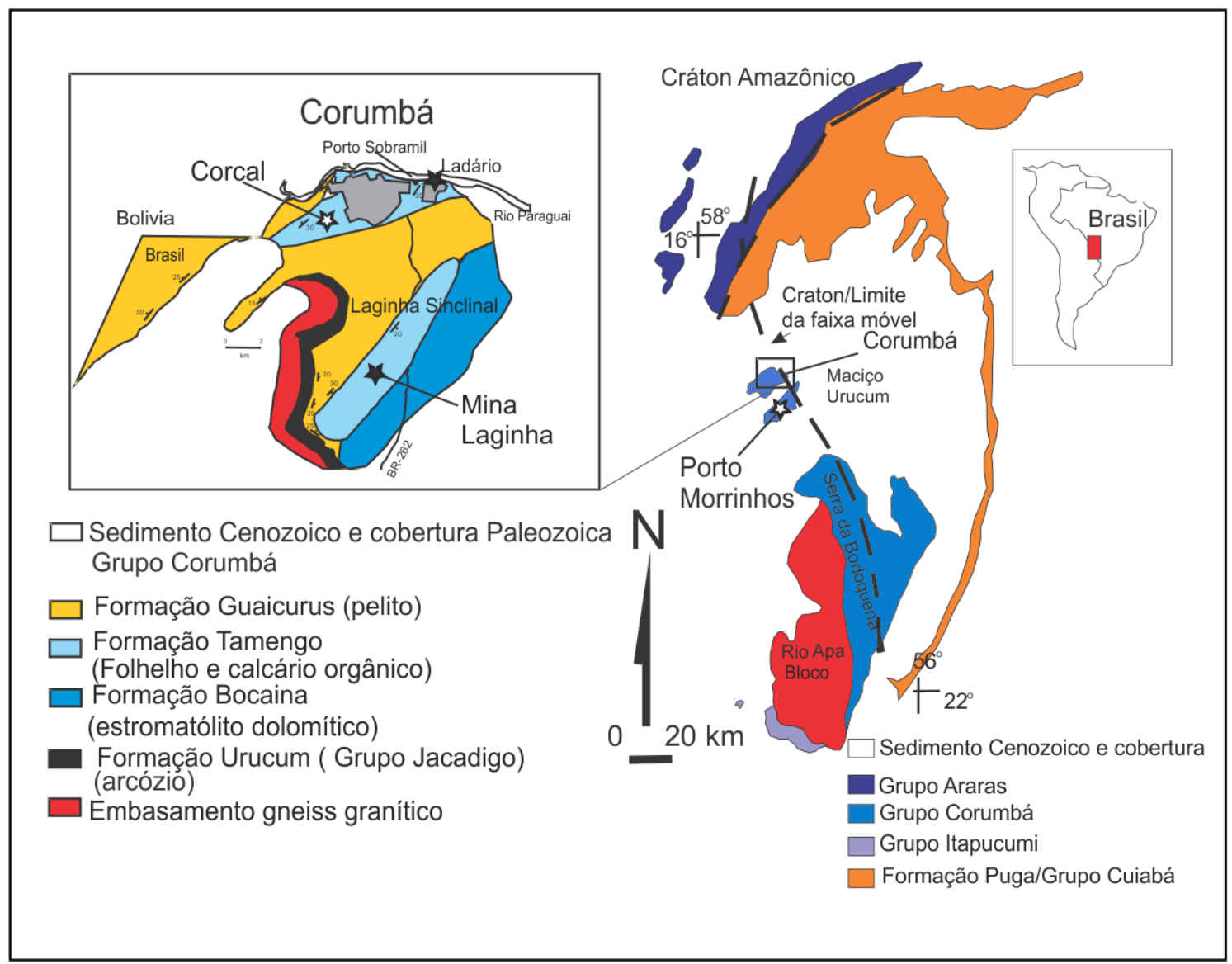

Figura 2. 2: Mapa geológico da região de Mato Grosso do Sul com enfoque ao Grupo Corumbá, retirado de Van iten et al. (2016) e Parry et al. (submetido).

A estratigrafia do Grupo Corumbá sofreu modificações durante seu tempo conforme autores dissertavam sobre o local, mas sendo considerado um maior destaque aos trabalhos de Almeida (1945, 1965a e 1968), Boggiani (1990 e 1998) e Boggiani et al. $(1993,2010)$ que conseguiram interpretar de melhor forma a região estudada.

Almeida (1945) subdividiu a Série Bodoquena em dois grupos, o Grupo Bocaina e o Grupo Tamengo. Sendo que o primeiro era caracterizado por ser basal, predominantemente dolomítico, cinza claro, homogêneo e de textura fina a média, no qual não foram encontradas estruturas sedimentares possivelmente, devido ao processo de dolomitização. Com a hipótese de ambiente deposicional marinho, devido ao processo de dolomitização necessitar de água marinha onde proveria $0 \mathrm{Mg}^{2+}$.

O Grupo Tamengo caracterizado por ser mais recente com calcários calcíferos cinza-escuros, folhelhos verdes, siltitos e arenitos que recobriam o Grupo Bocaina, com estruturas deltaicas no arenito e ripple marks e estratificações cruzadas no calcário e arenito. Com hipótese de ambiente deposicional também marinho, onde o 
calcário seria proveniente da precipitação de $\mathrm{Ca} \mathrm{CO}_{3}$ trazido pela corrente das águas frias auxiliando também na formação dos ripples, o arenito teria depositado em planície litorânea deltaica e os siltitos e folhelhos proveniente de elementos clásticos finos trazidos pelos rios do continente (Almeida, 1945).

Almeida (1965a) denominou as exposições da Serra da Bodoquena e de Corumbá como fazendo parte de um único grupo descrevendo-o como Grupo Corumbá subdividindo-o em Formação Cerradinho, Bocaina, Tamengo e Guaicurus atribuindo o ambiente gerador do Grupo Corumbá como depósito em meio marinho nerítico com clima quente, presença de material lutáceo e ocorrendo precipitação de carbonato levados por correntes. Boggiani (1997) acrescentou a base do Grupo Corumbá a Formação Cadiueus.

A Formação Cadiueus possui espessura média de $150 \mathrm{~m}$, é composta por ortoconglomerados polimítico, intercalados com arcósios de granulometria grossa. Apresenta contato inferior discordante com o embasamento e em seu topo apresenta uma transição faciológica progressiva entre seus sedimentos conglomeráticos e os arenitos e folhelhos da Formação Cerradinho. O ambiente deposicional ocorreu devido a retração glacial e abertura da Bacia Corumbá, com a formação de leques aluviais (Almeida 1965a; Boggiani, 1997).

A Formação Cerradinho apresenta espessura média de $150 \mathrm{~m}$ constituída de fácies subaquosas com conjunto de sedimentos variados entre arenosos a argilosos que teriam procedência terrígena, contém níveis de conglomerados que gradam para folhelhos de cor avermelhada e siltito intercalados com argilitos. Seu ambiente deposicional é interpretado como leques aluviais depositados diretamente em corpo aquoso após o afogamento dos leques aluviais correspondente a Formação Cadiueus durante a entrada do mar (Almeida 1965a; Corrêa et al., 1979; Boggiani, 1997).

A Formação Bocaina apresenta espessura máxima de $100 \mathrm{~m}$ onde em algumas partes ocorre transição gradual na base em contato com Formação Cerradinho e no topo para a Formação Tamengo. É formada por dolomitos estromatolíticos e calcários dolomíticos que foram o resultados de carbonatos precipitados em águas rasas pela ação de micro-organismos, podem estar silicificados e possuir intercalações de argila. O ambiente deposicional foi interpretado como uma extensa planície de maré 
resultado da transgressão pós glacial (Almeida 1965a; Corrêa et al., 1979; Boggiani, 1997; Moraes, 2013).

A Formação Tamengo apresenta discordância com a Formação Bocaina e transição gradacional com a Formação Guaicurus, possui fácies carbonosas como grainstones e mudstones alternados por pacotes de ritmitos e folhelhos. Possui registro fossilífero de metazoários como Corumbella werneri e Cloudina lucianoi. Com possível ambiente em águas mais profundas em talude indicando transgressão da Bacia Corumbá (Almeida 1965a; Boggiani, 1997; Boggiani et al., 2010).

A Formação Guaicurus: corresponde ao topo do Grupo Corumbá, possui contato gradacional com a Formação Tamengo, composta por sedimentação terrígena pelítica caracterizada por folhelhos de fácil alteração atribuído a um afogamento da plataforma carbonática (Boggiani, 1997).

Boggiani (1990) estudou as fácies sedimentares do Grupo Corumbá e o separou em duas partes: a zona Interna e zona Externa. A zona Interna representada pela parte leste do grupo apresentava deformação tectônica caracterizada por fácies sedimentares em plataforma carbonática tectonicamente estável e a zona Externa representada pela parte oeste do grupo com sedimentação terrígena que transitava para sedimentação carbonática.

A Bacia Corumbá foi portando associado a abertura de um oceano com uma estabilidade tectônica portanto uma margem continental passiva que tinha evoluído de uma bacia tipo rift, que fechou-se como resultado da colisão continental PanAfricana-Brasiliana. Além disso ocorria a presença de rochas fosfática juntamente com estromatólitos, sendo que a possível origem desses depósitos de fosfato sedimentar seria devido a correntes marinhas ascendentes em forma de ressurgência onde águas frias e profundas com alto teor de fosfato e nutrientes subiriam até a superfície auxiliando na intensa presença de atividade biológica (Boggiani et al., 1993, 2003). 


\subsection{Formação Tamengo}

A Formação Tamengo (Figura 2.2) possui aproximadamente 70 metros de espessura como proposto por Van Iten et al. (2016). Pode ser encontrada exposta em sete afloramentos em seis pontos na cidade de Corumbá, Ladário e seus arredores especificamente na Mina Corcal no Porto Sobramil antiga Mina Saladeiro ou pode ser encontra exposta de forma completa na Mina Laginha (Figura 2. 4: Mapa geográfico da cidade de Corumbá e Ladário com os respectivos pontos aflorantes da Fm. Tamengo. Marcados da direita para esquerda P1, P2, P3, P4, P5, P6 e P7. Pontos no Porto Sobramil e Pontos da Mina Corcal.. Sua base é caracterizada por quartzo, arenito e clastos de litologia diversificada podendo ser calcário, dolomito ou fosforito é muito comum a presença de calcários calcíticos carbonosos de cor preta com intercalação de folhelhos carbonosos e ritmitos, com principais estruturas sedimentares encontradas sendo estratificação plano-paralela, estratificação do tipo hummocky e marcas de onda (Almeida, 1965a; Boggiani, 1998). 


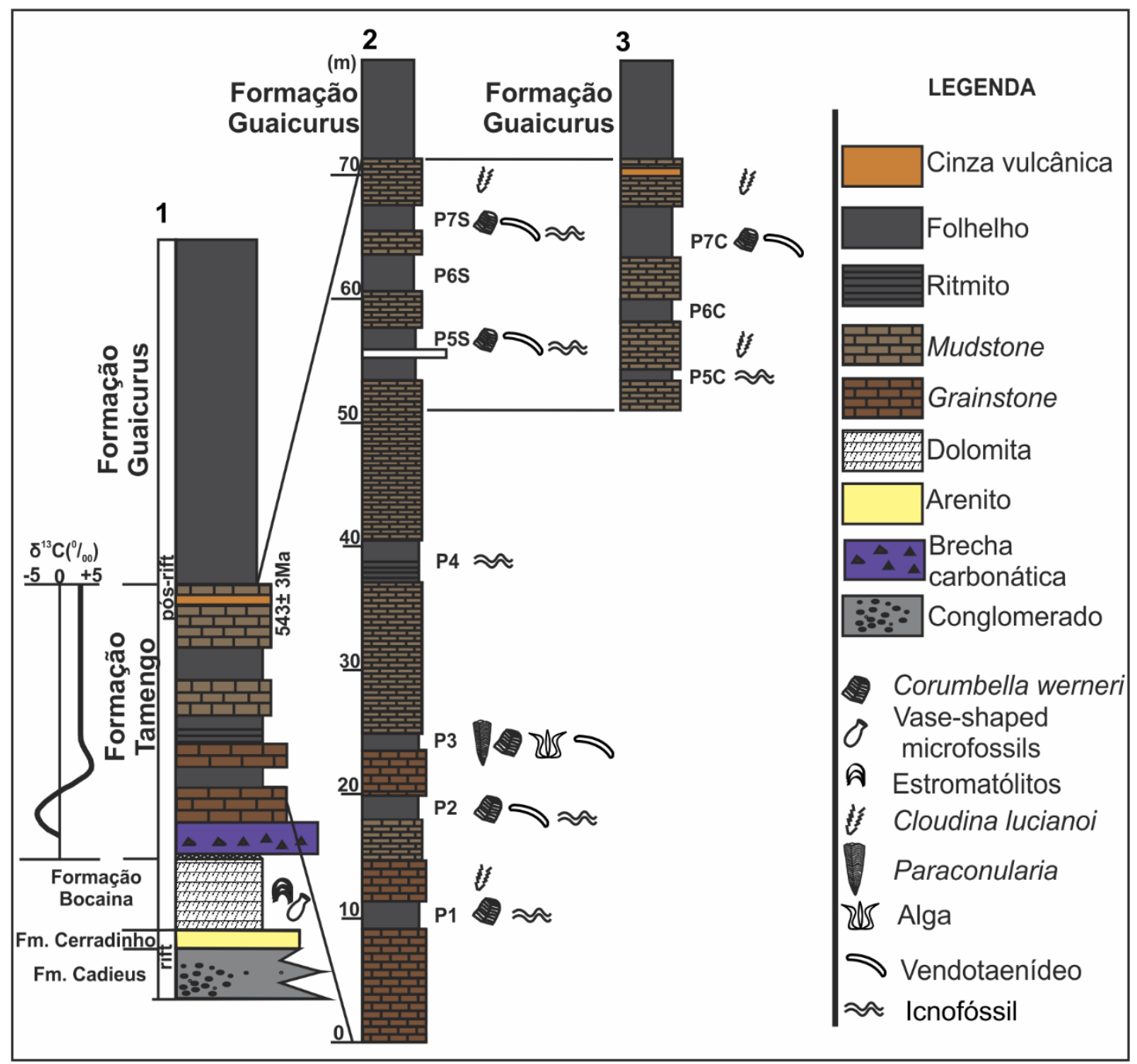

Figura 2.3: Coluna estratigráfica do Grupo Corumbá 1: formações do Grupo Corumbá, 2: detalhe da Fm. Tamengo, 3: correlação do topo da Fm. Tamengo na Mina Corcal. Modificada de Van Iten et al. (2016) e Parry et al. (submetido). 


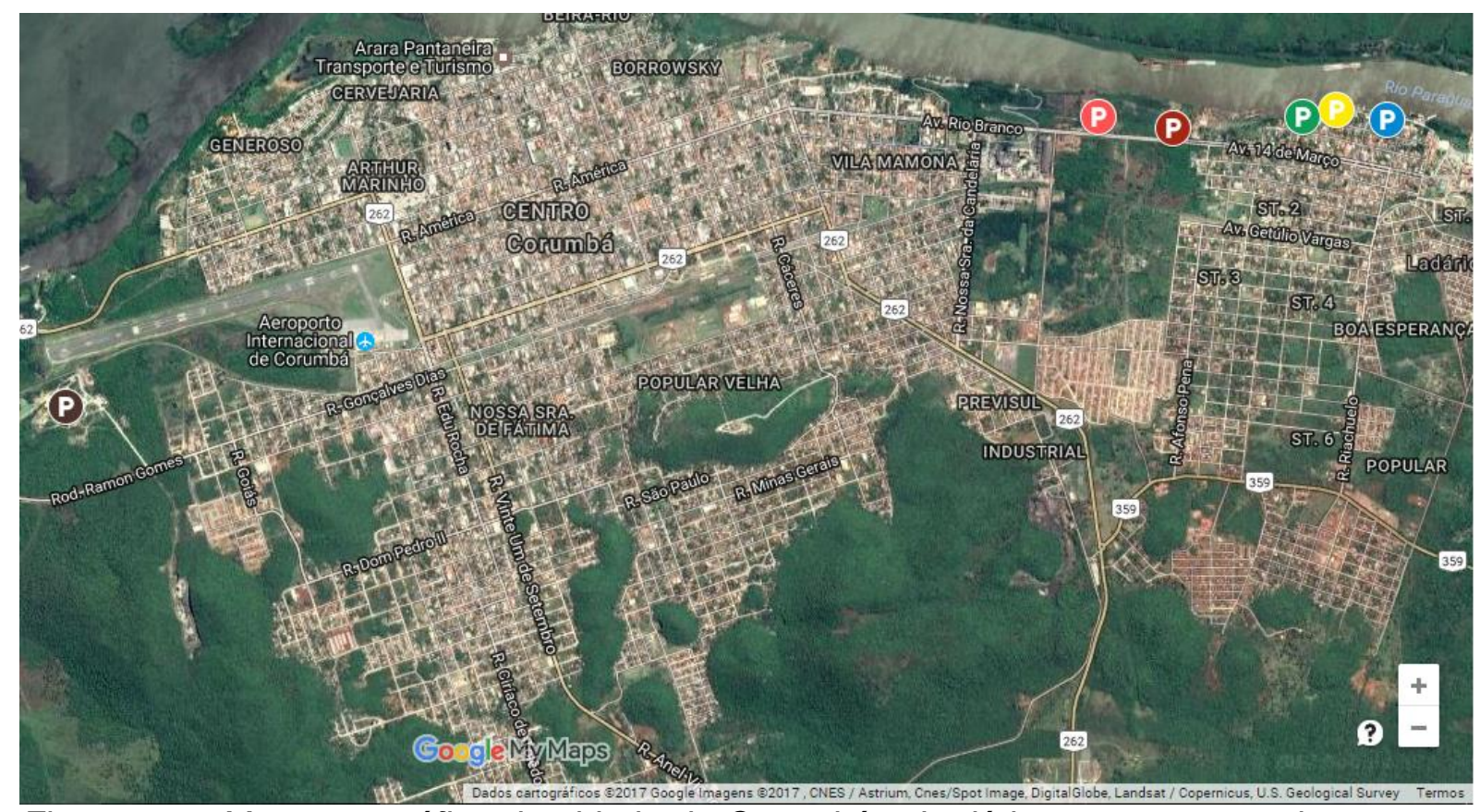

Figura 2. 4: Mapa geográfico da cidade de Corumbá e Ladário com os respectivos pontos aflorantes da Fm. Tamengo. Marcados da direita para esquerda P1, P2, P3, P4, P5, P6 e P7. Pontos no Porto Sobramil e Pontos da Mina Corcal.

Boggiani (1998) descreveu as fácies da Formação Tamengo (Figura 2.5), interpretando uma variação faciológica lateral de oeste para leste, na parte oeste presente o Craton Amazônico com uma maior diversidade de fácies, predominando ooid grainstones, ritmitos, mudstones e folhelhos carbonosos juntamente com a presença do registro fossilífero. Na parte leste presente a Faixa de dobramento ocorrem fácies de ritmitos e de mudstones.

As rochas carbonáticas estudadas na Formação Tamengo são atribuídas a rudstones com algumas intercalações de grainstones e mudstones, outros litotipos encontrados foram folhelhos de cores preta, cinza claro e amarelado quando intemperizados, arenito de granulometria muito fina a fina de cor avermelhada, siltito e ritmitos (Boggiani, 1998).

A presença de fácies de brechas intraformacionais de matriz micrítica com composição dolomítica, clastos constituídos de diferentes materiais provém de rochas da Formação Bocaina que foram transportadas, retrabalhadas e depositadas e as fácies de margas carbonosas que ocorrem em diversos níveis estratigráficos, é devido a ocorrência de minerais sulfetados como a pirita (Boggiani,1998). 


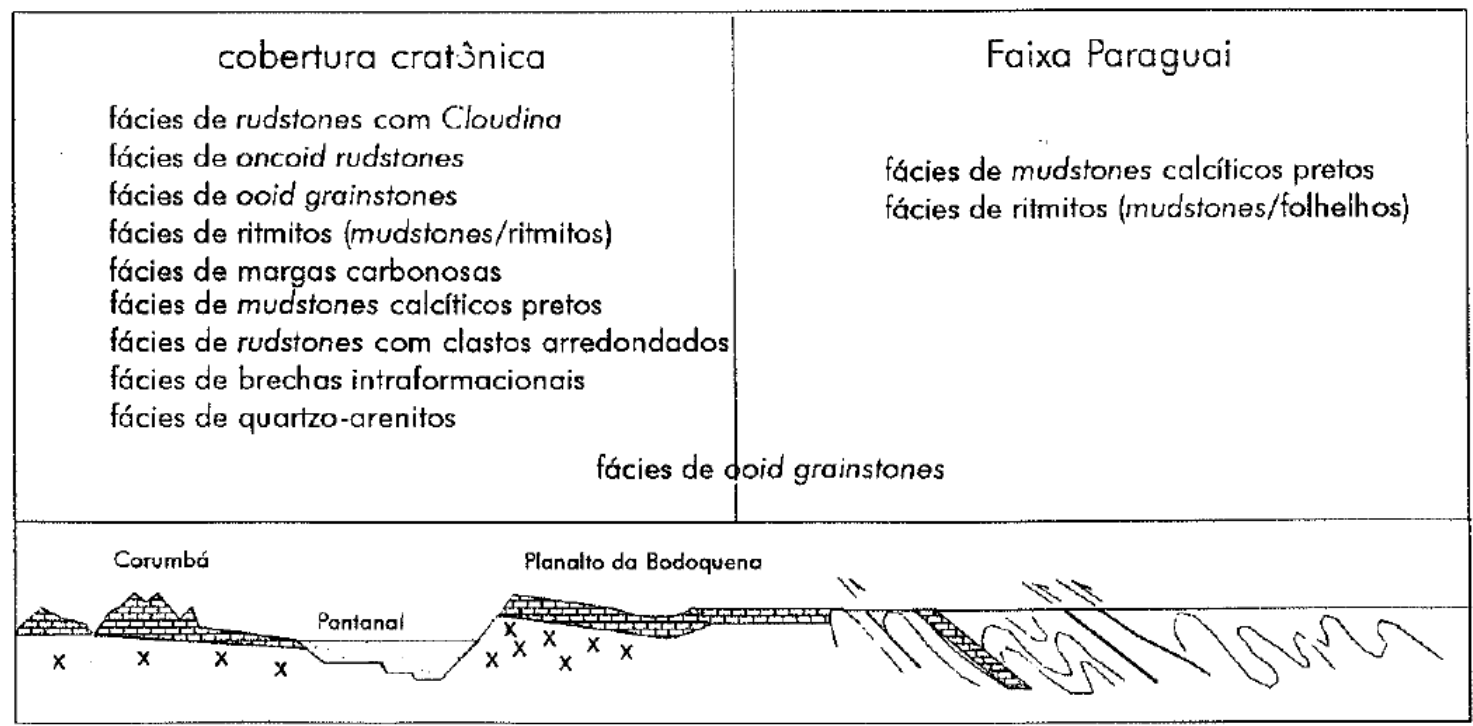

Figura 2.5: Relação das fácies encontradas na Formação Tamengo. Retirado de Boggiani (1998).

Boggiani (1998) e Boggiani et al. (2003) atribuíam valores isotópicos para $\delta^{13} \mathrm{C}$ de $-3 \%$ a $+5 \%$ para a Formação Tamengo, associando a incursão positiva de $\delta^{13} \mathrm{C}$ a seções pós-Varanger e ao soterramento generalizado em escala global de C orgânico. Oliveira (2010) atribuiu valores isotópicos para $\delta^{13} \mathrm{C}$ de $1,5 \%$ a $+5,4 \%$ para a Formação Tamengo retiradas da Mina Laginha e Mina Corcal associando ao aumento da atividade biológica.

Boggiani et al. (2010) realizaram um estudo de quimioestratigrafia isotópica da Formação Tamengo, atribuindo valores de isótopos de carbono em diversos pontos. A Mina Laginha localizada em Corumbá expõe toda a Formação, em brechas polimítcias cobertas por um pacote de wackestones e ritmitos mudstone/marga interpretadas como um processo de regressão seguida por uma subsequente transgressão na base da Formação, foram encontrados valores para $\delta^{13} \mathrm{C}$ de $-3.5 \%$. Acima nesse mesmo local, encontra-se um pacote de ritmito black mudstone/marga caracterizado como a parte intermediária da Formação Tamengo, com valores para $\delta^{13} \mathrm{CVPDB}_{\text {VP }}$ de $-3.5 \%$ o.Na parte superior da Formação, na Mina Laginha, em calcário wackstone homogêneo grosso com intercalações de rudstones encontraram valores para $\delta^{13} \mathrm{C}$ de $+3 \%$.

No Porto Sobramil e na Mina Corcal também atribuídas ao topo da Formação Tamengo e interpretadas como ambientes de nível de ondas de tempestades mais rasos que na Mina Laginha. Para o Porto Sobramil obtiveram valores para $\delta^{13} \mathrm{C}$ de 
$+4 \%$ e e $+5 \%$ o na maior parte da coluna e valores para $\delta^{13} \mathrm{C}$ de $+2 \%$ om seu topo. Para a Mina Corcal encontraram valores para $\delta^{13} \mathrm{C}$ de $+5 \%$ na maior parte da seção e obtiveram valores para $\delta^{13} \mathrm{C}$ de $+3 \%$ e $+4 \%$ tanto no topo quanto na base.

Valores de ${ }^{87} \mathrm{Sr} /{ }^{86} \mathrm{Sr}$ de 0.7086 foram obtidos de calcários na Mina Laginha representando a parte intermediaria da Formação Tamengo, valores de ${ }^{87} \mathrm{Sr} /{ }^{86} \mathrm{Sr}$ 0.07085 na Mina Corcal e valores de ${ }^{87} \mathrm{Sr} /{ }^{86} \mathrm{Sr} 0.7084$ e 0.785 no Porto Sobramil representando a parte superior da Formação, esses valores são comuns em estratigrafias que marcam a passagem do Neoproterozoico para o Cambriano (Boggiani, 1998; Babinski et al., 2008; Boggiani et al., 2010).

Através da datação radiométrica em SHRIMP com grãos de zircão presentes em tufo vulcânico em calcários com presença de C. lucianoi no topo da Formação Tamengo que ocorrem na Mina Corcal foi sugerida a idade máxima de $543 \pm 3 \mathrm{Ma}$ (Babinski et al., 2008). Parry et al. (submetido) analisaram três amostras de cinzas vulcânicas presentes no Grupo Corumbá, uma no topo da formação Bocaina e duas no Topo da Formação Tamengo através da datação de zircão definiram a idade para o topo da Formação Tamengo para 542 Ma. 


\subsection{Dados Paleontológicos}

Além de $C$. werneri já citada neste trabalho, a Formação Tamengo possui outras informações de registro fossilífero por toda a unidade.

Cloudina sp. (Beurlen \& Sommer) Germs, 1972 são metazoários bentônicos sésseis com possível afinidade com cnidários, carapaça de carbonato de cálcio secretada a partir de segmentos em funil dentro de seguimentos mais antigos com crescimento predominantemente vertical, presentes em calcários grainstones em uma zona definida aproximadamente entre 560 e 541 Ma (Germs, 1972; Hahn \& Pflug, 1985; Zaine \& Fairchild, 1985; Hua et al., 2005; Meira, 2011; Kerber, 2015). A ocorrência desse fóssil está centralizada no Paleoequador (Waggoner, 2003), podendo ser encontrada ao Sul da África no Grupo Nama (Grant, 1990), Sul da China na Formação Dengying (Hua et al., 2003, 2007), no México na Formação La Ciénega (Sour-tovar et al., 2007) e juntamente com C. werneri o fóssil de $C$. lucianoi Zaine \& Fairchild, 1985 é encontrada, no Paraguai no Grupo Itapucumi (Warren et al., 2011) e Brasil na Formação Tamengo (Zaine \& Fairchild, 1985; Meira, 2011; Kerber, 2015).

Conjunto de acritarcas presentes em siltitos no topo da Formação, repletas com a espécie Bavlinella faveolata (Schepeleva) Vidal, 1976 (Zaine, 1991; Gaucher et al., 2003). Microfósseis filamentosos e cocoidais mal preservados e raros carbonizados com coloração escura de calcários e folhelhos calcíferos, sendo os microfósseis cocoidais possivelmente plactônicos de diâmetro 7 a 15 micrometros (Zaine, 1991; Hidalgo, 2002). Finas estruturas denominadas vendotenídeos que variam de comprimento e largura com superfície lisa e homogênea sem estrutura celular aparente ou órgão reprodutores visíveis atribuídas a Tyrasotaenia sp. Gnilovskaya, 1979 (Zaine, 1991).

Hidalgo (2002) realizou um trabalho bioestratigráfico no Grupo Corumbá com microfósseis separando-os em categorias, na Formação Tamengo foram encontradas as categorias: microscópica contendo espécies cocoidais coloniais representados por Bavlinella faveolata e Eoentophysalis croxfordii (Muir) Butterfield et al. 1994 e as formas filamentosas representadas por Siphonophycus robustum Knoll 1991 e Siphonophycus sp. Knoll 1991, a categoria Incertae sedis: contendo micro ou macrofósseis de afinidades biológicas incertas atribuídos a acritarcas. 
Tobias (2014) realizou um estudo taxônomico descrevendo e identificando lâminas palinológicas, lâminas petrográficas e amostras de mão contendo macro e microfósseis da Formação Tamengo retiradas no afloramento Eco Parque Cacimba da Saúde. Tobias (2014) encontrou seis espécies de palinomorfos: sendo Leiosphaeridia crassa (Pykhova 1973), Leiosphaeridia tenuissima Eisenack, 1958, Bavlinella faveolata, Myxococcoides? sp.1 com formas esféricas simples, Rugosoopsis? sp.1 com forma filamentosa e Melanocyrillium? sp.1 com forma de vaso. E duas espécies mineralizadas representadas por Cloudina lucianoi e Corumbella werneri. Tobias (2014) então propôs um intervalo bioestratigráfico para o afloramento tendo a base marcada pelo aparecimento de $C$. wernerie o topo marcado pelo desaparecimento de $C$. lucianoi, sendo esse intervalo composto por espécies de Leiosphaeridia crassa, Leiosphaeridia tenuissima, Bavlinella faveolata, Myxococcoides? sp.1, Rugosoopsis? sp.1 e Melanocyrillium? sp.1. 


\section{MATERIAS E MÉTODOS}

\subsection{Material analisado}

Neste trabalho foram analisadas 160 amostras contendo diferentes registros fossilíferos sendo que 69 amostras possuíam 357 espécimes fósseis de $C$. werneri com posição estratigráfica descrita.

Dessa amostras, 43 foram coletadas em duas saídas a campo uma em maio de 2016 visando coletar e descrever a posição estratigráfica dos materiais encontrados, coordenada pela professora Juliana de Moraes Leme (GSA/IGc/USP) e participação dos professores Paulo César Boggiani (GSA/IGc/USP) e Alexander Liu (Cambridge University). E outra em setembro de 2016 com os professores Juliana de Moraes Leme e Paulo César Boggiani (GSA/IGc/USP), com o intuito de aumentar o número de informações, certificar as informações do campo anterior e esclarecer questões que surgiram no decorrer do trabalho.

As outras 26 amostras já estavam catalogadas no laboratório de coleção cientifica de Paleontologia do Instituto de Geociências da Universidade de São Paulo (IGc/USP), no qual possui um dos maiores acervos de $C$. werneri do mundo, esses materiais foram retirados da Formação Tamengo presente nas cidades Corumbá e Ladário no Mato Grosso do Sul em determinados pontos da cidade onde a Formação aflora e nas Minas Laginha e Corcal e no Porto Sobramil. De todos os fósseis de $C$. werneri presentes na coleção foram utilizados apenas para este trabalho aqueles que já possuíam de alguma forma a descrição de sua posição estratigráfica.

Após a coleta as amostras foram tombadas na coleção científica de Paleontologia do Instituto de Geociências (IGc/USP). Cada amostra recebeu um número único sobre o prefixo GP/1e que o atribui ao grupo dos invertebrados dentro da coleção e uma ficha contendo as principais informações da amostra. 


\subsection{Descrição do material}

Para realização da descrição e identificação dos fósseis foram realizadas imagens digitais e em Microscopia Eletrônica de Varredura, além da realização de medições de algumas características morfológicas e análises químicas através do EDS (Espectroscopia de Energia Dispersiva).

- Imagens digitais dos fósseis: Os espécimes estudados foram analisados e fotografados em estereomicroscópio Zeiss, modelo Stemi 508 com câmera digital, acoplada a um microcomputador PC e o software Zen. Esse método permitiu o alto poder de resolução e ampliação das imagens e possibilitou a obtenção das principais feições morfológicas dos fósseis, diretamente na tela do computador, sendo o método mais adequado e eficiente para o material em estudo.

- Imagens digitais em Microscópio Eletrônico de Varredura e EDS: Alguns dos espécimes examinados foram fotografados em VPSESEM (Variable Pressure Enviromental Scanning Electron Microscope) um Microscópio Eletrônico de Varredura de pressão variável e ambiental modelo QUANTA 250, da marca FEI. Esse método permitiu o alto poder de resolução e ampliação das imagens e possibilitou a observação das principais feições morfológicas dos fósseis e sua composição química.

\subsection{Análise tafonômica básica.}

Para a realização da análise tafonômica básica do material encontrado, foram selecionadas algumas assinaturas tafonômicas propostas por Holz \& Simões (2002) para a descrição e interpretação tafonômica.

- Grau de empacotamento (GDE): varia-se entre densamente empacotada, fracamente empacotada e dispersa inferindo diretamente ao contato físico, quantidade e o suporte em relação a matriz dos fósseis. Pode indicar aumento brusco na disponibilidade de indivíduos (mortalidade em massa) ou até mesmo deposição de restos orgânicos durante um longo tempo com baixa taxa de sedimentação (mistura temporal). 
- Fragmentação (FRAG): varia-se entre completa, incompleta e fragmentada. Pode ser causada em um ambiente de alta energia, efeito do transporte ou até mesmo longa duração no substrato devido à baixa taxa de sedimentação.

- Preservação da carapaça (PC): varia-se entre preservada, parcialmente preservada e molde. Pode indicar efeitos diagenéticos ou tempo de exposição no substrato.

\subsection{Seções Estratigráficas}

O estudo estratigráfico foi realizado em sete pacotes pelíticos (Figura 2.2) aqui denominadas pela letra "P" fazendo uma alusão a litologia pelítica da seção. Foram atribuídas ordens numéricas respectivas a sua posição na formação de P1 a P3 correspondendo a base, P4 correspondendo a parte intermediária e P5 a P7 correspondendo a parte superior, sendo este último grupo separados em P5S, P6S e P7S relacionados ao Porto Sobramil e P5C, P6C e P7C relacionados a Mina Corcal, que estão correlacionados estratificamente entre si.

Foi realizada a medição centímetrica das seções pelíticas estudadas e efetuou-se a descrição de fácies sedimentares correlacionando a medida com litologia, estruturas sedimentares, granulometria e conteúdo fossilífero com base em Dunham (1962). A partir desses dados foram confeccionados perfis litoestratigráficos em programas de desenho Corel Draw proporcionando o detalhamento da distribuição fossilífera e por consequência a interpretação da paleoecologia da Formação Tamengo e a variabilidade vertical das fácies sedimentares. 


\section{RESULTADOS}

\subsection{Análise Estratigráfica}

Foram elaboradas seções estratigráficas de detalhe dos níveis de ocorrência dos fósseis de $C$. werneri. Para isso, foram realizados dois trabalhos de campo na região de Ladário e Corumbá, MS para o levantamento das seções e detalhamento dos litotipos onde os fósseis ocorrem. A partir do levantamento estratigráfico realizado, foi possível estabelecer sete níveis de folhelhos, atribuídos aqui nesse trabalho, como níveis $\mathrm{P} 1$ a P7, conforme a posição da base para o topo da seção (Figura 2.2). Nas seções estratigráficas de detalhe dos folhelhos, foi possível pontuar as posições dos fósseis e icnofósseis, em escala centimétrica, além de realizar uma descrição dos litótipos.

\subsubsection{Seção Estratigráfica - $P 1$}

Essa seção estratigráfica corresponde a porção mais basal aflorante da Formação Tamengo. Encontra-se no município de Ladário, MS, próximo ao Porto Ladário (19ำ 00' 09" S $57^{\circ} 60^{\prime}$ 13" W) (Figura 4.1).

A seção possui $220 \mathrm{~cm}$ de espessura, a base é demarcada por calcário mudstone laminado, acima ocorre um pacote de $55 \mathrm{~cm}$ de folhelho entre dois níveis de ritmito folhelho/calcário um com $5 \mathrm{~cm}$ e outro com $15 \mathrm{~cm}$ de espessura respectivamente. Subsequente há um arenito fino avermelhado com $5 \mathrm{~cm}$ de espessura, imediato ocorrem camadas de $3 \mathrm{~cm}$ de ritmito folhelho/calcário, $5 \mathrm{~cm}$ de ritmito folhelho/siltito. Novamente, ocorrem $10 \mathrm{~cm}$ de folhelho acinzentado, seguido de $2 \mathrm{~cm}$ de arenito e 10 $\mathrm{cm}$ de siltito maciço. Segue um pacote de $30 \mathrm{~cm}$ de folhelho e $10 \mathrm{~cm}$ de arenito, imediato a uma camada de $5 \mathrm{~cm}$ de argilito, subsequente a $15 \mathrm{~cm}$ de ritmito arenito/calcário e $40 \mathrm{~cm}$ de ritmito folhelho/ arenito, separados por $10 \mathrm{~cm}$ de calcário mudstone. Calcário grainstone demarcam o topo da seção (Figura 4.2).

Foram coletadas 7 amostras em 4 posições fossilíferas contendo 14 espécimes de $C$. werneri todas incompletas. A primeira posição está a $75 \mathrm{~cm}$ da base da seção, representado por uma amostra contendo uma $C$. werneri incompleta. A segunda posição ocorre entre $190 \mathrm{~cm}$ a $192 \mathrm{~cm}$, sendo duas amostras contendo 9 espécimes 
de $C$. werneri caracterizando como nível fossilífero por obter um número maior de 5 espécimes em uma distância menor de $5 \mathrm{~cm}$. Os dois últimos níveis com $C$. werneri estão a $200 \mathrm{~cm}$ e $220 \mathrm{~cm}$. Nos dois níveis foram coletados duas espécimes de $C$. werneri incompletas em duas amostras. A $100 \mathrm{~cm}$ da base da seção, foi encontrada uma amostra com icnofósseis. Também foram encontrados amostras de calcários, que estavam rolados, contendo icnofósseis.
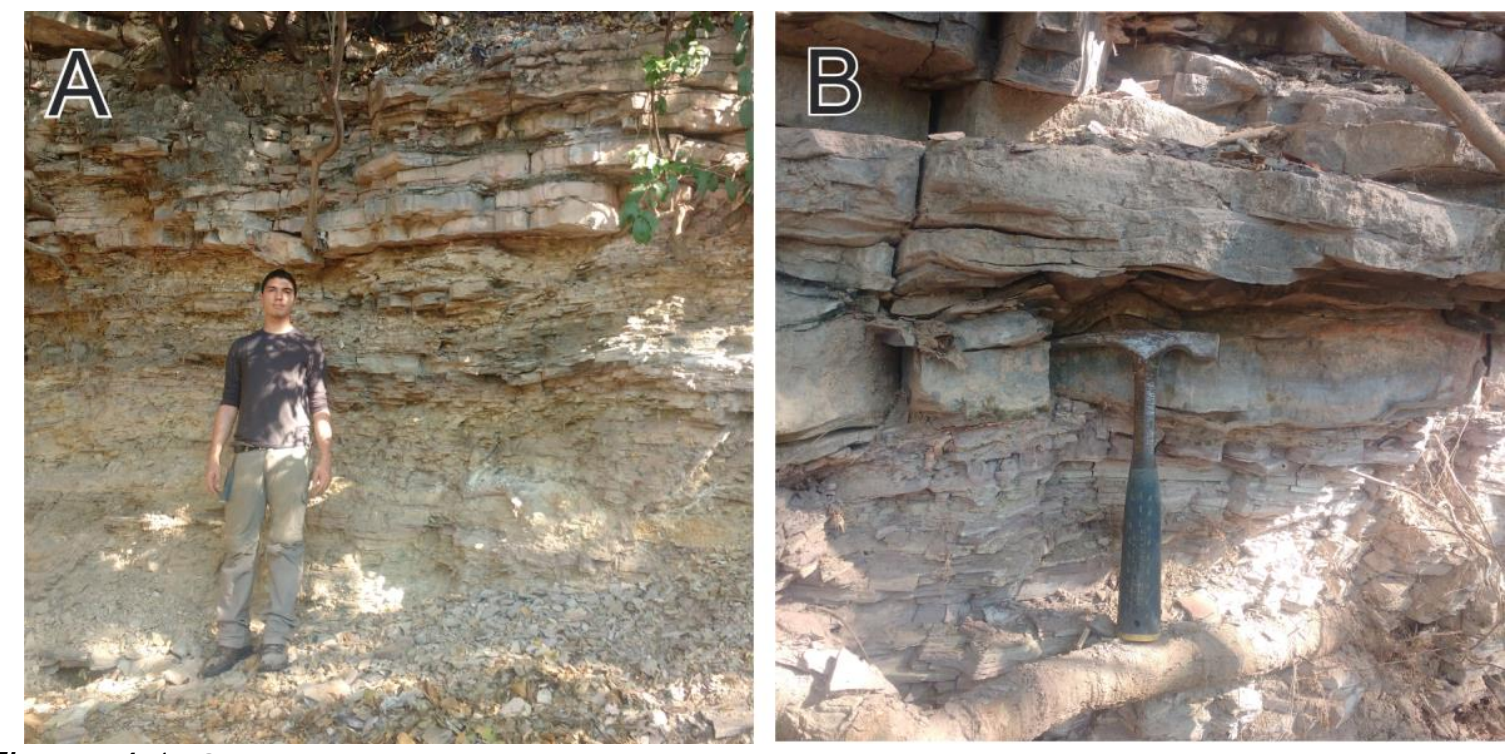

Figura 4.1: Seção P1 da base da Formação Tamengo. A: Imagem completa da seção. B: Detalhe da Seção apresentando calcário e ritmitos. 


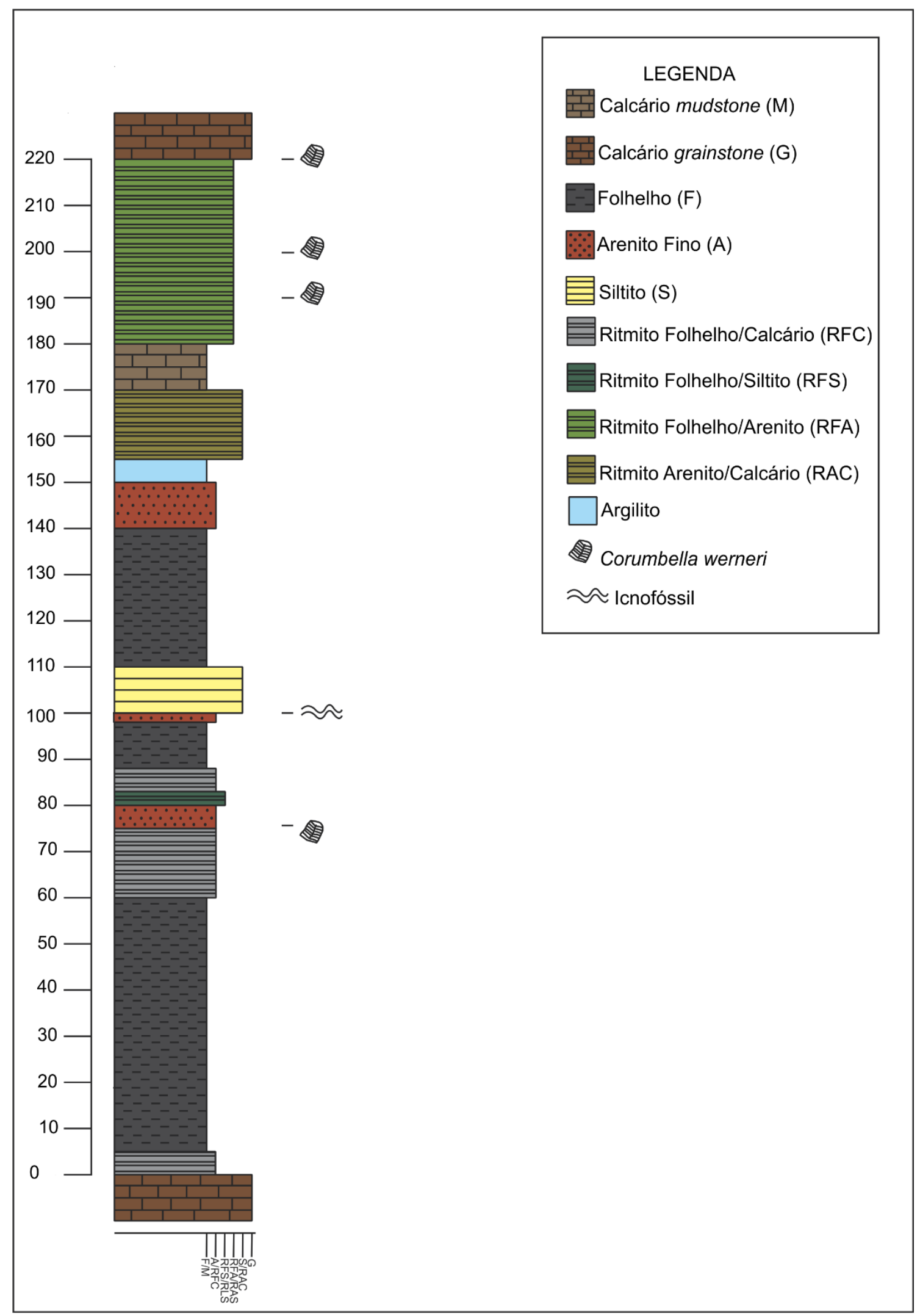

Figura 4.2 Seção estratigráfica do pacote de pelito - $P 1$ da base da exposição da Formação Tamengo. Unidade de medida da Seção em $\mathrm{cm}$. 


\subsubsection{Seção Estratigráfica - $P 2$}

A seção estratigráfica P2 ocorre em Ladário, MS, abaixo da Pousada Pantanal em frente ao rio Paraguai (19०00'04" S $57^{\circ} 60^{\prime} 42^{\prime \prime}$ W) (Figura 4.3).

A seção estratigráfica possui $160 \mathrm{~cm}$ em seu total, é caracterizada por ser homogênea. Na base ocorrem calcários mudstone, acima ocorre um pacote de ritmito folhelho/siltito de $120 \mathrm{~cm}$, seguido por uma camada de $15 \mathrm{~cm}$ de calcário mudstone. Subsequente há uma outra camada de ritmito folhelho/siltito de $25 \mathrm{~cm}$ de espessura. O topo da seção é demarcado por calcário grainstone com hummocky (Figura 4.4).

Foram encontradas 15 amostras em cinco posições fossilíferas com $C$. werneri todos no ritmito folhelho/siltito, com um total de 74 exemplares incompletos e 4 amostras contendo fragmentos. O primeiro nível ocorre entre 28 e $30 \mathrm{~cm}$ contendo 39 exemplares de $C$. werneri em sete amostras. $O$ segundo, está a $40 \mathrm{~cm}$ contendo 12 espécimes de $C$. werneri em duas amostras. Outra posição está a $50 \mathrm{~cm}$ contendo 4 espécimes de $C$. werneri em uma amostra. O próximo nível ocorre entre 57 a $60 \mathrm{~cm}$ contendo 10 espécimes em duas amostras. A última posição está a $100 \mathrm{~cm}$ contendo 9 exemplares $C$. werneri em três amostras sendo que nesta última posição também foi coletada uma amostra contendo icnofósseis. A $147 \mathrm{~cm}$ foi encontrada uma amostra com fóssil que se assemelha a um filamento (veja item 4.3, mais adiante).
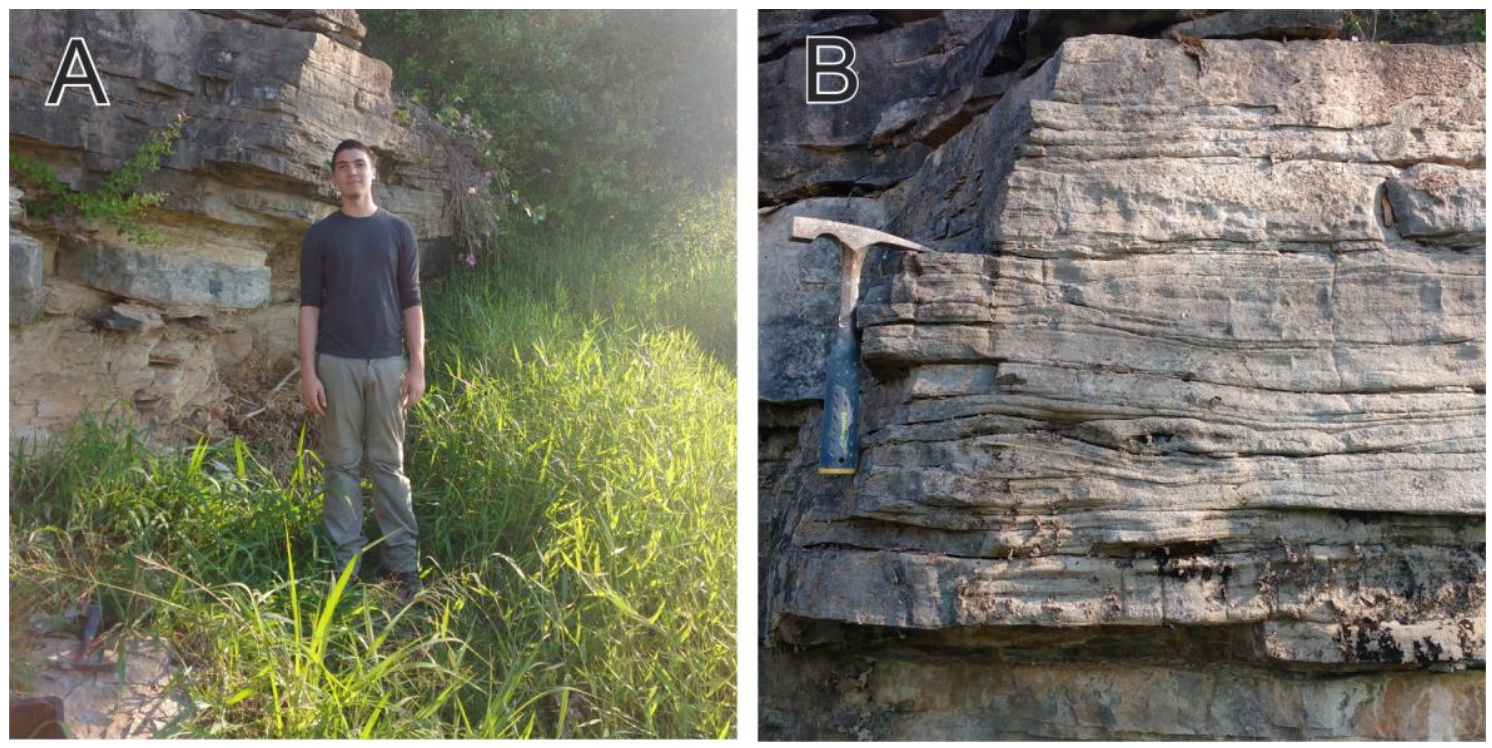

Figura 4.3: Seção estratigráfica $P 2$, parte inferior da Formação Tamengo. A: Imagem completa da seção. B: Detalhe da Seção apresentando o calcário e estrutura sedimentar estilo hummocky. 


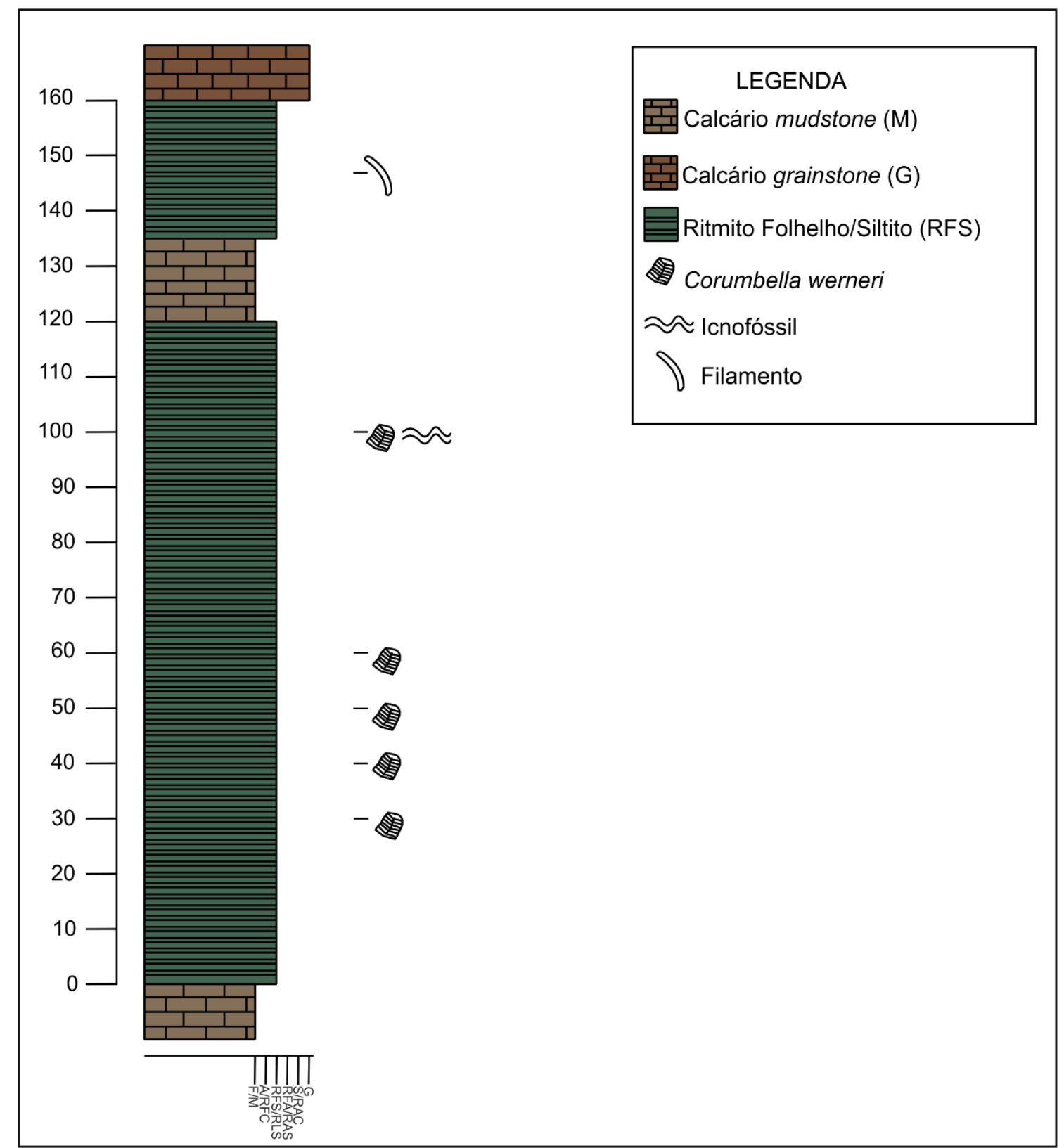

Figura 4.4: Seção do pacote de pelito - P2 exposto em Ladário subsequente a P1 da Formação Tamengo. Unidade de medida da Seção em $\mathrm{cm}$.

\subsubsection{Seção Estratigráfica - P3}

A seção estratigráfica P3 encontra-se na cidade de Ladário, MS beirando o rio Paraguai $\left(19^{\circ} 00^{\prime} 11^{\prime \prime} \mathrm{S} 57^{\circ} 60^{\prime} 80^{\prime \prime} \mathrm{W}\right)$ (Figura 4.5).

O tamanho total da seção são de $140 \mathrm{~cm}$ de espessura, na base ocorre calcário grainstone seguido por $30 \mathrm{~cm}$ de siltito e um grande pacote de folhelho com $90 \mathrm{~cm}$ de espessura intercalado com duas camadas finas de calcário mudstone e duas camadas 
de ritmito folhelho/siltito com $10 \mathrm{~cm}$ e $5 \mathrm{~cm}$ de espessura respectivamente, o topo da coluna é demarcado por calcário mudstone (Figura 4.6).

Foram coletadas 28 amostras em 10 posições ao longo da coluna estratigráfica com a presença de 167 espécimes de $C$. werneri. O primeiro nível ocorre entre $40 \mathrm{~cm}$ a $43 \mathrm{~cm}$ contendo 47 espécimes em cinco amostras. O segundo nível ocorre entre 45 a $48 \mathrm{~cm}$ contendo 39 exemplares de $C$. werneri em cinco amostras. Em $55 \mathrm{~cm}$ ocorre 1 exemplar em uma amostra, em $61 \mathrm{~cm}$ ocorrem 8 indivíduos em uma amostra e em $70 \mathrm{~cm}$ e $75 \mathrm{~cm}$ em uma amostra cada ocorre 1 indivíduo. Outro nível aparece entre 80 a $83 \mathrm{~cm}$ contendo 24 espécimes em quatro amostras. Em $91 \mathrm{~cm}$ ocorrem 2 individuos em uma amostra e em $93 \mathrm{~cm} 1$ exemplar em uma amostra. Em $115 \mathrm{~cm}$ coletou-se uma amostra contendo 8 individuos, em $120 \mathrm{~cm}$ na mesma amostra há 10 espécimes de $C$. werneri e em outra camada apresenta fósseis que se assemelham a filamentos e em $133 \mathrm{~cm}$ a 135 contendo 25 individuos em seis amostras.

Em especial na posição de $75 \mathrm{~cm}$ em uma mesma amostra além de apresentar uma espécime de Corumbella werneri, também encontra-se organismos que se assemelham a filamentos e em uma outra amostra encontrada ocorre a presença de uma possível alga (veja item 4.3, mais adiante). Quatro espécimes de filamentos são encontrados em um nível entre 50 a $53 \mathrm{~cm}$ em duas amostras. O fóssil de Paraconularia sp. já havia sido descoberta e classificada nesta seção (Van iten et al., 2016) e outra espécie de alga foi encontrada em uma amostra rolada próxima a seção estratigráfica.
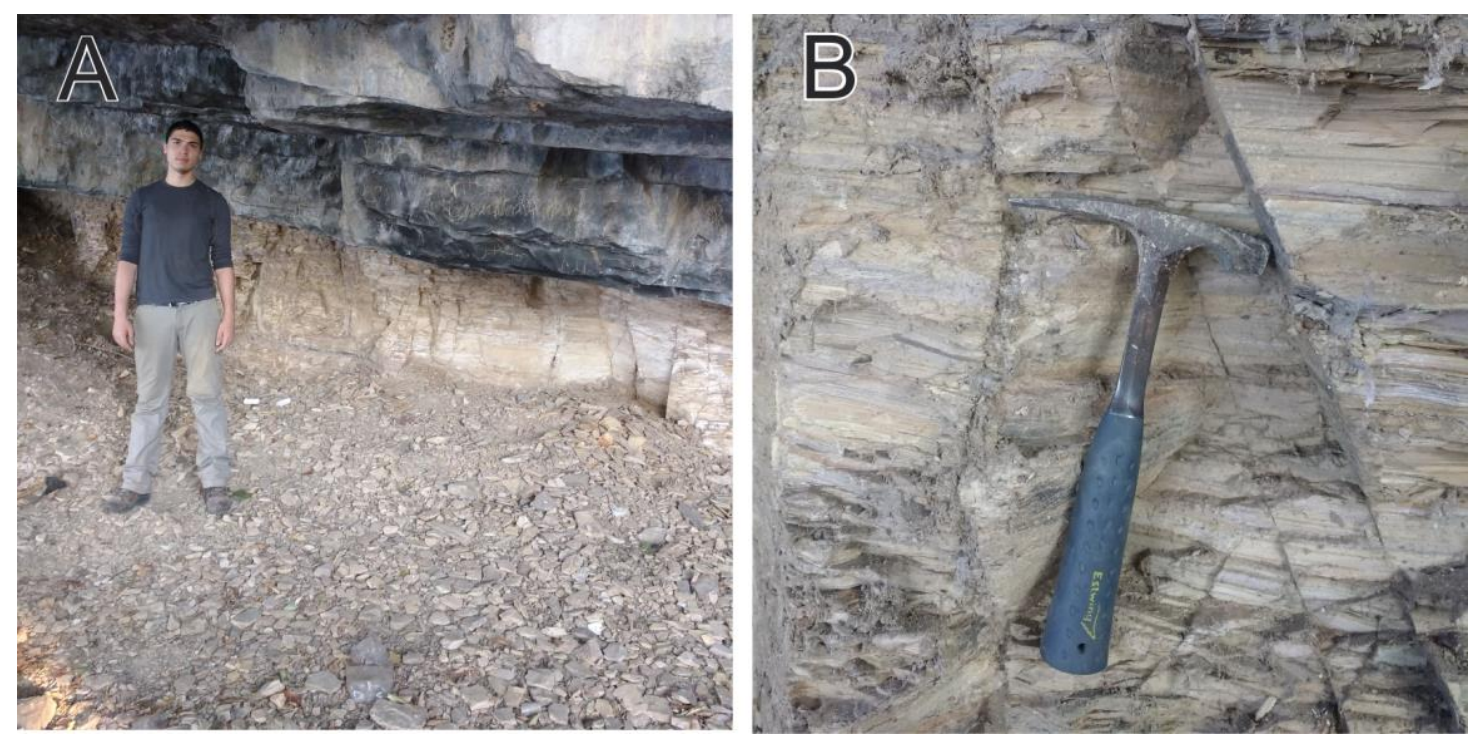

Figura 4.5: Seção P3, parte inferior da Formação Tamengo. A: Imagem completa da seção. B: Detalhe da Seção apresentando ritmitos. 


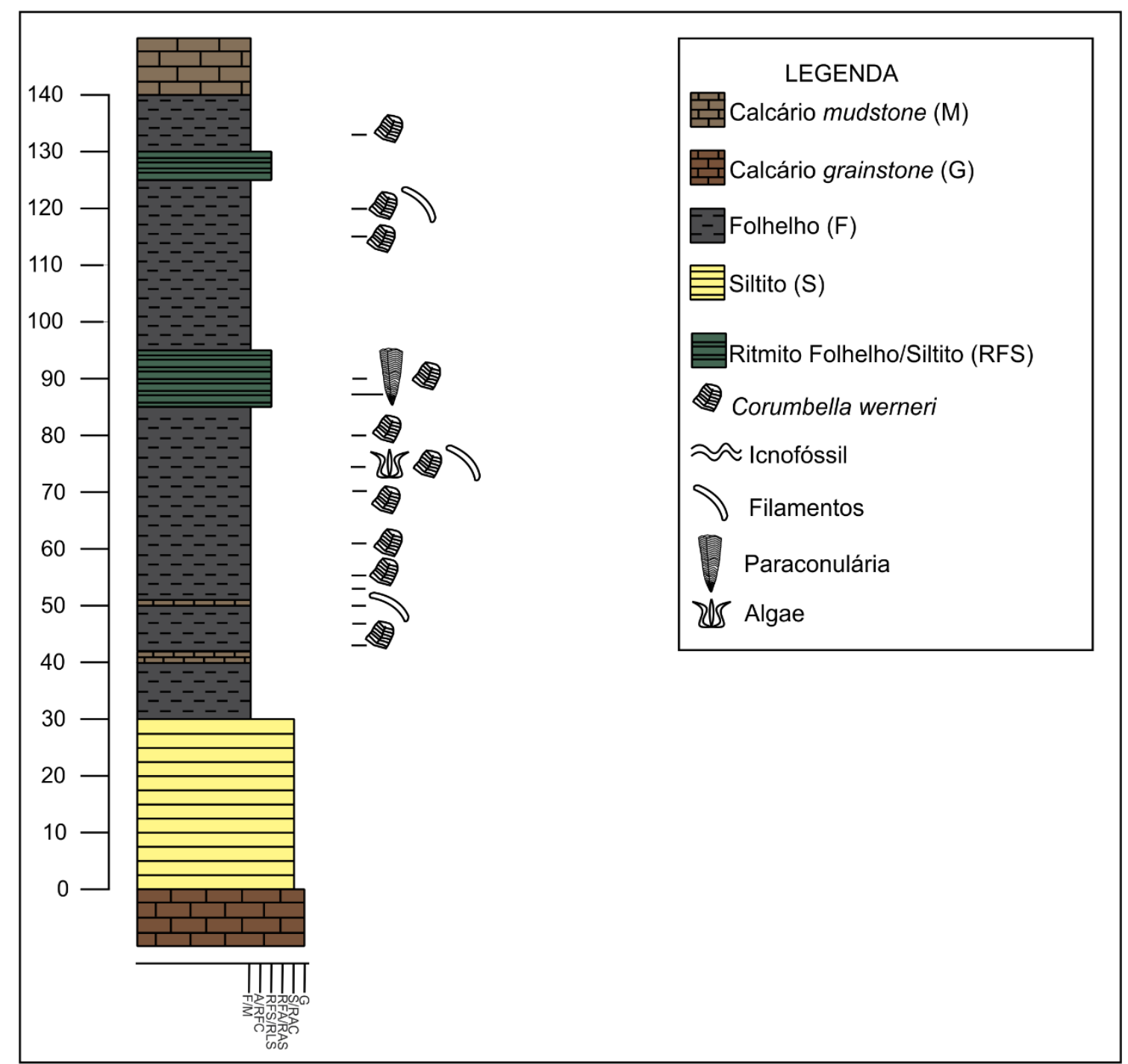

Figura 4.6: Seção estratigráfica do pacote de pelito - $P 3$ em Ladário subsequente a $P 2$ da Formação Tamengo. Unidade de medida da Seção em $\mathrm{cm}$.

\subsubsection{Seção Estratigráfica - P4}

A seção denominada P4 ocorre na cidade de Corumbá no território do Hotel Gold Fish (1000' 15" S $57^{\circ} 61^{\prime} 41^{\prime \prime}$ W) (Figura 4.7).

A seção possui em seu total $320 \mathrm{~cm}$ de espessura, tanto a base quanto o topo estão delimitados por calcário mudstone, a litologia da seção é homogênea, contendo um pacote de siltito laminado com $220 \mathrm{~cm}$ de espessura seguido por um pacote de arenito muito fino com $100 \mathrm{~cm}$ de espessura (Figura 4.8).

Nessa seção estratigráfica não foram encontrados fósseis de Corumbella werneri ou de qualquer fóssil corpóreo. No entanto, foram encontradas 26 amostras em oito posições ao longo da seção que contém icnofósseis, no siltito foram encontradas 25 
amostras e estão demarcados na medida de $15 \mathrm{~cm}, 30 \mathrm{~cm}, 40 \mathrm{~cm}, 50 \mathrm{~cm}, 115 \mathrm{~cm}$, $130 \mathrm{~cm}$ e $140 \mathrm{~cm}$, no arenito foi encontrada uma amostra em $250 \mathrm{~cm}$.

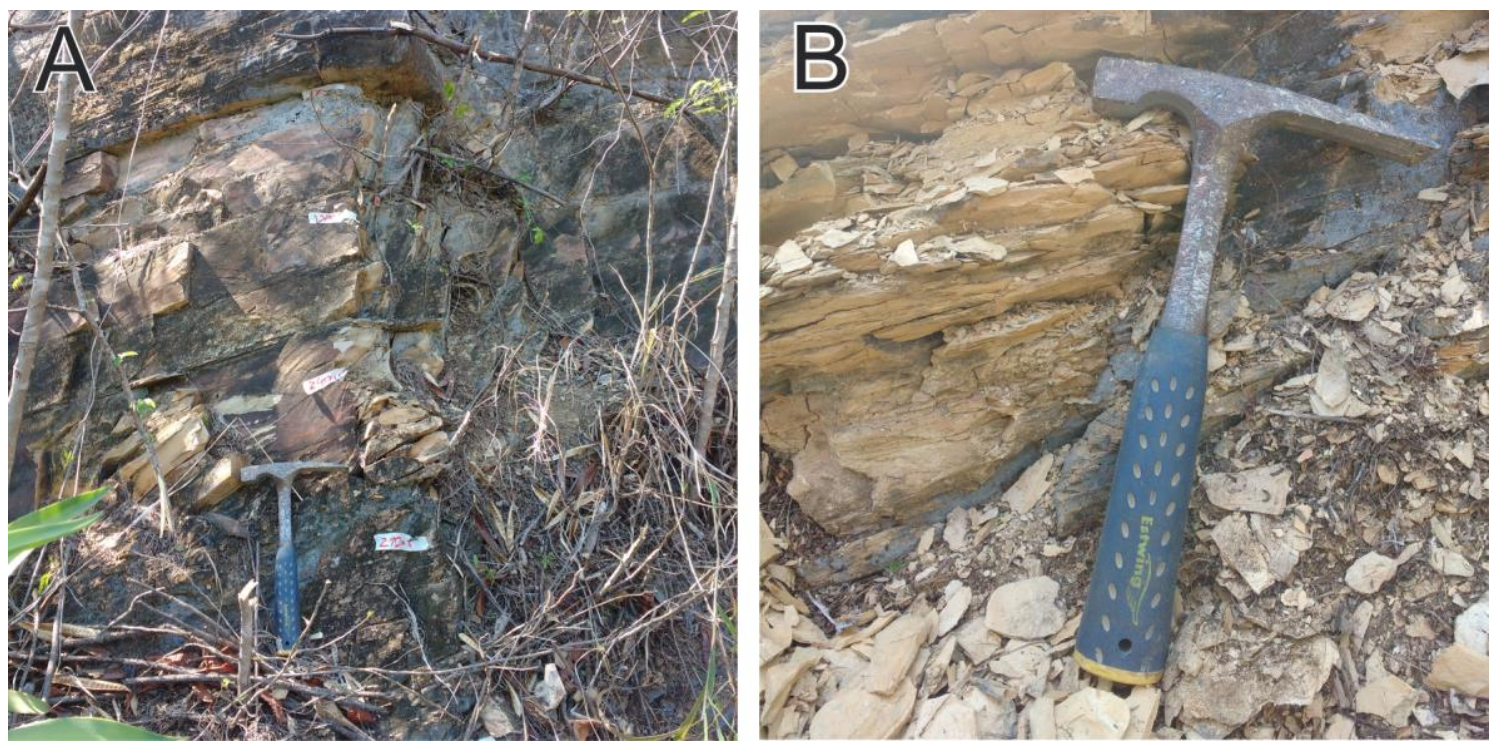

Figura 4.7: Seção P4, parte intermediária da Formação Tamengo. A: Imagem ampla da seção. B: Detalhe da Seção apresentando siltito. 


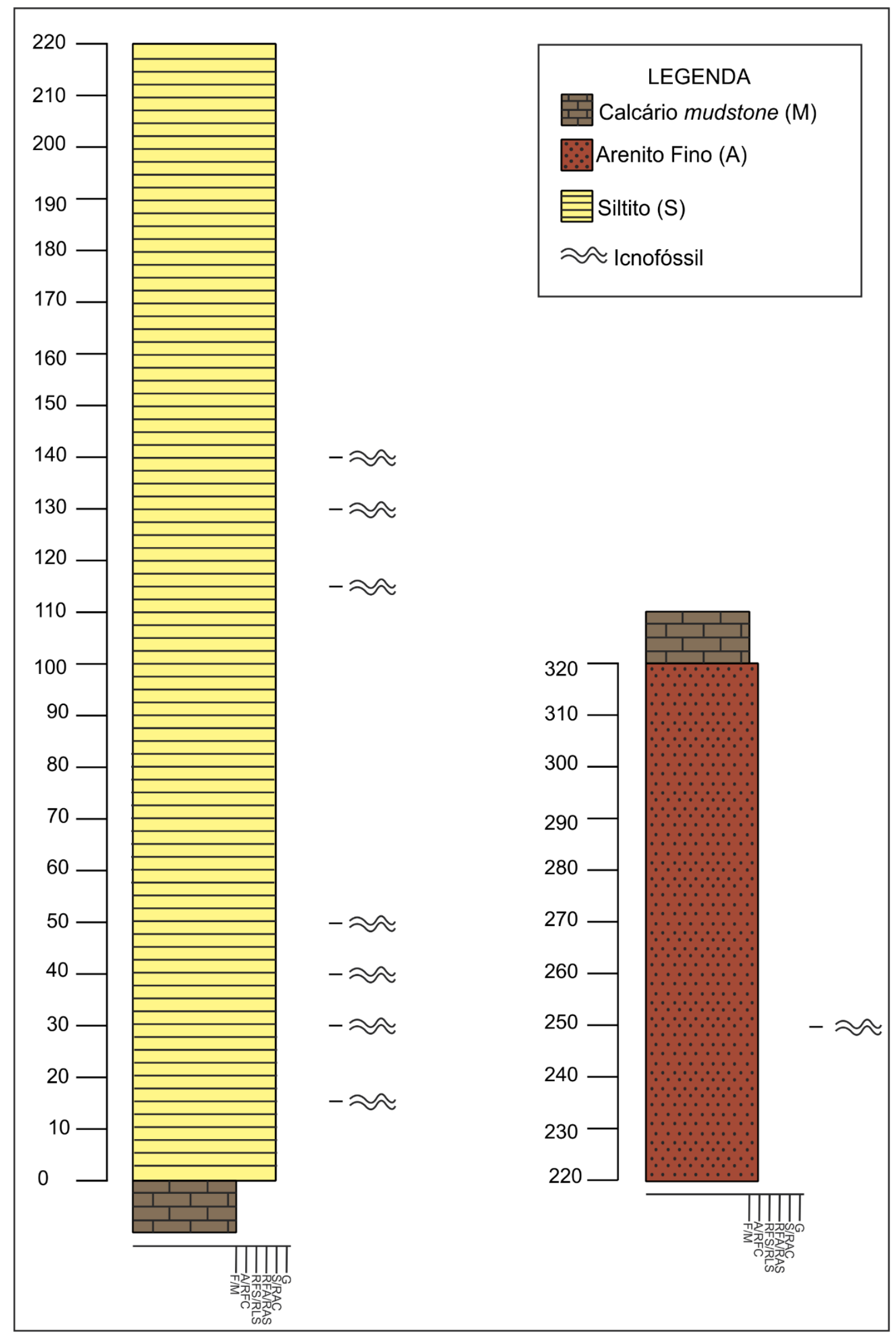

Figura 4.8: Seção estratigráfica do pacote de pelito - P4, exposto no Hotel Gold Fish em Corumbá subsequente a P3 da Formação Tamengo. Unidade de medida da Seção em $\mathrm{cm}$. 


\subsubsection{Seção Estratigráfica - P5S}

A seção estratigráfica correspondente a P5S representa o topo da Formação Tamengo, ocorre na bancada intermediária do Porto Sobramil (19०00' 01" S $57^{\circ} 62^{\prime}$ 02" W) (Figura 4.9).

Possui $370 \mathrm{~cm}$ de espessura com litologia heterogênea, a base é composta por calcário mudstone, seus primeiros $70 \mathrm{~cm}$ não possuem exposição impossibilitando a identificação do litotipo, logo em seguida existe $100 \mathrm{~cm}$ de siltito estratificado, posterior a ele ocorre uma camada de $25 \mathrm{~cm}$ de ritmito arenito muito fino/siltito, seguido de uma fina camada de $5 \mathrm{~cm}$ de arenito muito fino e maciço deformado com estruturação vertical. Logo após ocorre uma camada de $50 \mathrm{~cm}$ de ritmito arenito fino/siltito, seguido de $40 \mathrm{~cm}$ de siltito estratificado e de duas camadas de ritmito folhelho/siltito com 50 $\mathrm{cm}$ e $15 \mathrm{~cm}$ de espessura separadas por uma camada de $15 \mathrm{~cm}$ de arenito fino. $\mathrm{O}$ topo da coluna também é demarcado por calcário mudstone (Figura 4.10).

Foram coletadas 10 amostras em cinco posições estratigráficas contendo 23 espécimes de Corumbella werneri, sendo que oito dessas amostras também apresentam espécimes fragmentadas. A primeira posição ocorre em $170 \mathrm{~cm}$ contendo 1 indivíduo, em três amostras distintas na mesma posição também foram coletadas amostras contendo icnofósseis. Um nível aparecem entre 319 a $324 \mathrm{~cm}$ contendo 7 espécimes em três amostras, outro nível ocorre em $350 \mathrm{~cm}$ contendo 15 indivíduos em cinco amostras e a última posição em $365 \mathrm{~cm}$ com espécimes fragmentadas onde também há ocorrência de icnofósseis mas em uma outra camada da amostra. Foram encontrados 12 amostras contendo icnofósseis ao longo da seção estratigráfica, mas especificamente em $120 \mathrm{~cm}, 130 \mathrm{~cm}$, em 190 a $193 \mathrm{~cm}$ apresentando 3 amostras, em $250 \mathrm{~cm}$ com duas amostras onde também ocorrem filamentos e uma amostra em 270 $\mathrm{cm}$ no siltito. 

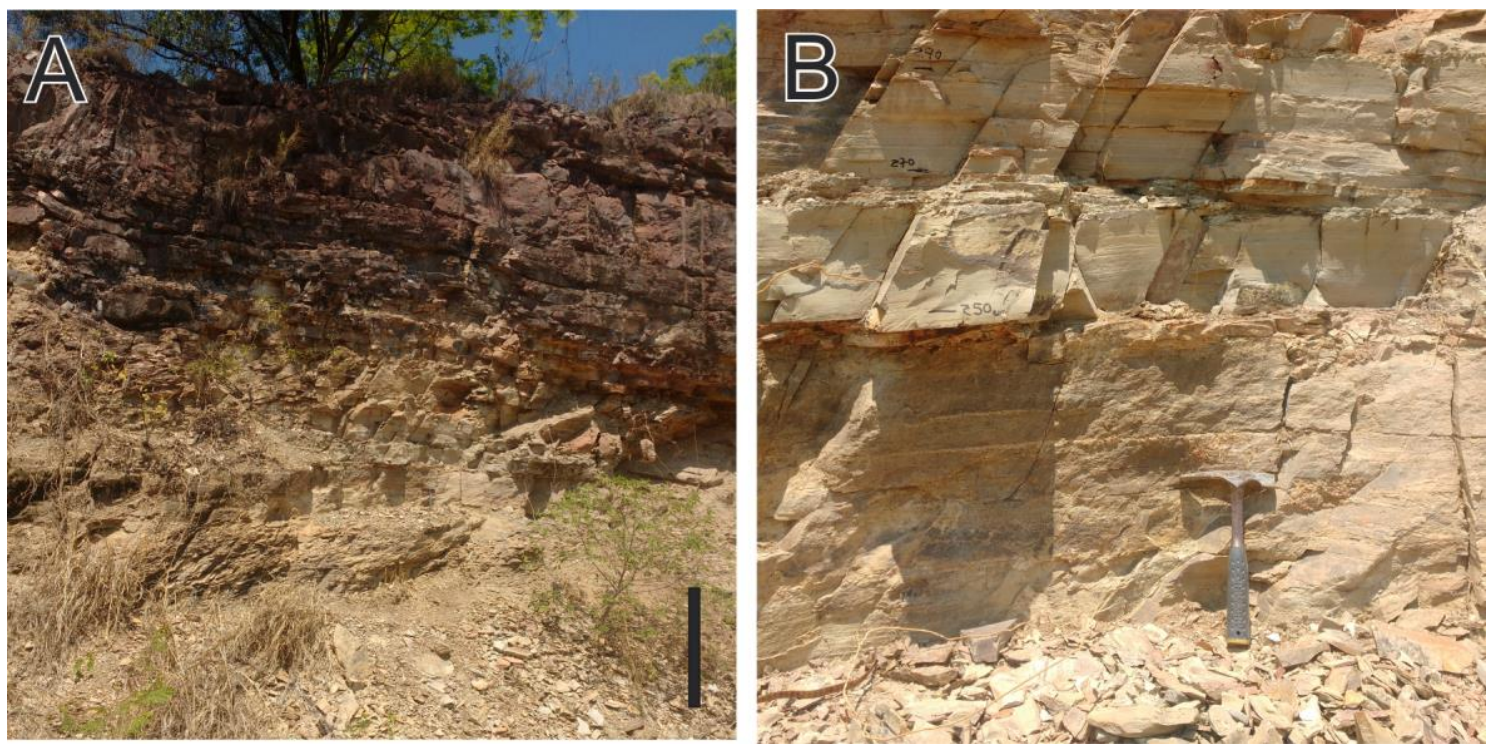

Figura 4.9: Seção P5S, parte superior da Formação Tamengo. A: Imagem ampla da seção, Escala: 1,4 m. B: Detalhe da seção apresentando siltito e ritmitos. 


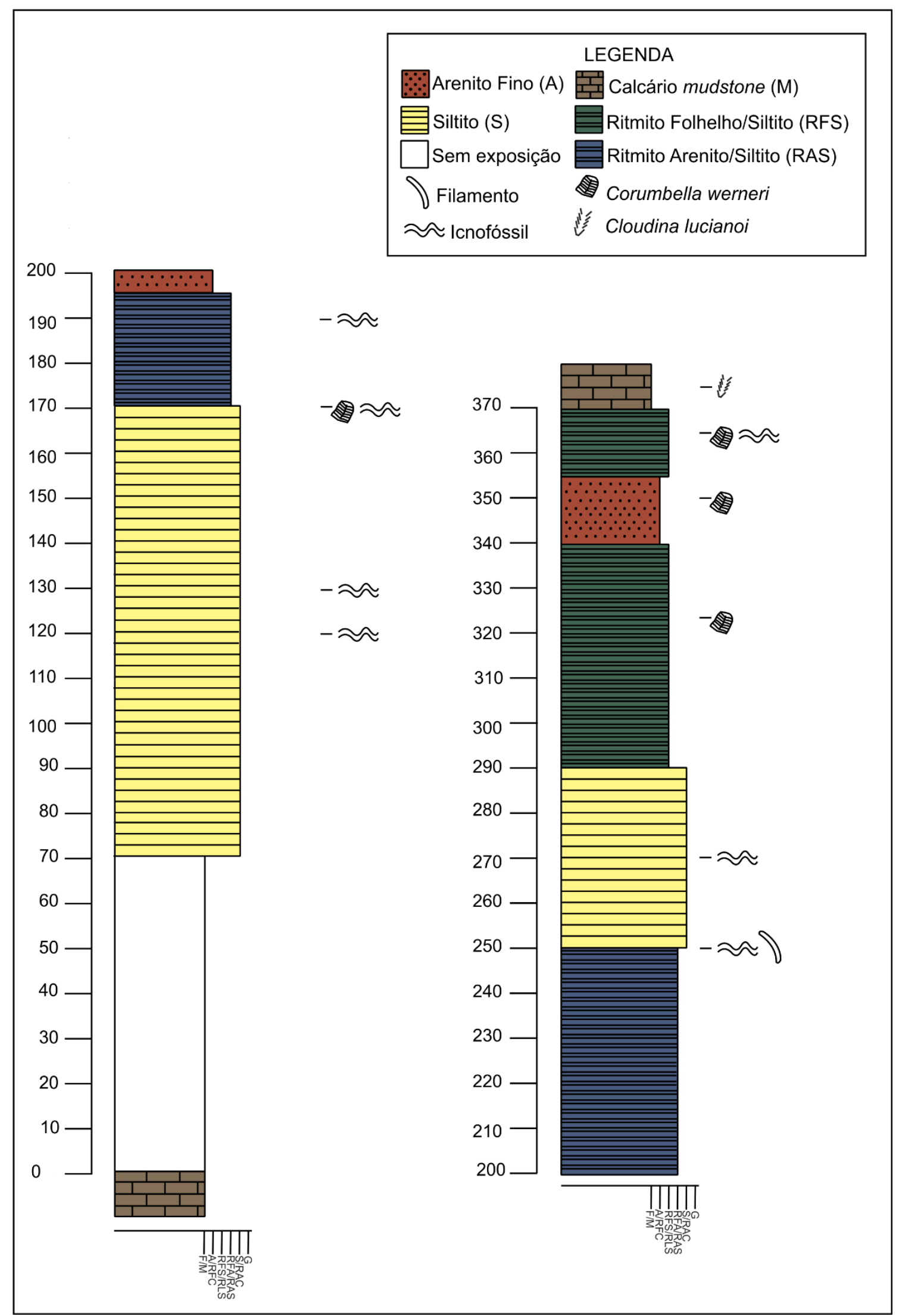

Figura 4.10: Seção estratigráfica do pacote de pelito - P5S exposto no Porto Sobramil em Corumbá, subsequente a P4 da Formação Tamengo. Unidade de medida da Seção em $\mathrm{cm}$. 


\subsubsection{Seção Estratigráfica - P6S}

A seção correspondente a P6S ocorre na parte inferior do Porto Sobramil (19० 00' 01" S $57^{\circ} 62^{\prime}$ 00" W) (Figura 4.11). A seção possui $250 \mathrm{~cm}$ de espessura, tanto a base quanto o topo estão demarcados por calcário mudstone seguido por duas camadas de ritmito folhelho/siltito de $50 \mathrm{~cm}$ de espessura cada, separada por um pacote de 50 $\mathrm{cm}$ de folhelho, os últimos $100 \mathrm{~cm}$ da coluna estratigráfica é composto por um pacote de ritmito folhelho/arenito muito fino.

O pacote pelítico dessa seção aparenta ter sofrido intemperismo devido a vegetação que encobre seu redor. Dessa forma, não foi encontrado nenhum registro fossilífero contendo Corumbella werneri ou icnofósseis (Figura 4.12).

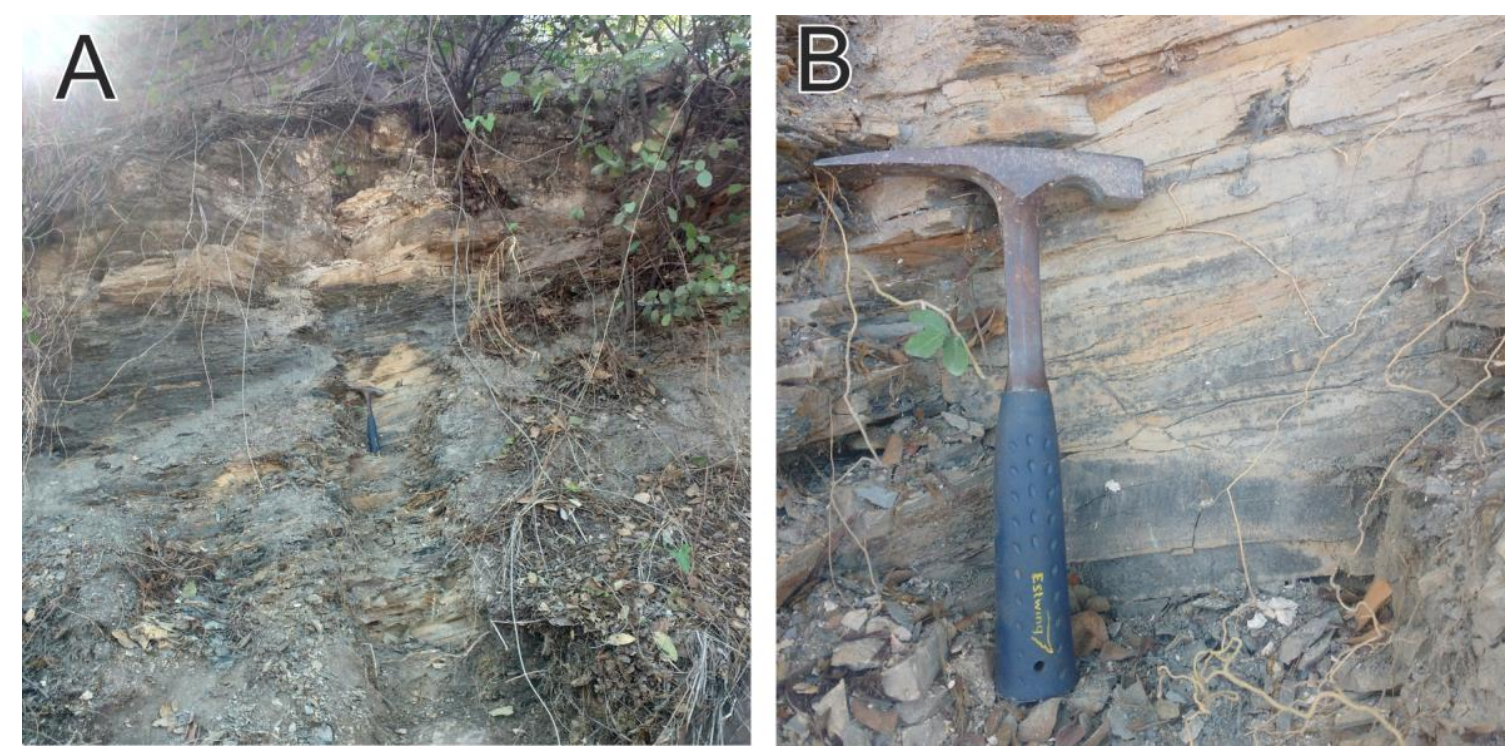

Figura 4.11: Seção P6S, parte superior da Formação Tamengo. A: Imagem ampla da seção. B: Detalhe da seção apresentando folhelho. 


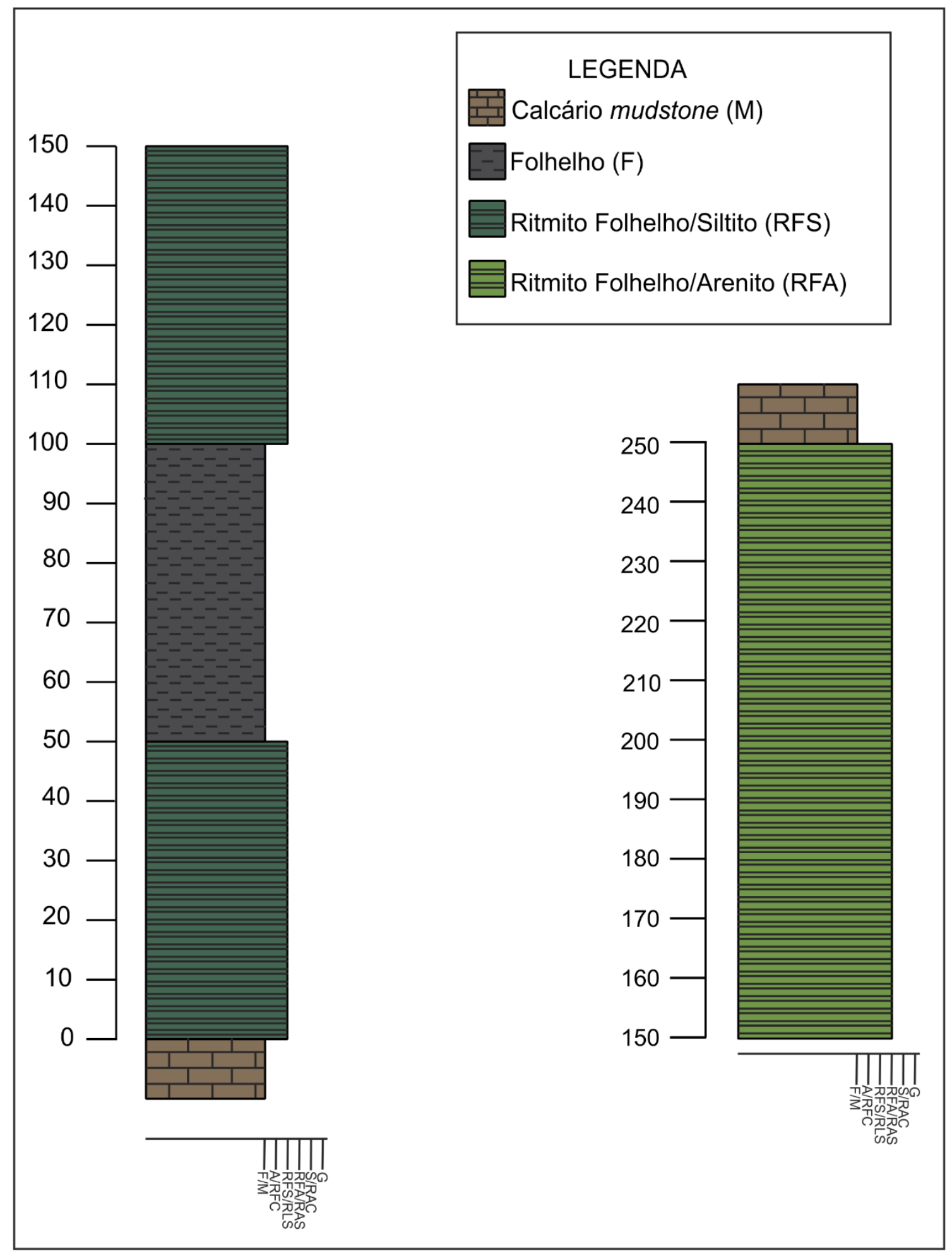

Figura 4.12: Seção estratigráfica do pacote de pelito P6S exposto na parte inferior do Porto Sobramil em Corumbá, subsequente a P5S da Formação Tamengo. Unidade de medida da Seção em $\mathrm{cm}$. 


\subsubsection{Seção Estratigráfica - P7S}

A seção correspondente a P7S está localizada no Porto Sobramil na parte inferior das bancadas (18 99' 97' S 5761' 97') (Figura 4.13).

Tanto a base quanto o topo estão demarcados por calcário mudstone, os primeiros $30 \mathrm{~cm}$ da coluna estratigráfica não possuem exposição impossibilitando a identificação do litotipo, mas logo após ocorrem duas camadas de ritmito folhelho/siltito com $70 \mathrm{~cm}$ e $25 \mathrm{~cm}$ de espessura respectivamente, são separadas por uma camada de $10 \mathrm{~cm}$ de siltito avermelhado. No topo da seção existe um pacote de $70 \mathrm{~cm}$ de calcário grainstone e uma camada de folhelho nos últimos $10 \mathrm{~cm}$ (Figura 4.14).

Foram coletadas 3 amostras em duas posições onde ocorrem 30 espécimes de Corumbella werneri todas incompletas, mas duas dessas amostras também apresentam outras espécimes fragmentadas. O primeiro nível ocorre em $95 \mathrm{~cm}$, contém 25 espécimes de $\mathrm{C}$. werneri separadas em duas amostras sendo que em uma delas também ocorrem estruturas filamentosas, a segunda posição ocorre em $122 \mathrm{~cm}$ representada por uma amostra contendo 5 indivíduos, uma outra amostra nessa mesma posição contém icnofósseis. As estruturas filamentosas também aparecem em outras três amostras em $73 \mathrm{~cm}, 98 \mathrm{~cm}$ e $115 \mathrm{~cm}$. Os icnofósseis também são encontrados em $75 \mathrm{~cm}$. E no calcário grainstone já foram descobertas amostras contendo fósseis de Cloudina lucianoi.
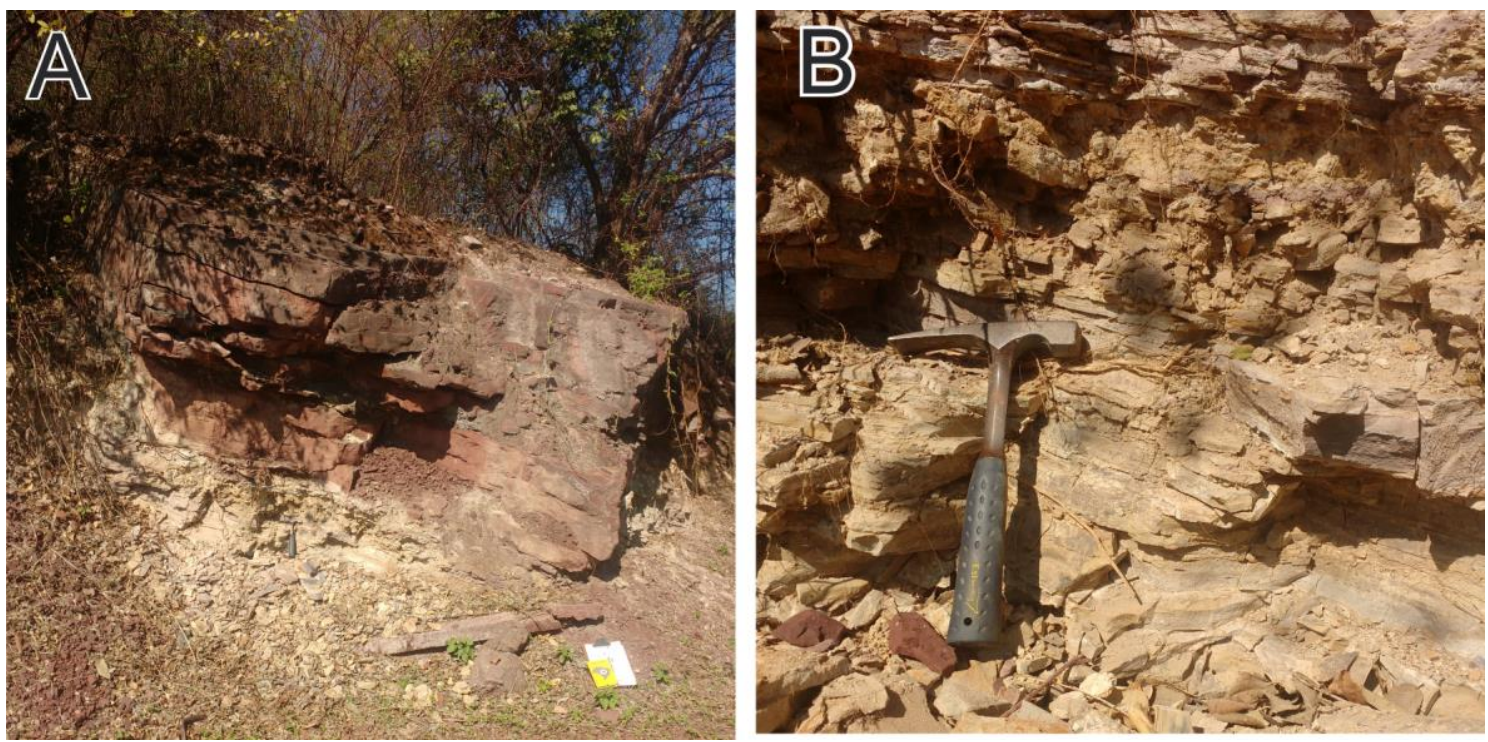

Figura 4.13: Seção P7S, parte superior da Formação Tamengo. A: Imagem ampla da seção.

B: Detalhe da seção apresentando siltito e ritmitos. 


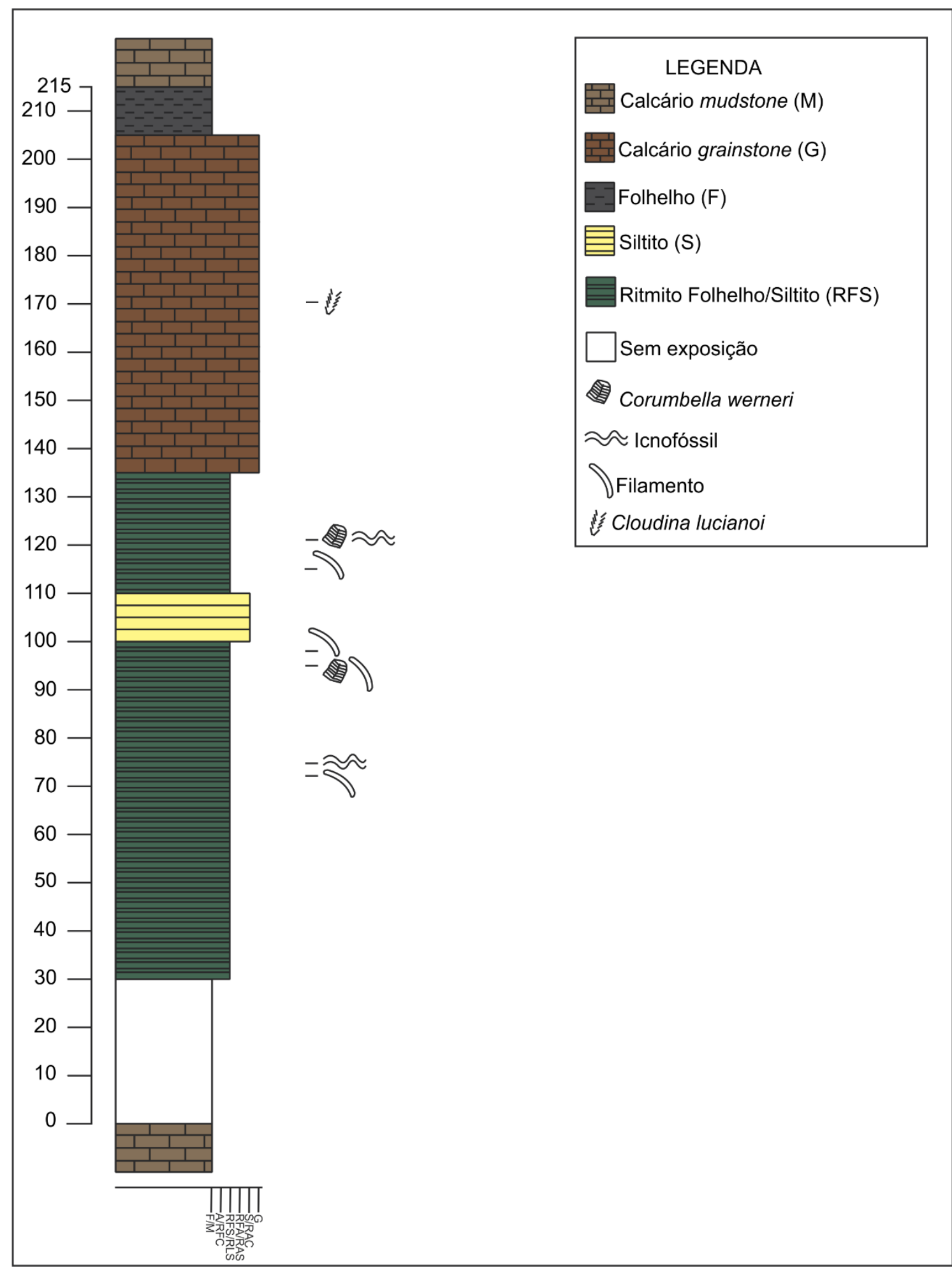

Figura 4.14: Seção estratigráfica do pacote de pelito - P7S exposto na parte inferior do Porto Sobramil em Corumbá, subsequente a P6S da Formação Tamengo . Unidade de medida da Seção em $\mathrm{cm}$. 


\subsubsection{Seção Estratigráfica - P5C}

A seção estratigráfica correspondente a P5C está localizada na parte superior da Mina Corcal (190 01' 84" S 57 68' 30") (Figura 4.15).

A base da seção é demarcada por um pacote de calcário mudstone, seguido por $105 \mathrm{~cm}$ de ritmito argilito/siltito e $45 \mathrm{~cm}$ de siltito laminado com uma camada de cinza vulcânica, o topo também está demarcado por calcário mudstone (Figura 4.16).

Não foi encontrado nenhum registro de Corumbella werneri neste local, mas foram encontradas três amostras de icnofósseis em três posições diferentes em $50 \mathrm{~cm}, 80$ $\mathrm{cm}$ e $100 \mathrm{~cm}$.

Figura 4.15: Seção P5C, parte superior da Formação Tamengo. Imagem ampla da seção apresentando calcários e siltitos. Escala $1 \mathrm{~m}$. 


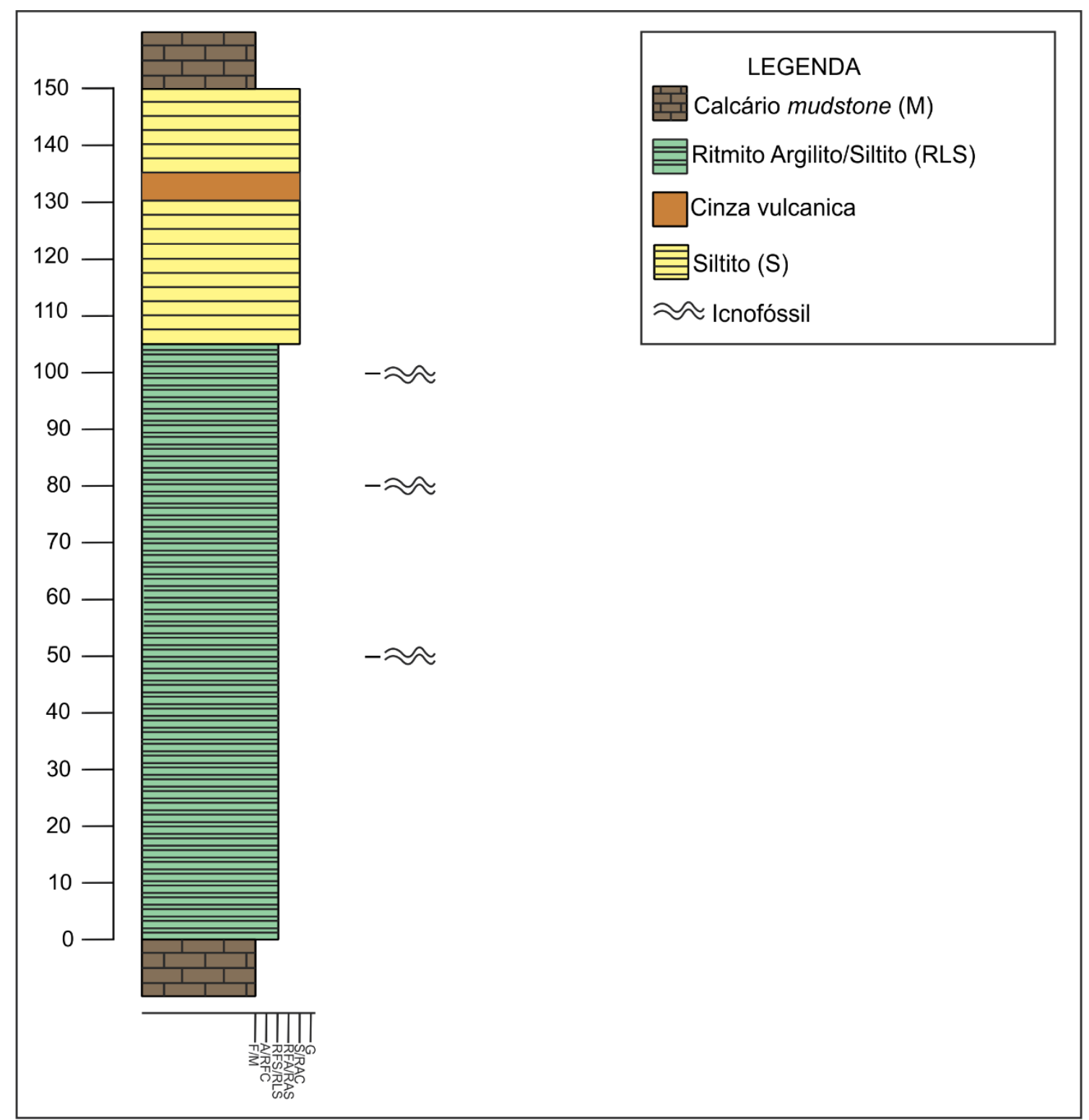

Figura 4.16: Seção estratigráfica do pacote de pelito P5C, exposto na parte superior da Pedreira Corcal em Corumbá, correspondente a seção P5S da Formação Tamengo. Unidade de medida da Seção em $\mathrm{cm}$. 


\subsubsection{Seção Estratigráfica - $P 6 C$}

A seção estratigráfica P6C está presente na parte intermediária da Mina Corcal em Corumbá (1901' 82" 57 68' 29") (Figura 4.17).

Possui litotipo homogêneo, tanto a base quanto o topo estão demarcados por calcário grainstone e os $40 \mathrm{~cm}$ da seção são de ritmito argilito alterado com a cor avermelhada e siltito. Não foi encontrado nenhum registro fossilífero nessa localidade (Figura 4.18).

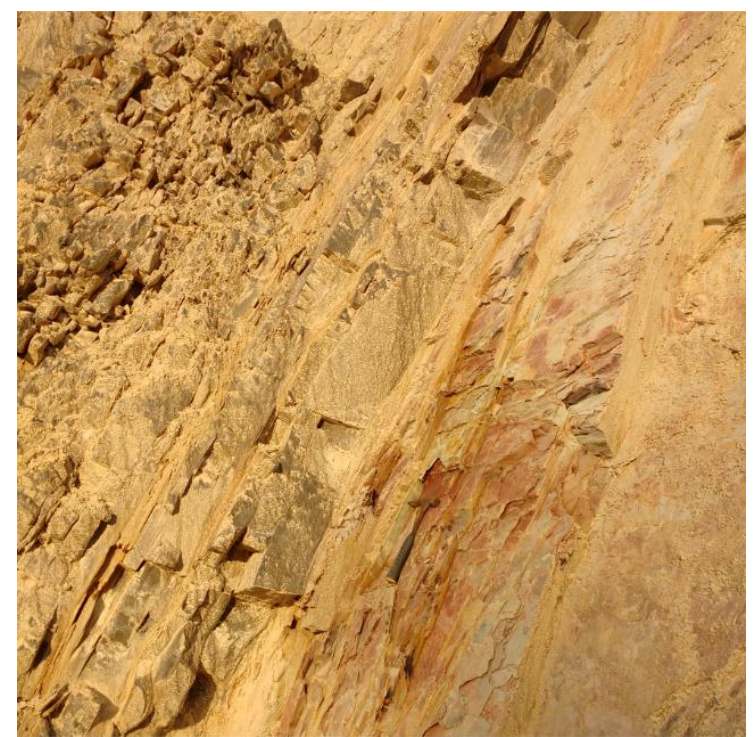

Figura 4.17: Seção P6C, parte superior da Formação Tamengo. Imagem ampla da seção. Apresentando calcários e ritmito.

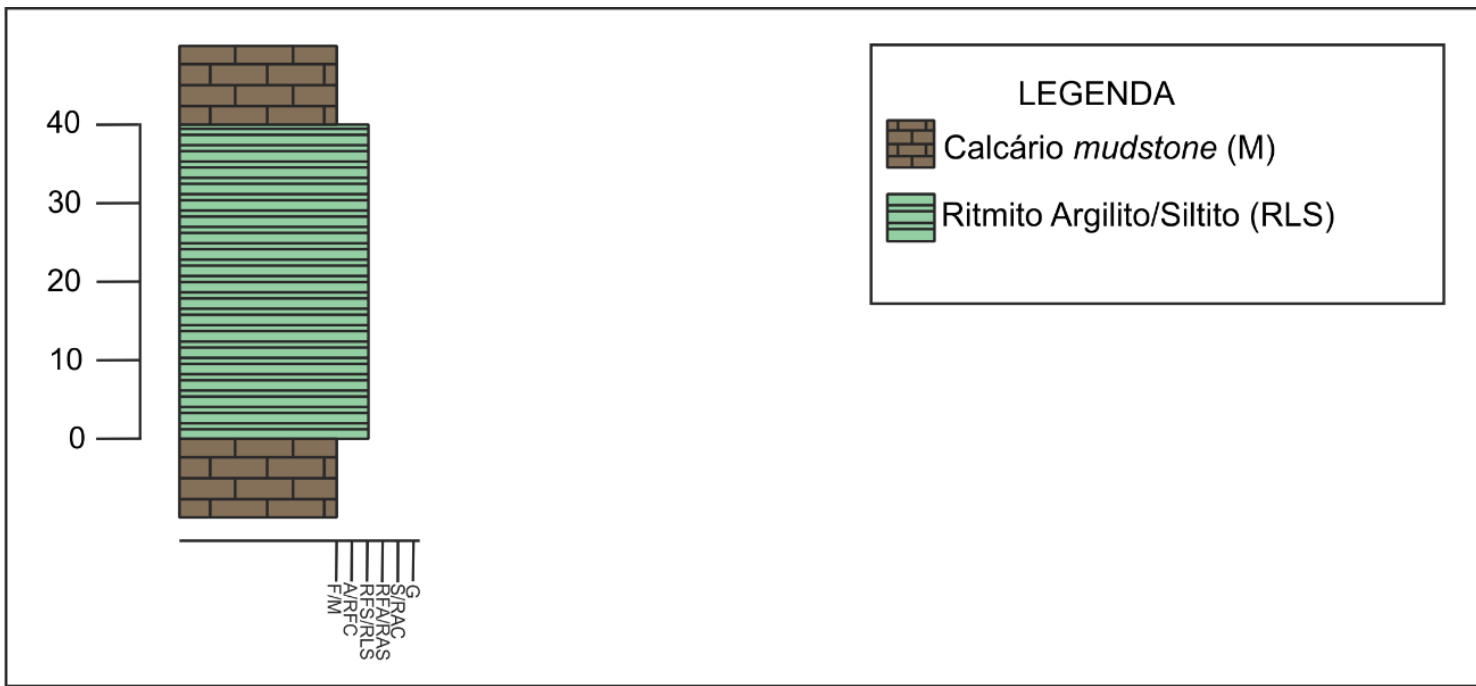

Figura 4.18: Seção estratigráfica do pacote de pelito - P6C, exposto na parte intermediária da Pedreira Corcal em Corumbá, correspondente a seção P6S e subsequente a seção P5C da Formação Tamengo. Unidade de medida da Seção em cm. 


\subsubsection{Seção Estratigráfica - P7C}

A seção estratigráfica P7C (Figura 4.20) está presente na parte inferior da Mina Corcal em Corumbá (Latitude 1901' 81" 57 68' 29").

A seção está demarcada tanto na base quanto no topo por calcário mudstone, possui $420 \mathrm{~cm}$ de intercalações entre pacotes de siltito laminado com $40 \mathrm{~cm}, 325 \mathrm{~cm}$ e $10 \mathrm{~cm}$ de espessura respectivamente e calcário mudstone laminado com camadas de $25 \mathrm{~cm}$ e $20 \mathrm{~cm}$ de espessura respectivamente.

Foram encontradas 6 amostras em cinco posições ao longo da seção com 49 espécimes de Corumbella werneri incompletas sendo uma dessas amostras com espécimes fragmentadas. O primeiro nível ocorre em $200 \mathrm{~cm}$, foi encontrada uma amostra com 10 espécimes, outra amostra contendo 15 espécimes foi localizada em $310 \mathrm{~cm}$ e uma amostra contendo 3 indivíduos foi encontrada em $330 \mathrm{~cm}$. Em $350 \mathrm{~cm}$ foi localizada uma amostra contendo 1 exemplar de Corumbella werneri associada a fósseis que se assemelham a filamentos. $O$ último nível que apresenta $C$. werneri de forma incompleta e fragmentada ocorre entre $410 \mathrm{~cm}$ a $412 \mathrm{~cm}$ contendo 20 indivíduos.

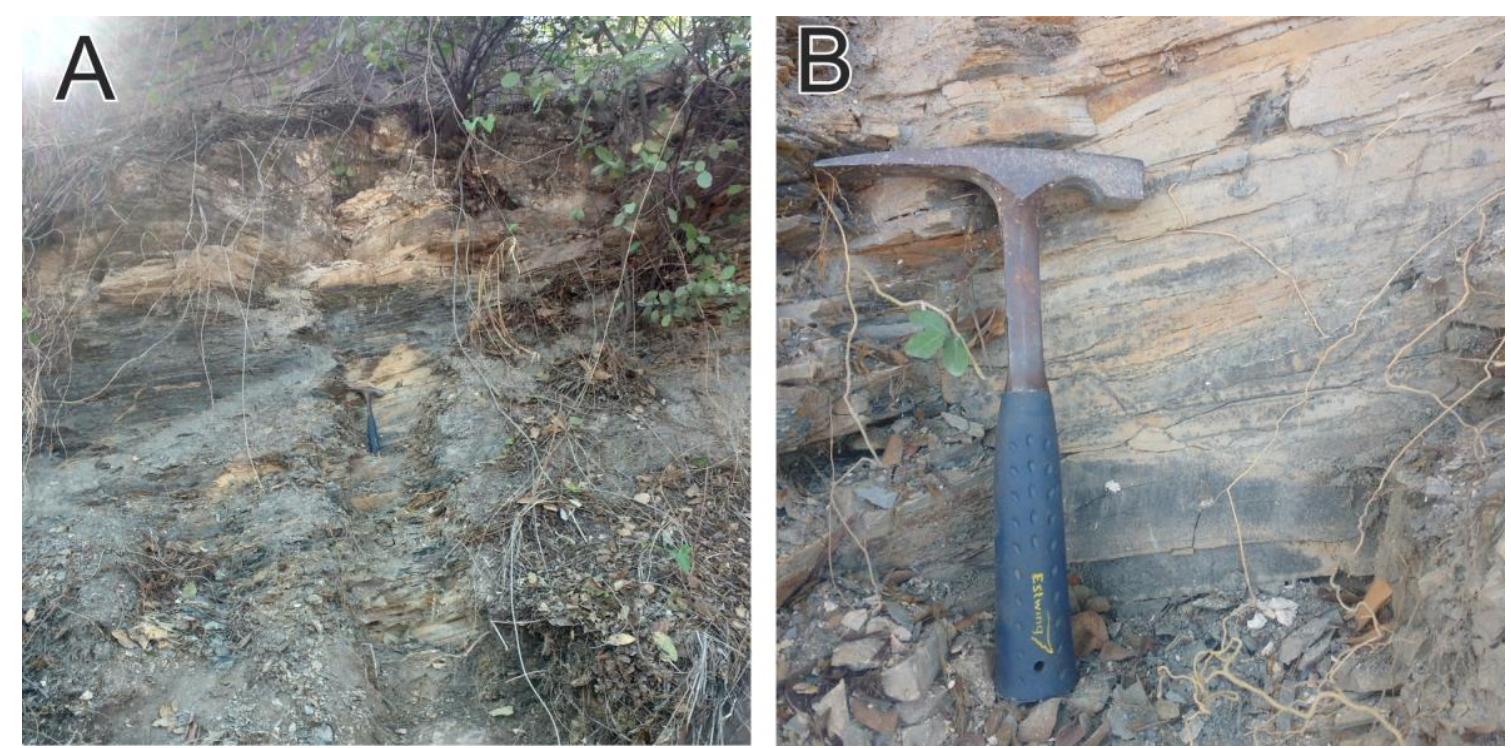

Figura 4.19: Seção P6C, parte superior da Formação Tamengo. A: Imagem ampla da seção Escala 1,4 m. B: detalhe da formação apresentando siltito. 


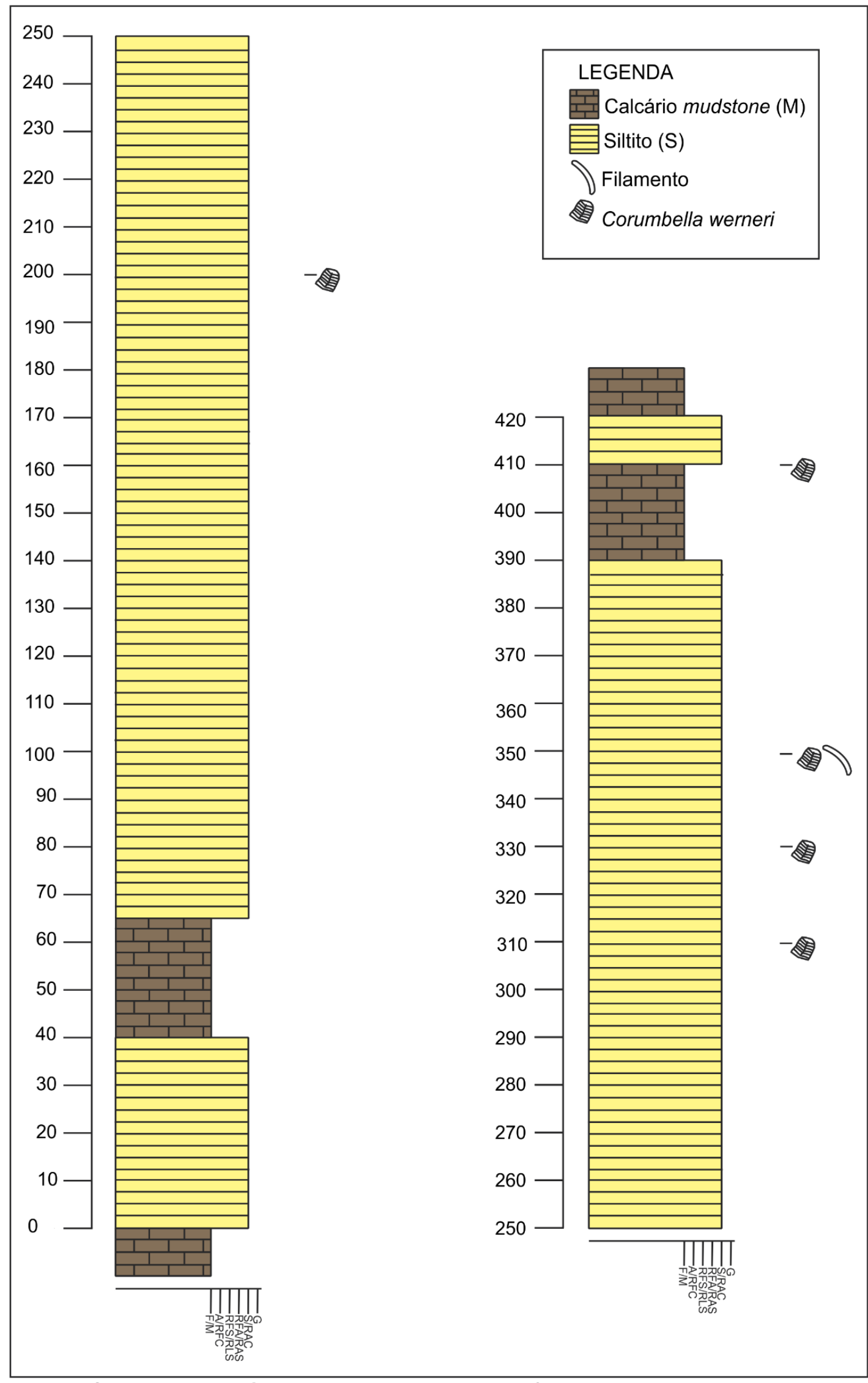

Figura 4.20: Seção estratigráfica do pacote de pelito P7C exposto na parte inferior da Pedreira Corcal em Corumbá, correspondente a seção P7S da Formação Tamengo . Unidade de medida da Seção em $\mathrm{cm}$. 


\subsection{Análise Tafonômica}

A análise tafonômica básica foi fundamentada nas seguintes assinaturas tafonômicas: Grau de empacotamento (GDE); Fragmentação (FRAG) e preservação da carapaça $(P C)$ e das amostras que possuem duas ou mais espécimes também foram observadas sua ocorrência (OCR) relacionando a sobreposição dos espécimes. (Tabelas 4.1-4.6).

A maior parte dos espécimes examinados retém sinais indicativos da presença do material esqueletal, observado pela presença de uma fina película escura, onde as feições morfológicas externas estão preservadas. Essa película pode estar, entretanto, total ou parcialmente ausente. Em geral, os espécimes estudados, em sua grande maioria, apresentam-se incompletos, com as regiões oral e basal ausentes. Entretanto, foram encontradas algumas amostras com os exemplares completamente fragmentados. Em relação ao grau de empacotamento as amostras que não se encontram isoladas em sua maioria estão fracamente empacotadas suportadas pela matriz e somente quatro amostras estão densamente empacotadas.

As tabelas a seguir apresentam de forma detalha as assinaturas tafonômicas presentes em cada amostra que estão agrupadas pelo local da coleta em cada coluna estratigráfica: 
Tabela 4.1: Informações do Fóssil de Corumbella werneri encontrados na Seção P1.

\begin{tabular}{|c|c|c|c|c|c|c|c|c|c|c|c|}
\hline GP/1E & ESPÉCIE & LOCAL & COLUNA & POSIÇÃO & OBSERVAÇÃO & ROCHA & \begin{tabular}{|c|} 
PRESERVAÇÃO \\
CARAPAÇA
\end{tabular} & QNTD & GE & OCR & FRAG \\
\hline 11070 & C. werneri & Ladário & P1 & $075 \mathrm{~cm}$ & - & Arenito & $\begin{array}{l}\text { Parcialmente } \\
\text { preservada }\end{array}$ & 1 & Isolada & - & Incompleta \\
\hline 11017 & C. werneri & Ladário & $\mathrm{P} 1$ & $190 \mathrm{~cm}$ & - & $\begin{array}{l}\text { Rit. folhelho/ } \\
\text { arenito }\end{array}$ & $\begin{array}{c}4 \text { Moldes } 3 \\
\text { Preservadas }\end{array}$ & 7 & $\begin{array}{l}\text { Fracamente } \\
\text { empacotado }\end{array}$ & Sobreposta & Incompleta \\
\hline 11014 & C. werneri & Ladário & P1 & $192 \mathrm{~cm}$ & - & $\begin{array}{l}\text { Rit. folhelho/ } \\
\text { arenito } \\
\end{array}$ & Preservada & 2 & $\begin{array}{l}\text { Fracamente } \\
\text { empacotado }\end{array}$ & Sobreposta & Incompleta \\
\hline 11016 & C. werneri & Ladário & $\mathrm{P} 1$ & $200 \mathrm{~cm}$ & B Contraparte & $\begin{array}{l}\text { Rit. folhelho/ } \\
\text { arenito }\end{array}$ & Molde & 1 & Isolada & - & Incompleta \\
\hline 11071 & C. werneri & Ladário & P1 & $200 \mathrm{~cm}$ & - & $\begin{array}{l}\text { Rit. folhelho/ } \\
\text { arenito }\end{array}$ & Molde & 1 & Isolada & - & Incompleta \\
\hline 11072 & C. werneri & Ladário & $\mathrm{P} 1$ & $220 \mathrm{~cm}$ & B Contraparte & $\begin{array}{l}\text { Rit. folhelho/ } \\
\text { arenito }\end{array}$ & Preservada & 1 & Isolada & - & Incompleta \\
\hline 11229 & C. werneri & Ladário & P1 & $220 \mathrm{~cm}$ & - & $\begin{array}{l}\text { Rit. folhelho/ } \\
\text { arenito }\end{array}$ & Molde & 1 & Isolada & - & Incompleta \\
\hline
\end{tabular}


Tabela 4.2: Informações do Fóssil de Corumbella werneri encontrados na Seção P2.

\begin{tabular}{|c|c|c|c|c|c|c|c|c|c|c|c|}
\hline GP/1E & ESPÉCIE & LOCAL & COLUNA & POSIÇÃO & OBSERVAÇÃO & ROCHA & \begin{tabular}{|c|} 
PRESERVAÇÃO \\
CARAPAÇA
\end{tabular} & QNTD & GE & OCR & FRAG \\
\hline 11024 & C. werneri & Ladário & $\mathrm{P} 2$ & $028 \mathrm{~cm}$ & $\begin{array}{c}\mathrm{A} \text { ao C/C } \\
\text { contrapArte de B }\end{array}$ & $\begin{array}{l}\text { Rit. folhelho/ } \\
\text { siltito }\end{array}$ & Preservada & \begin{tabular}{|c|}
1 em cada \\
amostra
\end{tabular} & Isolada & - & Incompleta \\
\hline 11031 & C. werneri & Ladário & $\mathrm{P} 2$ & $028 \mathrm{~cm}$ & $\begin{array}{l}\text { B contraparte } \\
\text { (frag nivel mais } \\
\text { baixo) }\end{array}$ & $\begin{array}{l}\text { Rit. folhelho/ } \\
\text { siltito }\end{array}$ & $\begin{array}{l}\text { Parcialmente } \\
\text { preservada }\end{array}$ & 3 & $\begin{array}{l}\text { Fracamente } \\
\text { empacotado }\end{array}$ & - & Incompleta \\
\hline 11032 & C. werneri & Ladário & $\mathrm{P} 2$ & $030 \mathrm{~cm}$ & B contraparte & $\begin{array}{l}\text { Rit. folhelho/ } \\
\text { siltito } \\
\end{array}$ & $\begin{array}{l}\text { Parcialmente } \\
\text { preservada }\end{array}$ & 13 & $\begin{array}{l}\text { Fracamente } \\
\text { empacotado }\end{array}$ & Sobreposta & Incompleta \\
\hline 11033 & C. werneri & Ladário & P2 & $030 \mathrm{~cm}$ & $\mathrm{~A}$ ao $\mathrm{C}$ & $\begin{array}{l}\text { Rit. folhelho/ } \\
\text { siltito }\end{array}$ & $\begin{array}{l}\text { Parcialmente } \\
\text { preservada }\end{array}$ & 7 & Disperso & - & Incompleta \\
\hline 11034 & C. werneri & Ladário & P2 & $030 \mathrm{~cm}$ & B contraparte & $\begin{array}{l}\text { Rit. folhelho/ } \\
\text { siltito }\end{array}$ & $\begin{array}{l}\text { Parcialmente } \\
\text { preservada }\end{array}$ & 10 & $\begin{array}{l}\text { Fracamente } \\
\text { empacotado }\end{array}$ & Sobreposta & Incompleta \\
\hline 11036 & C. werneri & Ladário & $\mathrm{P} 2$ & $030 \mathrm{~cm}$ & - & $\begin{array}{l}\text { Rit. folhelho/ } \\
\text { siltito }\end{array}$ & $\begin{array}{l}\text { Parcialmente } \\
\text { preservada }\end{array}$ & 1 & Isolada & - & Incompleta+frag \\
\hline 11037 & C. werneri & Ladário & $\mathrm{P} 2$ & $030 \mathrm{~cm}$ & - & $\begin{array}{l}\text { Rit. folhelho/ } \\
\text { siltito }\end{array}$ & $\begin{array}{l}\text { Parcialmente } \\
\text { preservada }\end{array}$ & 2 & $\begin{array}{l}\text { Fracamente } \\
\text { empacotado }\end{array}$ & Sobreposta & Incompleta \\
\hline 11028 & C. werneri & Ladário & P2 & $040 \mathrm{~cm}$ & - & $\begin{array}{l}\text { Rit. folhelho/ } \\
\text { siltito }\end{array}$ & Molde & $10+$ Frag & $\begin{array}{l}\text { Fracamente } \\
\text { empacotado }\end{array}$ & Sobreposta & Incompleta+frag \\
\hline 11227 & C. werneri & Ladário & P2 & $040 \mathrm{~cm}$ & B contraparte & $\begin{array}{l}\text { Rit. folhelho/ } \\
\text { siltito }\end{array}$ & $\begin{array}{l}\text { Parcialmente } \\
\text { preservada }\end{array}$ & 2 & Disperso & - & Incompleta+frag \\
\hline 11035 & C. werneri & Ladário & $\mathrm{P} 2$ & $050 \mathrm{~cm}$ & - & $\begin{array}{l}\text { Rit. folhelho/ } \\
\text { siltito }\end{array}$ & Molde & 4 & Disperso & Sobreposta & Incompleta+frag \\
\hline 11027 & C. werneri & Ladário & $\mathrm{P} 2$ & $057 \mathrm{~cm}$ & $A-B$ & $\begin{array}{l}\text { Rit. folhelho/ } \\
\text { siltito }\end{array}$ & Molde & 1 & Isolada & - & Incompleta \\
\hline 11021 & C. werneri & Ladário & $\mathrm{P} 2$ & $060 \mathrm{~cm}$ & - & $\begin{array}{l}\text { Rit. folhelho/ } \\
\text { siltito }\end{array}$ & Molde & 9 & $\begin{array}{l}\text { Fracamente } \\
\text { empacotado }\end{array}$ & Sobreposta & Incompleta \\
\hline 11023 & C. werneri & Ladário & $\mathrm{P} 2$ & $100 \mathrm{~cm}$ & - & $\begin{array}{l}\text { Rit. folhelho/ } \\
\text { siltito }\end{array}$ & Molde & 3 & $\begin{array}{l}\text { Fracamente } \\
\text { empacotado }\end{array}$ & Sobreposta & Incompleta \\
\hline 11025 & C. werneri & Ladário & P2 & $100 \mathrm{~cm}$ & $\begin{array}{c}\text { A ao C / B } \\
\text { contraparte de A }\end{array}$ & $\begin{array}{l}\text { Rit. folhelho/ } \\
\text { siltito }\end{array}$ & Preservada & $\begin{array}{c}1 \mathrm{em} \mathrm{C} \mathrm{/} 4 \\
\mathrm{em} \mathrm{B}\end{array}$ & $\begin{array}{l}\text { Fracamente } \\
\text { empacotado }\end{array}$ & Sobreposta & Incompleta \\
\hline 11026 & C. werneri & Ladário & $\mathrm{P} 2$ & $100 \mathrm{~cm}$ & - & $\begin{array}{l}\text { Rit. folhelho/ } \\
\text { siltito }\end{array}$ & Molde & 1 & Isolada & - & Incompleta \\
\hline
\end{tabular}


Tabela 4.3: Informações do Fóssil de Corumbella werneri encontrados na Seção P3.

\begin{tabular}{|c|c|c|c|c|c|c|c|c|c|c|c|}
\hline GP/1E & ESPÉCIE & LOCAL & COLUNA & POSIÇÃO & OBSERVAÇÃO & ROCHA & \begin{tabular}{|c|} 
PRESERVAÇÃO \\
CARAPAÇA
\end{tabular} & QNTD & GE & OCR & FRAG \\
\hline 9942 & C. werneri & Ladário & P3 & $040 \mathrm{~cm}$ & - & Folhelho & Molde & 6 & Dispersa & - & Incompleta \\
\hline 9933 & C. werneri & Ladário & P3 & $043 \mathrm{~cm}$ & - & Folhelho & $\begin{array}{l}\text { Parcialmente } \\
\text { preservada }\end{array}$ & 7 & $\begin{array}{l}\text { Fracamente } \\
\text { empacotada }\end{array}$ & Sobreposta & Incompleta \\
\hline 9934 & C. werneri & Ladário & P3 & $043 \mathrm{~cm}$ & $A-B$ & Folhelho & Molde & 29 & $\begin{array}{l}\text { Densamente } \\
\text { empacotada }\end{array}$ & Sobreposta & Incompleta \\
\hline 9936 & C. werneri & Ladário & P3 & $043 \mathrm{~cm}$ & - & Folhelho & Molde & 2 & Dispersa & - & Incompleta \\
\hline 9972 & C. werneri & Ladário & P3 & $043 \mathrm{~cm}$ & - & Folhelho & Molde & 3 & Dispersa & - & Incompleta \\
\hline 9932 & C. werneri & Ladário & P3 & $045 \mathrm{~cm}$ & - & Folhelho & $\begin{array}{l}\text { Parcialmente } \\
\text { preservada }\end{array}$ & 10 & $\begin{array}{l}\text { Fracamente } \\
\text { empacotada }\end{array}$ & Sobreposta & Incompleta \\
\hline 9943 & C. werneri & Ladário & P3 & $045 \mathrm{~cm}$ & & Folhelho & $\begin{array}{l}\text { Parcialmente } \\
\text { preservada }\end{array}$ & 20 & $\begin{array}{l}\text { Fracamente } \\
\text { empacotada }\end{array}$ & Sobreposta & Incompleta \\
\hline 9930 & C. werneri & Ladário & P3 & $048 \mathrm{~cm}$ & - & Folhelho & Molde & 5 & Dispersa & - & Incompleta \\
\hline 9935 & C. werneri & Ladário & P3 & $048 \mathrm{~cm}$ & - & Folhelho & Molde & 3 & Dispersa & - & Incompleta \\
\hline 10927 & C. werneri & Ladário & P3 & $048 \mathrm{~cm}$ & B contraparte & Folhelho & Molde & 1 & Dispersa & - & Incompleta \\
\hline 9928 & C. werneri & Ladário & P3 & $055 \mathrm{~cm}$ & - & Folhelho & Molde & 1 & - & - & Incompleta \\
\hline 9926 & C. werneri & Ladário & P3 & $\begin{array}{c}062-061 \\
\mathrm{~cm}\end{array}$ & B contraparte & Folhelho & $\begin{array}{l}\text { Parcialmente } \\
\text { preservada }\end{array}$ & 8 & $\begin{array}{l}\text { Fracamente } \\
\text { empacotada }\end{array}$ & Sobreposta & Incompleta \\
\hline 9938 & C. werneri & Ladário & P3 & $070 \mathrm{~cm}$ & $\begin{array}{c}\text { Presença de } \\
\text { vendotaenídeos }\end{array}$ & Folhelho & $\begin{array}{l}\text { Parcialmente } \\
\text { preservada }\end{array}$ & 1 & Dispersa & - & Incompleta \\
\hline 10922 & C. werneri & Ladário & P3 & $075 \mathrm{~cm}$ & $\begin{array}{c}\text { Presença de } \\
\text { vendotaenídeos }\end{array}$ & Folhelho & $\begin{array}{c}\text { Parcialmente } \\
\text { preservada }\end{array}$ & 1 & $\begin{array}{l}\text { Fracamente } \\
\text { empacotada }\end{array}$ & Sobreposta & Incompleta \\
\hline 9919 & C. werneri & Ladário & P3 & $080 \mathrm{~cm}$ & - & Folhelho & $\begin{array}{l}\text { Parcialmente } \\
\text { preservada }\end{array}$ & 5 & $\begin{array}{l}\text { Fracamente } \\
\text { empacotada }\end{array}$ & Sobreposta & Incompleta \\
\hline 9927 & C. werneri & Ladário & P3 & $080 \mathrm{~cm}$ & B contraparte & Folhelho & $\begin{array}{l}\text { Parcialmente } \\
\text { preservada }\end{array}$ & 10 & $\begin{array}{l}\text { Fracamente } \\
\text { empacotada }\end{array}$ & Sobreposta & Incompleta \\
\hline 10931 & C. werneri & Ladário & P3 & $080 \mathrm{~cm}$ & - & Folhelho & Molde & 4 & Dispersa & - & Incompleta \\
\hline
\end{tabular}




\begin{tabular}{|c|c|c|c|c|c|c|c|c|c|c|c|}
\hline 9929 & C. werneri & Ladário & P3 & $083 \mathrm{~cm}$ & - & Folhelho & Preservada & 5 & Dispersa & - & Incompleta \\
\hline 9917 & C. werneri & Ladário & P3 & $091 \mathrm{~cm}$ & - & $\begin{array}{c}\text { Rit. Folhelho/ } \\
\text { siltito }\end{array}$ & Molde & 2 & Dispersa & - & Incompleta \\
\hline 9918 & C. werneri & Ladário & P3 & $093 \mathrm{~cm}$ & - & \begin{tabular}{|c|}
$\begin{array}{c}\text { Rit. Folhelho/ } \\
\text { siltito }\end{array}$ \\
\end{tabular} & Molde & 1 & Dispersa & - & Incompleta \\
\hline 9921 & C. werneri & Ladário & P3 & $115 \mathrm{~cm}$ & - & Folhelho & $\begin{array}{c}\text { Parcialmente } \\
\text { preservada }\end{array}$ & 8 & $\begin{array}{l}\text { Fracamente } \\
\text { empacotada }\end{array}$ & Sobreposta & Incompleta \\
\hline 9920 & C. werneri & Ladário & P3 & $120 \mathrm{~cm}$ & $\begin{array}{c}\text { A - C; B contraparte } \\
\text { de A e C; C } \\
\text { vendotaenídeos }\end{array}$ & Folhelho & Molde & 10 & $\begin{array}{l}\text { Fracamente } \\
\text { empacotada }\end{array}$ & Sobreposta & $\begin{array}{c}\text { incompleta }+ \\
\text { frag }\end{array}$ \\
\hline 9923 & C. werneri & Ladário & P3 & $133 \mathrm{~cm}$ & $A-B$ & Folhelho & Molde & 1 & - & - & Incompleta \\
\hline 9925 & C. werneri & Ladário & P3 & $133 \mathrm{~cm}$ & B e C contraparte & Folhelho & Molde & 5 & $\begin{array}{l}\text { Fracamente } \\
\text { empacotada }\end{array}$ & Sobreposta & Incompleta \\
\hline 9937 & C. werneri & Ladário & P3 & $133 \mathrm{~cm}$ & - & Folhelho & Molde & 1 & dispersa & - & Incompleta \\
\hline 9940 & C. werneri & Ladário & P3 & $133 \mathrm{~cm}$ & $A-B$ & Folhelho & Molde & 9 & $\begin{array}{l}\text { Fracamente } \\
\text { empacotada }\end{array}$ & Sobreposta & Incompleta \\
\hline 9941 & C. werneri & Ladário & P3 & $133 \mathrm{~cm}$ & B contraparte & Folhelho & Molde & 5 & $\begin{array}{l}\text { Fracamente } \\
\text { empacotada }\end{array}$ & Sobreposta & Incompleta \\
\hline 10928 & C. werneri & Ladário & P3 & $135 \mathrm{~cm}$ & B contraparte & Folhelho & Molde & 4 & $\begin{array}{l}\text { Fracamente } \\
\text { empacotada }\end{array}$ & - & Incompleta \\
\hline
\end{tabular}


Tabela 4.4: Informações do Fóssil de Corumbella werneri encontrados na Seção P5S.

\begin{tabular}{|c|c|c|c|c|c|c|c|c|c|c|c|}
\hline GP/1E & ESPÉCIE & LOCAL & COLUNA & POSIÇÃO & OBSERVAÇÃO & ROCHA & $\begin{array}{c}\text { PRESERVAÇÃO } \\
\text { CARAPAÇA }\end{array}$ & QNTD & GE & OCR & FRAG \\
\hline 11185 & C. werneri & $\begin{array}{c}\text { Pto } \\
\text { Sobramil }\end{array}$ & P5S & $170 \mathrm{~cm}$ & $\begin{array}{l}\text { Presença de } \\
\text { Icnofóssil }\end{array}$ & $\begin{array}{l}\text { Rit. arenito/ } \\
\text { siltito }\end{array}$ & Parcialmente preservada & 1 & Isolada & - & Incompleta \\
\hline 11175 & C. werneri & $\begin{array}{c}\text { Pto } \\
\text { Sobramil }\end{array}$ & P5S & $319 \mathrm{~cm}$ & - & $\begin{array}{l}\text { Rit. folhelho/ } \\
\text { siltito }\end{array}$ & Parcialmente preservada & 1 & Dispersa & - & $\begin{array}{c}\text { Incompleta + } \\
\text { frag }\end{array}$ \\
\hline 11176 & C. werneri & $\begin{array}{c}\text { Pto } \\
\text { Sobramil }\end{array}$ & P5S & $319 \mathrm{~cm}$ & - & $\begin{array}{l}\text { Rit. folhelho/ } \\
\text { siltito }\end{array}$ & $\begin{array}{l}\text { Preservada e molde / } \\
\text { frag preservado }\end{array}$ & 2 & $\begin{array}{l}\text { Fracamente } \\
\text { empacotada }\end{array}$ & Sobreposta & $\begin{array}{c}\text { Incompleta }+ \\
\text { frag }\end{array}$ \\
\hline 11174 & C. werneri & $\begin{array}{l}\text { Pto } \\
\text { Sobramil }\end{array}$ & P5S & $324 \mathrm{~cm}$ & - & $\begin{array}{l}\text { Rit. folhelho/ } \\
\text { siltito }\end{array}$ & $\begin{array}{c}\text { Parcialmente preservada } \\
\text { / frag parcialmente } \\
\text { preservado }\end{array}$ & 4 & $\begin{array}{l}\text { Fracamente } \\
\text { empacotada }\end{array}$ & Sobreposta & $\begin{array}{c}\text { Incompleta + } \\
\text { frag }\end{array}$ \\
\hline 11040 & C. werneri & $\begin{array}{c}\text { Pto } \\
\text { Sobramil }\end{array}$ & P5S & $350 \mathrm{~cm}$ & - & Arenito & Parcialmente preservada & 4 & $\begin{array}{l}\text { Fracamente } \\
\text { empacotada }\end{array}$ & Sobreposta & $\begin{array}{c}\text { Incompleta + } \\
\text { frag }\end{array}$ \\
\hline 11041 & C. werneri & $\begin{array}{c}\text { Pto } \\
\text { Sobramil }\end{array}$ & P5S & $350 \mathrm{~cm}$ & $A-B$ & Arenito & $\begin{array}{c}\text { Parcialmente preservada } \\
\text { / frag molde }\end{array}$ & 2 & $\begin{array}{l}\text { Fracamente } \\
\text { empacotada }\end{array}$ & - & $\begin{array}{c}\text { Incompleta }+ \\
\text { frag }\end{array}$ \\
\hline 11045 & C. werneri & $\begin{array}{c}\text { Pto } \\
\text { Sobramil }\end{array}$ & P5S & $350 \mathrm{~cm}$ & - & Arenito & Preservada & 1 & Dispersa & - & incompleta \\
\hline 11046 & C. werneri & $\begin{array}{c}\text { Pto } \\
\text { Sobramil }\end{array}$ & P5S & $350 \mathrm{~cm}$ & - & Arenito & Parcialmente preservada & 3 & $\begin{array}{l}\text { Densamente } \\
\text { empacotada }\end{array}$ & Sobreposta & $\begin{array}{c}\text { Incompleta + } \\
\text { frag }\end{array}$ \\
\hline 11047 & C. werneri & $\begin{array}{c}\text { Pto } \\
\text { Sobramil }\end{array}$ & P5S & $350 \mathrm{~cm}$ & - & Arenito & $\begin{array}{c}\text { Parcialmente preservada } \\
\text { / frag molde }\end{array}$ & 5 & $\begin{array}{l}\text { Densamente } \\
\text { empacotada }\end{array}$ & Sobreposta & $\begin{array}{c}\text { Incompleta }+ \\
\text { frag }\end{array}$ \\
\hline 11058 & C. werneri & $\begin{array}{c}\text { Pto } \\
\text { Sobramil }\end{array}$ & P5S & $365 \mathrm{~cm}$ & $\begin{array}{c}\text { Presença de } \\
\text { Icnofóssil }\end{array}$ & $\begin{array}{l}\text { Rit. folhelho/ } \\
\text { siltito }\end{array}$ & Parcialmente preservada & fragmentada & $\begin{array}{l}\text { Densamente } \\
\text { empacotada }\end{array}$ & Sobreposta & fragmentado \\
\hline
\end{tabular}


Tabela 4.5: Informações do Fóssil de Corumbella werneri encontrados na Seção P7S.

\begin{tabular}{|c|c|c|c|c|c|c|c|c|c|c|c|}
\hline GP/1E & ESPÉCIE & LOCAL & COLUNA & POSIÇÃO & OBSERVAÇÃO & ROCHA & $\begin{array}{c}\text { PRESERVAÇÃO } \\
\text { CARAPAÇA }\end{array}$ & QNTD & GE & OCR & FRAG \\
\hline 11059 & C. werneri & $\begin{array}{l}\text { Pto. } \\
\text { Sobramil }\end{array}$ & P7S & $095 \mathrm{~cm}$ & $\begin{array}{l}\text { Presença de } \\
\text { Icnofóssil }\end{array}$ & $\begin{array}{l}\text { Rit. folhelho/ } \\
\text { siltito }\end{array}$ & $\begin{array}{c}\text { Parcialmente preservada } \\
\text { e molde }\end{array}$ & 5 & $\begin{array}{l}\text { Fracamente } \\
\text { empacotada }\end{array}$ & Sobreposta & Incompleta \\
\hline 11073 & C. werneri & $\begin{array}{l}\text { Pto. } \\
\text { Sobramil }\end{array}$ & P7S & $095 \mathrm{~cm}$ & - & $\begin{array}{l}\text { Rit. folhelho/ } \\
\text { siltito }\end{array}$ & Molde & 20 & $\begin{array}{l}\text { Fracamente } \\
\text { empacotada }\end{array}$ & Sobreposta & Incompleta \\
\hline 11060 & C. werneri & $\begin{array}{l}\text { Pto. } \\
\text { Sobramil }\end{array}$ & P7S & $122 \mathrm{~cm}$ & B contra parte & $\begin{array}{l}\text { Rit. folhelho/ } \\
\text { siltito }\end{array}$ & $\begin{array}{c}\text { Parcialmente preservada } \\
\text { e molde }\end{array}$ & 5 & $\begin{array}{l}\text { Fracamente } \\
\text { empacotada }\end{array}$ & - & $\begin{array}{l}\text { Incompleta }+ \\
\text { frag }\end{array}$ \\
\hline
\end{tabular}

Tabela 4.6: Informações do Fóssil de Corumbella werneri encontrados na Seção P7C.

\begin{tabular}{|c|c|c|c|c|c|c|c|c|c|c|c|}
\hline GP/1E & ESPÉCIE & LOCAL & COLUNA & POSIÇÃO & OBSERVAÇÃO & ROCHA & $\begin{array}{c}\text { PRESERVAÇÃO } \\
\text { CARAPAÇA }\end{array}$ & QNTD & GE & OCR & FRAG \\
\hline 11061 & C. werneri & $\begin{array}{l}\text { Mina } \\
\text { Corcal }\end{array}$ & P7C & $200 \mathrm{~cm}$ & B contraparte & Siltito & $\begin{array}{c}\text { Parcialmente } \\
\text { preservada }\end{array}$ & 10 & $\begin{array}{l}\text { Fracamente } \\
\text { empacotada }\end{array}$ & Sobreposta & Incompleta \\
\hline 11062 & C. werneri & $\begin{array}{l}\text { Mina } \\
\text { Corcal }\end{array}$ & P7C & $310 \mathrm{~cm}$ & - & Siltito & Molde & 15 & $\begin{array}{l}\text { Fracamente } \\
\text { empacotada }\end{array}$ & Sobreposta & Incompleta \\
\hline 11064 & C. werneri & $\begin{array}{l}\text { Mina } \\
\text { Corcal }\end{array}$ & P7C & $330 \mathrm{~cm}$ & - & Siltito & Molde & 3 & Dispersa & - & Incompleta \\
\hline 11066 & C. werneri & $\begin{array}{l}\text { Mina } \\
\text { Corcal }\end{array}$ & P7C & $350 \mathrm{~cm}$ & $\begin{array}{c}\text { Presença de } \\
\text { vendotaenídeos }\end{array}$ & Siltito & Preservada & 1 & Isolada & - & Incompleta \\
\hline 11065 & C. werneri & $\begin{array}{l}\text { Mina } \\
\text { Corcal }\end{array}$ & P7C & $410 \mathrm{~cm}$ & B contraparte & Siltito & $\begin{array}{c}\text { Parcialmente } \\
\text { preservada }\end{array}$ & $\begin{array}{c}\text { Fragmentad } \\
\text { a } \\
\end{array}$ & $\begin{array}{l}\text { Fracamente } \\
\text { empacotada }\end{array}$ & - & Fragmentada \\
\hline 11063 & C. werneri & $\begin{array}{c}\text { Mina } \\
\text { Corcal }\end{array}$ & P7C & $412 \mathrm{~cm}$ & - & Siltito & Molde & 20 & $\begin{array}{l}\text { Fracamente } \\
\text { empacotada }\end{array}$ & Sobreposta & Incompleta \\
\hline
\end{tabular}


A partir da análise das assinaturas tafonômicas, foram descritos dois grupos tafonômicos distintos, baseados, principalmente no grau de fragmentação dos indivíduos.

O primeiro grupo (Figura 4.21) possui espécimes de $C$. werneri com o corpo incompleto, faltando a parte oral e basal. Apresentam entre uma a três faces da estrutura poliédrica e podem estar preservadas em 3D, sendo que uma face pode medir entre $0,7 \mathrm{~mm}$ a 2,15 $\mathrm{mm}$, duas faces podem medir de $2 \mathrm{~mm}$ a $4 \mathrm{~mm}$ e três faces podem medir entre $2,5 \mathrm{~mm}$ a $4,7 \mathrm{~mm}$. Essas medidas não foram utilizadas para estabelecer a classe de tamanho, pois ocorre diferença em sua largura na região basal a na região apical, uma vez que o fóssil está incompleto não se tem certeza se aquela parte está mais próxima de qual região. Dessa forma, foi então realizado a comparação de seu comprimento, em uma mesma amostra foram encontrados indivíduos entre $2,5 \mathrm{~cm}$ e $3 \mathrm{~cm}$ ou entre 3,5 e $4 \mathrm{~cm}$ mantendo um padrão de variação de $0,5 \mathrm{~cm}$. Em amostras maiores tiveram uma maior variação, sendo encontradas espécimes entre $4 \mathrm{~cm}$ e $10 \mathrm{~cm}$ de comprimento. Podem ser encontradas isoladas ou em grupos de até 20 indivíduos fracamente empacotados podendo estar sobrepostos uns aos outros. Das 280 espécimes de $C$. werneri estudadas $5 \%$ possuem carapaça preservada, $28 \%$ possuem carapaça parcialmente preservada e $72 \%$ possuem forma de molde.
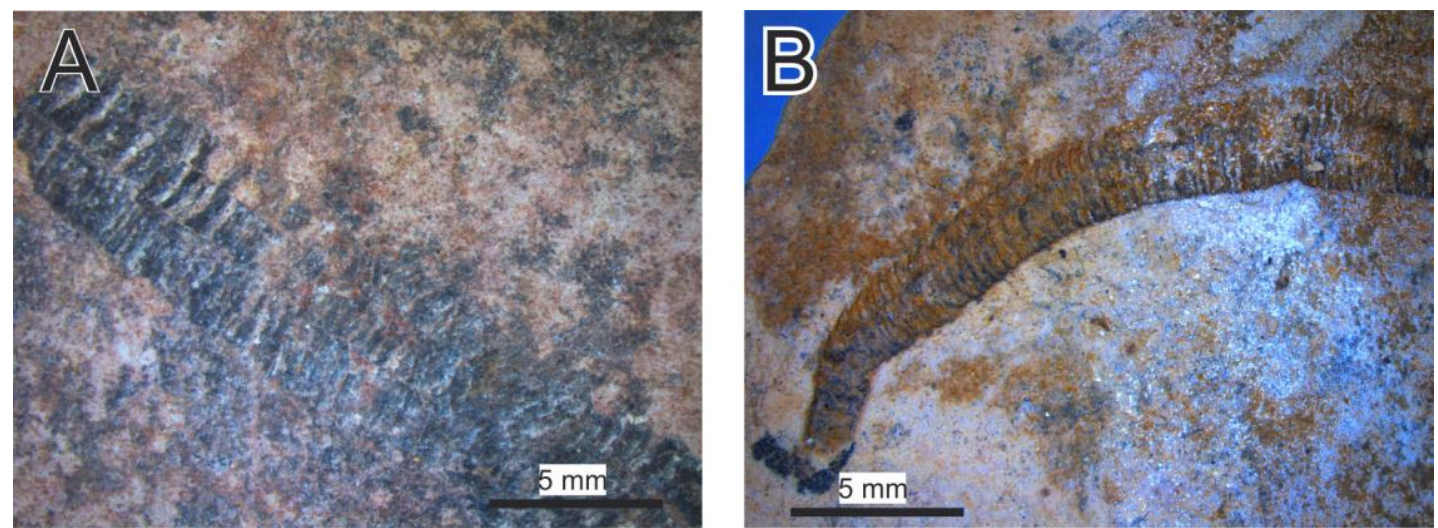

Figura 4.21: Primeiro grupo tafonômico representado por espécimes de C. werneri incompletas com dois tipos de preservação distintos de carapaça. A: preservada tridimensionalmente. B: carapaça parcialmente preservada.

O segundo grupo (Figura 4.22) possui espécimes de $C$. werneri fragmentadas representadas por apenas uma face da estrutura poliédrica, não ocorrendo nenhum exemplar em 3D. Seu comprimento está diretamente relacionado com 
a quantidade de anéis que estão preservados, um anel preservado possui comprimento de 0,18 a 0,20 mm, dois anéis preservado possuem 0,28 a 0,35 $\mathrm{mm}$ com um fragmento apresentando $0,90 \mathrm{~mm}$, três anéis apresentam 0,41 a $0,60 \mathrm{~mm}$, por mais que tenha uma variação de tamanho a diferença não chega nem a $1 \mathrm{~mm}$. Das 17 amostras que possuem fragmentos, 6\% deles possuem carapaça preservada, 53\% possuem carapaça parcialmente preservada e $41 \%$ possuem forma de molde, estão fracamente empacotadas sendo suportados pela matriz. Na maioria dos casos ocorre a presença de uma ou mais espécimes de $C$. werneri incompletas, juntamente com os fragmentos.
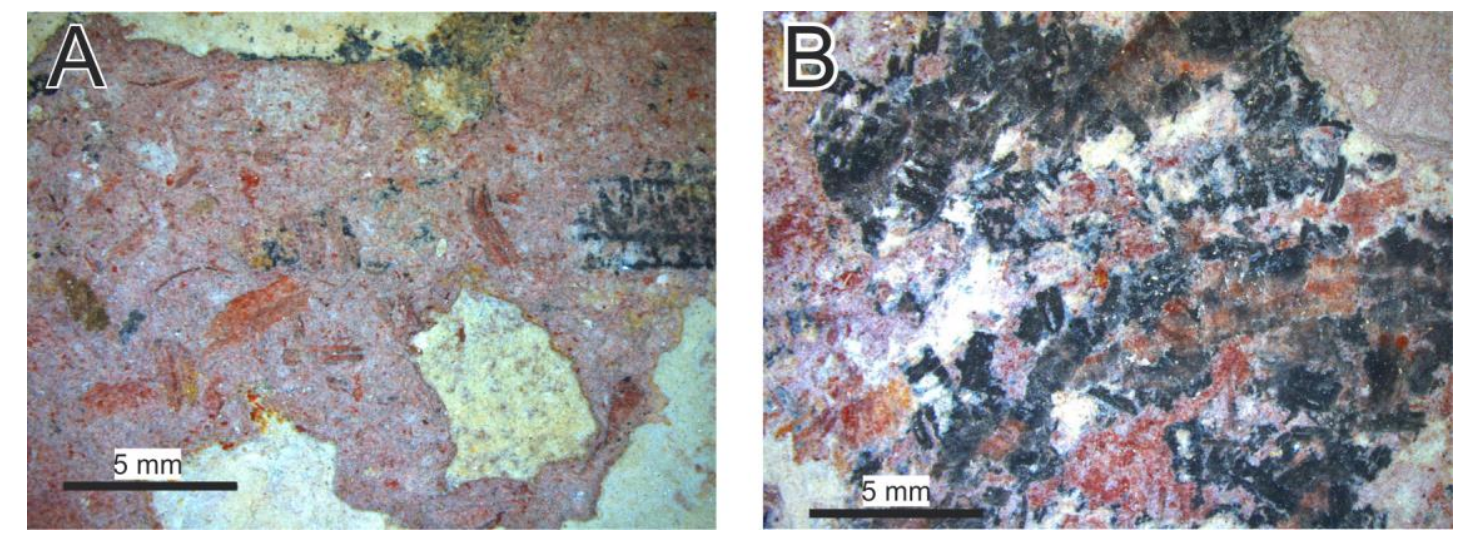

Figura 4.22: Segundo grupo tafonômicos representado por espécimes de C. werneri fragmentadas com dois tipos de preservação distintos A: carapaça preservada e B: carapaça parcialmente preservada.

\subsection{Novas ocorrências de Fósseis na Formação Tamengo}

O levantamento estratigráfico em detalhe permitiu encontrar novas ocorrências fósseis. Algumas delas, como as algas, filamentos e icnofósseis, foram pontuadas nas seções estratigráficas apresentadas. Outras novas ocorrências serão descritas aqui, apenas em relação às suas características morfológicas, na tentativa de diferenciar se representam estruturas biológicas ou inorgânicas e não foram pontuadas nas seções estratigráficas, embora tenham a posição estratigráfica demarcada. 


\subsubsection{Algas}

Foram encontrados três exemplares de macroalgas. Esses registros representam as primeiras ocorrências de algas na Formação Tamengo. Os exemplares são descritos a seguir.

A primeira amostra representa fóssil de alga com $1,5 \mathrm{~cm}$ de comprimento (Figura 4.23). Maior espessura na base de aproximadamente $0,4 \mathrm{~mm}$ de largura e menor espessura no topo de $0,15 \mathrm{~mm}$ de espessura. Talo estriado, indicando ser pseudo-parenquimatoso (Figura 4.23 B) (Reviers, 2006), com ramificações dicotômicas regulares por todo comprimento (Figura $4.23 \mathrm{C}$ ). Em sua base ocorrem estruturas circulares, com $1 \mathrm{~mm}$ de diâmetro (Figura $4.23 \mathrm{D}$ ). No ápice, os talos se sobrepõe uns aos outros e em sua extremidade estão preservados prováveis estruturas circulares entre $0,08 \mathrm{~mm}$ e $0,15 \mathrm{~mm}$ de espessura interpretada como estruturas com maior atividade de divisão celular responsável pelo crescimento (Figura 4.23 E) (Reviers, 2006).

Fotos em Microscopia Eletrônica de Varredura (MEV) demonstram que ainda possuem uma película por todo o fóssil principalmente na parte apical (Figura 4.23 F). Dados de espectroscopia de energia dispersiva (EDS) mostram a presença de carbono na película recobrindo o fóssil e de sílica na rocha (Figura 4.23 G e H). Amostra GP/1E - 10989, retirada em Ladário, MS na seção estratigráfica $\mathrm{P} 3$, a $75 \mathrm{~cm}$. 

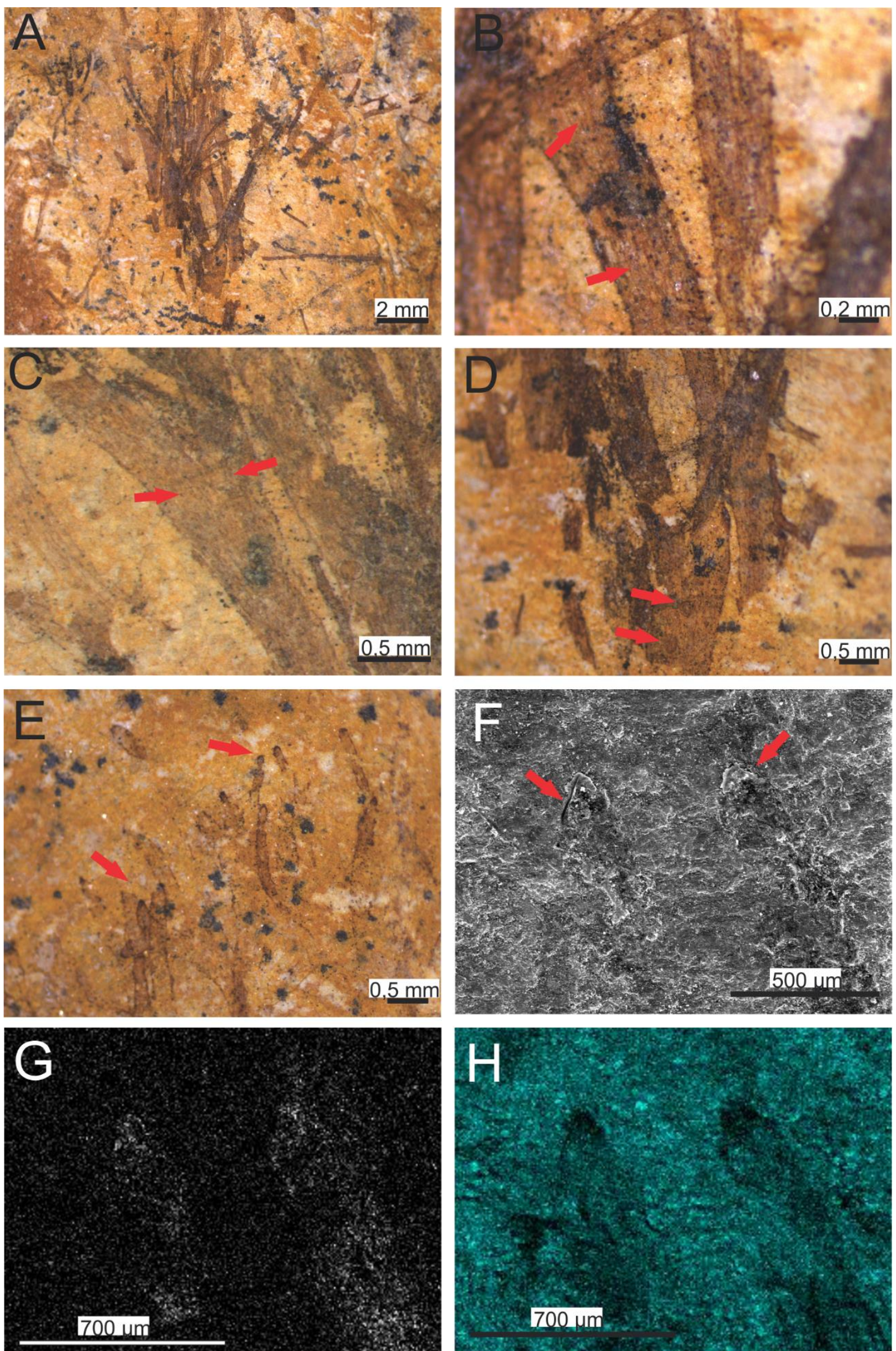

Figura 4.23: Amostra GP/1E - 10989 macroalga pseudo-parenquimatosa com provável estrutura de crescimento em seu ápice. A: visão geral do espécime. B: estriamento longitudinal ao longo do talo. C: Talo apresentando dicotomia (SETAS). D: parte basal com estruturas circulares (SETAS) E: 
parte apical com provável estrutura de crescimento, (SETAS). F: imagem retirada em MEV demonstrando parte da película na parte apical (SETAS). G: imagem em EDS marcando a presença de carbono no fóssil. H: imagem em EDS marcando a presença de sílica na rocha.

O segundo exemplar representa provável espécie de alga de $35 \mathrm{~mm}$ de altura, com ramificações dicotômicas regulares que podem ocorrem duas vezes no mesmo seguimento (Figura $4.24 \mathrm{~B}$ ). Possui talos estriados, indício de ser pseudo-parenquimatoso (Figura $4.24 \mathrm{C}$ ). Não possui muita diferença de espessura ao longo do corpo, em sua base apresenta entre $0,35 \mathrm{~mm}$ e 0,45 mm e na parte superior entre $0,30 \mathrm{~mm}$ e $0,45 \mathrm{~mm}$. Apresentam ao longo dos talos estruturas que se assemelham a espinhos (Figura 4.24 D) e na parte apical uma estrutura interpretada como uma membrana que conecta os talos dicotomizados (Figura $4.24 \mathrm{E}$ ). Fóssil muito frágil e de fácil fragmentação, aparenta estar achatado devido as formas que apresentam os espinhos ao longo do talo (Figura 4.24 D).

Fotos em Microscopia Eletrônica de Varredura (MEV) demonstram o achatamento do fóssil (Figura 4.24 F). Análises de EDS evidenciam o carbono presente no fóssil, indício para preservação por incarbonização, e sílica na rocha (Figura 4.24 G e H). Amostra GP/1E - 10990, coletada em Ladário, MS, na seção estratigráfica $\mathrm{P} 3$ sem posição estratigráfica, pois estava rolada próximo ao afloramento. 

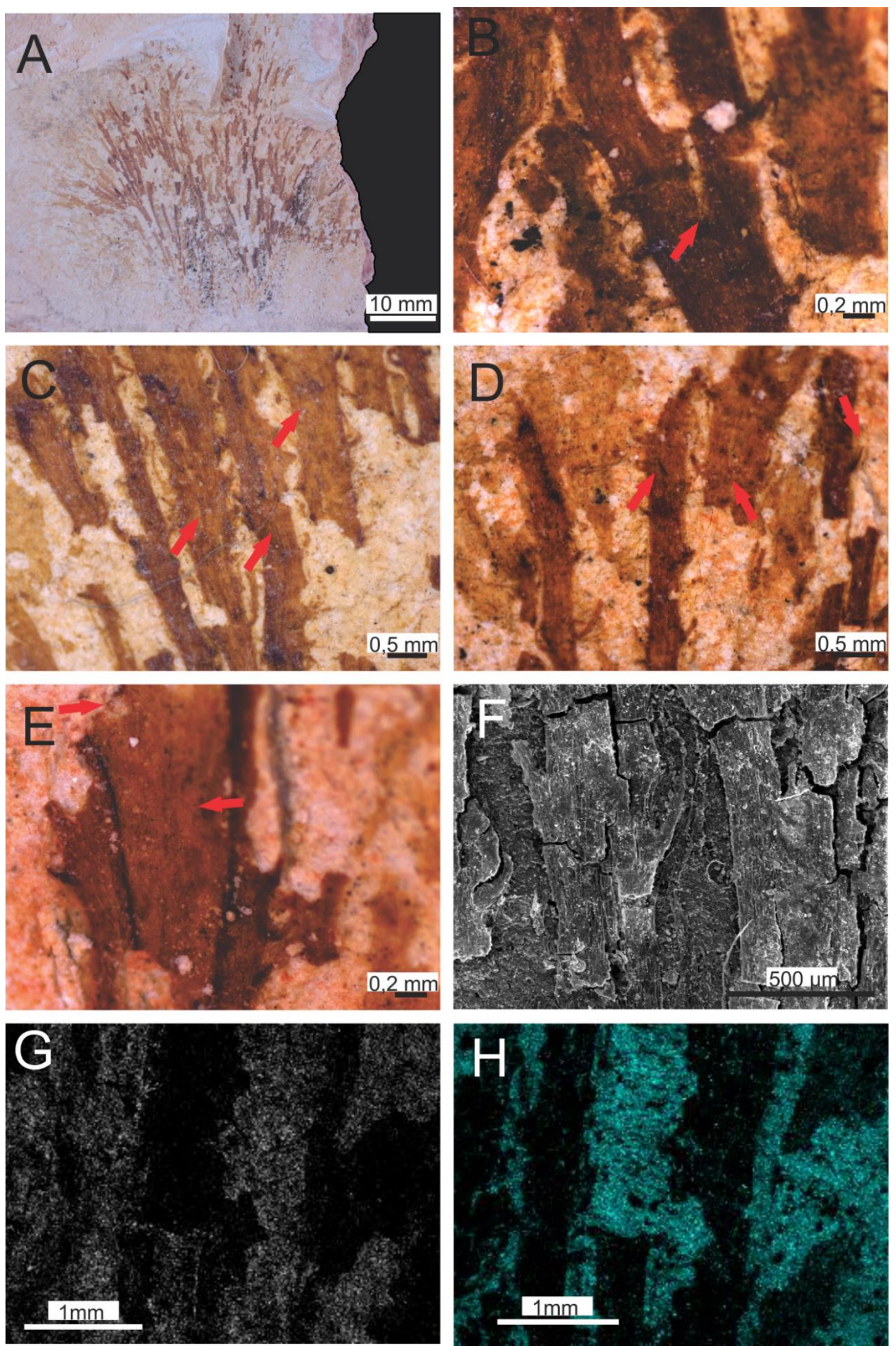

Figura 4.24: Amostra GP/1E - 10990 macroalga pseudo-parenquimatosa. A: visão geral da espécime. B: Presença de dicotomia (SETAS). C e D: talos com estruturas similares a espinhos (SETAS). E:Membrana interligando os talos (SETAS). F: imagem geral do espécime em MEV. G: imagem em EDS marcando a presença de carbono no fóssil. H: imagem em EDS marcando a presença de sílica na rocha, escala $1 \mathrm{~mm}$. 
O último exemplar, aqui interpretado como possível alga, apresenta $11 \mathrm{~mm}$ de comprimento e, aproximadamente, $0,05 \mathrm{~mm}$ de largura. Possui talos estriados, também indicando ser pseudo-parequimatoso, que se dicotomizam (Figura 4.25 A e B). Em alguns talos ocorre uma estrutura longitudinal espessa central (Figura 4.25 B - setas). Amostra GP/1E - 11187, encontrada em Corumbá, MS, no Porto Sobramil, seção estratigráfica P5S, a $250 \mathrm{~cm}$ da base da seção.

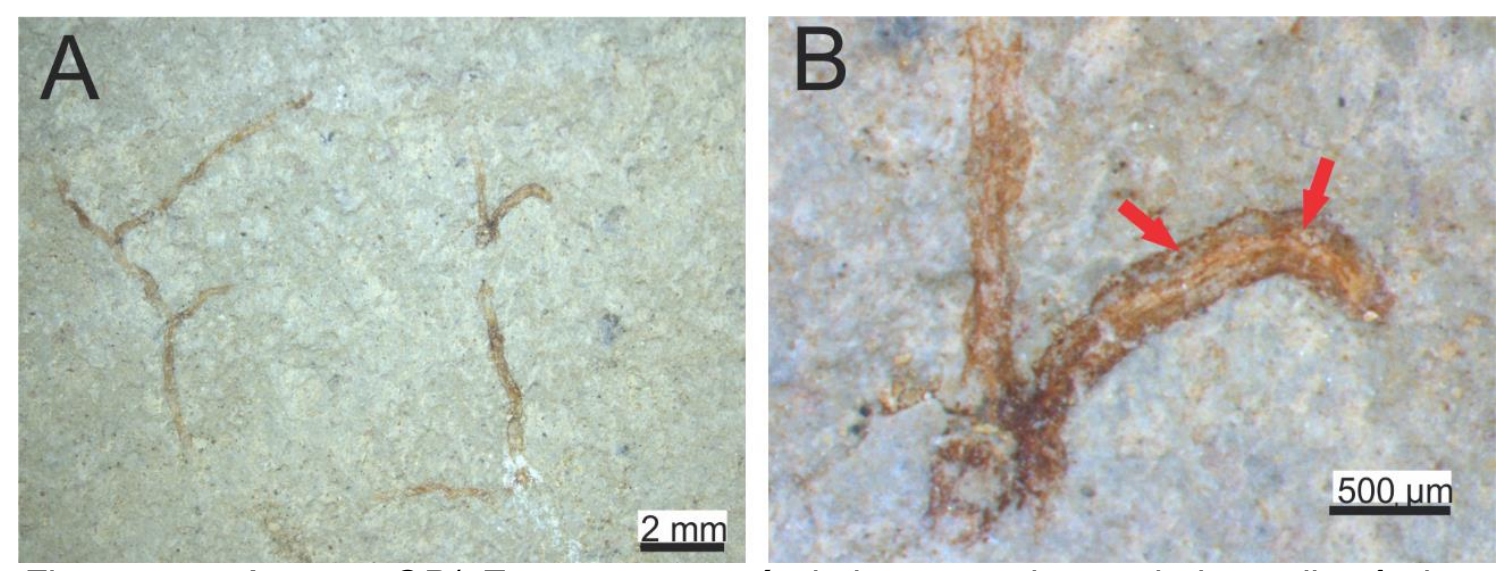

Figura 4.25: Amostra GP/1E - 11187, possível alga com talos estriados e dicotômicos. A: visão geral da alga. B: detalhe do talo estriado, com estrutura longitudinal espessa central (SETAS).

Análises taxonômicas em algas fósseis do Proterozoico são complicadas, pois características celulares, bioquímicas e reprodutivas são difíceis de se preservarem. Por essa razão, a classificação ocorre fundamentalmente nas descrições morfológicas, portando uma determinada espécie pode agregar a um grupo polifilético de organismos e uma determinada característica pode ser adquirida através de convergência evolutiva (Xiao et al., 1998a).

As algas vermelhas (Rhodophyceae) formam um grupo monofilético, classificadas por apresentar uma estrutura formada por proteínas que bloqueia a abertura presente na parede celular chamada sinapse e simultaneamente não apresentam flagelo durante todo seu ciclo de vida. Podem ocupar tanto água doce quanto água salgada, se apresentam de forma multicelular e somente os organismos primitivos são unicelulares capazes de formarem colônias em forma de filamentos dicotômicos. As algas vermelhas multicelulares podem se apresentar de forma calcária de maioria filamentosa multiaxial com crescimento apical, esse filamentos se agregam formando um pseudo-parenquima. Em seu 
talo podem haver células especializadas capazes de secretar substancias e algumas espécies podem apresentar membranas que interligam os talos como é o caso da Delesseriacea (Trainor, 1978; Lee, 1980; Ricker, 1987; Reviers, 2006; Yoon et al., 2006; Lin \& Hommersand, 2016).

As algas marrons (Phaeophyceae) já são datadas para o Neoproterozoico (Xiao et al., 1998a, 1998b) possuem dimensões variadas, são multicelulares, mas somente seu órgão reprodutor é capaz de chegar a nível unicelular flagelado. Apresentam uma grande diversidade morfológica podendo ser filamentosas, em formas de leque, com nervuras, perfuradas e formas arbustivas. Possuem estruturas externas denominadas "pelos" que constituem em células alongadas estreitas pobres em plastídios que nascidas a partir do ápice de um filamento com o intuito de absorção de nutrientes (Trainor, 1978; Lee, 1980; Reviers, 2006).

Ocorrências de possíveis algas na Formação Lantian (Ediacarano) no Sul da China na forma de compressões carbonáticas megascópias, foram classificadas como Doushantuophyton sp. Chen et Xiao, 1991 (Wu et al., 2010; Yuan et al., 2011). Apresentam morfologia similar ao segundo exemplar (GP/1E - 10990) aqui descrito, uma vez que possuem o estilo arbustivo e talos com dicotomia, mas a presença de algas no Neoproterozoico (Xiao et al., 1998a, 1998b, 2004; Xiao and Knoll, 2007; Yuan et al., 2011, 2013), indicam que elas já começaram a divergir a partir do Mesoproterozoico e no Neoproterozoico já possuiriam uma maior complexidade morfológicas, reprodutiva e taxonômica (Xiao et al., 2002).

Portanto a presença de uma macroalga possivelmente eucarionte multicelular não seria novidade para o Neoproterozoico, entretanto, características como estruturas semelhantes a espinhos e membranas interligando os talos, conforme observado no segundo exemplar (GP/1E 10990), não foram ainda descritas na literatura para o Ediacarano, sendo apresentadas aqui pela primeira vez. Mesmo com essas características morfológicas distintas é difícil a classificação, uma vez que essas características morfológicas podem ser encontradas em diversos grupos de algas atuais, mas existe a possibilidade desse exemplar brasileiro ser interpretado como uma nova espécie primitiva. 


\subsubsection{Icnofósseis}

Além de encontrar amostras de possíveis fósseis também foi notada a ocorrência de icnofósseis ao longo de toda a Formação Tamengo. Esses representam as primeiras ocorrências de icnofósseis na Formação Tamengo. Foram encontradas dez amostras em P1, uma amostra em P2, vinte e seis amostras em P3, doze amostras em P4, cinco amostras em P7S e três amostras em P5C.

Os icnofósseis apresentam pequeno tubos curtos, sub-horizontais e sinuosos entre 0,20 e 0,26 mm de largura que se sobrepõem uns aos outros formando uma rede com várias camadas (Figura 4.26 A e B). Possuem uma cor diferente da rocha matriz e parecem ter sido preenchidos por outro material aparentemente oxidado. Ao lado desses canais também ocorrem estruturas circulares com a margem também oxidada e preenchimento similar interpretado como um tubo vertical em corte transversal (Figura $4.26 \mathrm{C}$ e D).

Icnofósseis são a representação de atividades de organismos registradas no sedimento, estão presentes desde o Pré-Cambriano, mas ocorre um aumento tanto em sua quantidade quanto em sua diversidade durante o limite Neoproterozoico - Cambriano. Icnofósseis do Pré-Cambriano são conhecidos por serem horizontais, não serem escavadores e ramificados, estarem presentes mais próximos a superfície do sedimento e são importantes por estão diretamente ligados as primeiras aparições de animais (Jensen, 2003; Seilacher, 1956, 2007).

São atribuídos e classificados em icnoespécie e icnogênero a partir de suas características morfológicas que por mais que seja uma forma objetiva de classificação pode criar alguns equívocos pois, um icnofóssil designado a partir de uma mesma espécie, pode ocorrer em diferentes sedimentos alterando sua preservação e criando aspectos morfológicos diferentes, também pode ocorrer a preservação de diversas partes distintas de um mesmo icnofóssil. Jensen et al. (2000) e Jensen (2003) propõem para icnofósseis do Neoproterozoico uma observação voltada para as características semelhantes juntamente com uma visão tafonômica para que assim seja possível encontrar ligações entre os icnofósseis do Neoproterozoico e do Cambriano. 
Parry et al. (submetido) atribui os icnofósseis encontrados para a Formaça Tamengo a Multina mínima Uchman, 2001 devido ao modo dos tubos estarem em forma de rede mal organizadas, serem curtos e empilhados verticalmente, além do próprio tamanho e morfologia irregular e sinuosa da galeria (Figura 4.26 A). A presença desses icnofósseis indica que o substrato da Formação Tamengo era, provavelmente, oxigenado.
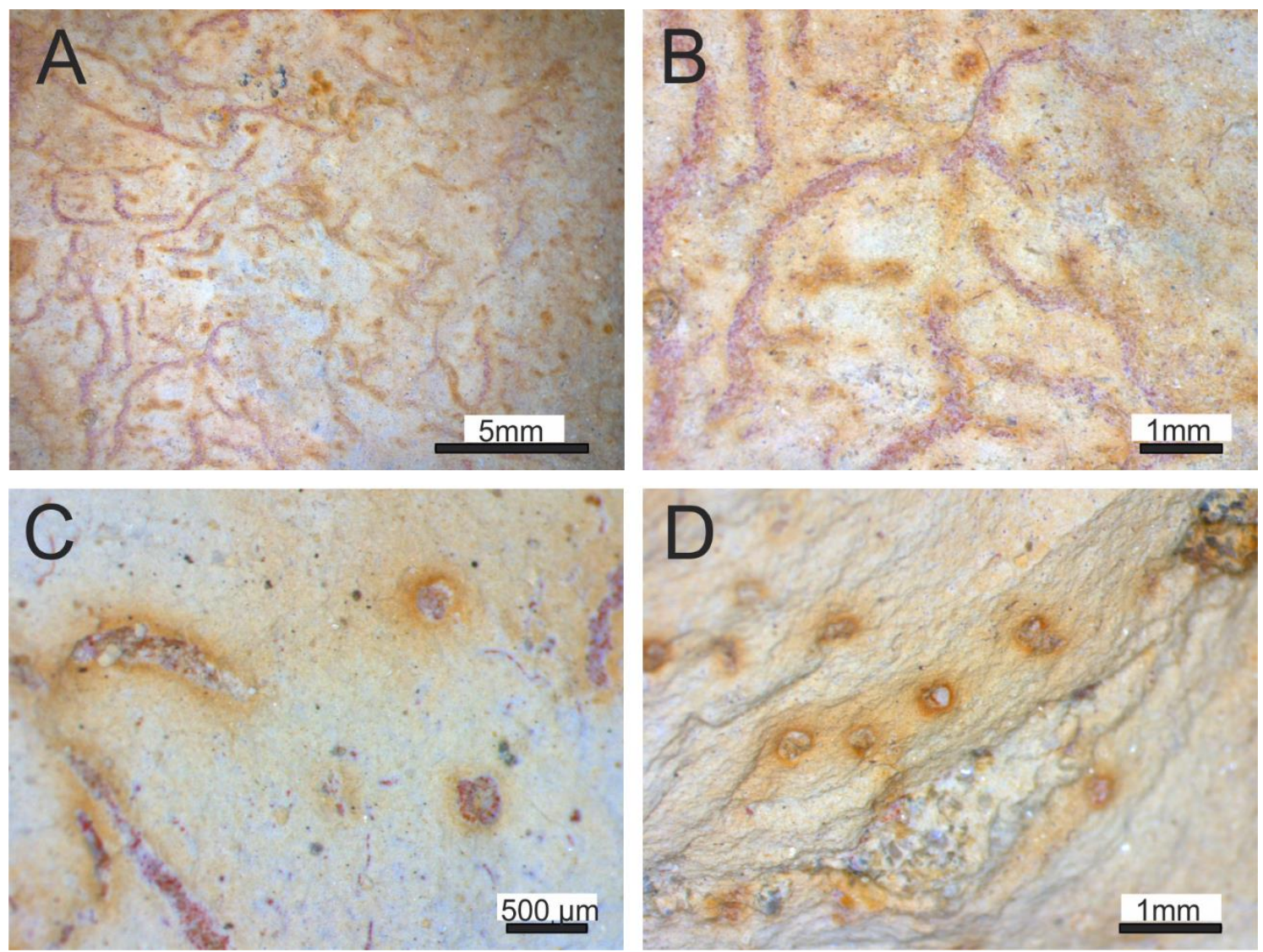

Figura 4.26: Amostra GP/1E - 11005. Icnofósseis de Multina minima encontrados na Formação Tamengo em P1, representados por: $\boldsymbol{A}$ e B: pequenos tubos curtos sub-horinzontais sinuosos com preenchimento diferente da matriz rochosa. $\boldsymbol{C}$ e $\boldsymbol{D}$ : estruturas circulares associadas com o mesmo tipo de preservação. 


\subsubsection{Filamentos}

Foram observadas novas amostras com estruturas filamentosas alongadas de comprimento máximo de $10 \mathrm{~cm}$ e largura entre 0,4 a $1 \mathrm{~mm}$. Aparenta estriamento longitudinal, podendo ser linear ou curvilíneo agrupados sobrepondo ao próprio corpo (Figura 4.27 A) ou ocorrem isolados (Figura 4.27 B). Possuem pelo menos dois tipos de preservação, uma com aspecto mais brilhante, e outra com película escura, indicando incarbonização (Figura 4.27) e em algumas amostras apresentam bordas mais demarcadas (Figura 4.27 D e E).

Zaine (1991) descreveu fósseis de filamentos como compressões carbonosas, cobertas por uma película de gipsita, cinza esbranquiçada, lineares em forma de fita com as bordas uniformes que podem ser enrolados ou que se sobrepõem, possuindo alcance máximo de $58 \mathrm{~mm}$ de comprimento e 0,3 a $1 \mathrm{~mm}$ de largura sem variação ao longo do corpo, não foram encontradas evidencias de órgãos de reprodução como esporângios nem estrutura celular (Figura 4.28). Atribuiu esses fósseis ao grupo dos Vendotaenídeos, que são talos em forma de filme ou fitas, ramificados ou não, delgados, elásticos, com a superfície lisa ou filamentosa com provável afinidade a algas marrons. De acordo com Gnilovskaya $(1971,1979,1985)$ esse grupo de algas pode ser subdividido em dois grupos a partir de suas características morfológicas. Indivíduos que não possuem ramificação e mantém um formato de fita, fazem parte do grupo dos Vendotaenídeos, e os que possuem estruturas filamentosas, visivelmente ramificadas, lisas ou com estruturas, fazem parte do grupo dos Eoholynídeos.

Zaine (1991) atribui esses filamentos mais especificamente, dentre os Vendotenídeos, a espécie Tyrasotaenia sp., que representam formas de fitas ou tubulares achatadas, com talo fino entre 0,3 de $0,5 \mathrm{~mm}$, com superfície lisa e homogênea sem descrição de órgãos reprodutores e estrutura celular (Gnilovskaya, 1985). 

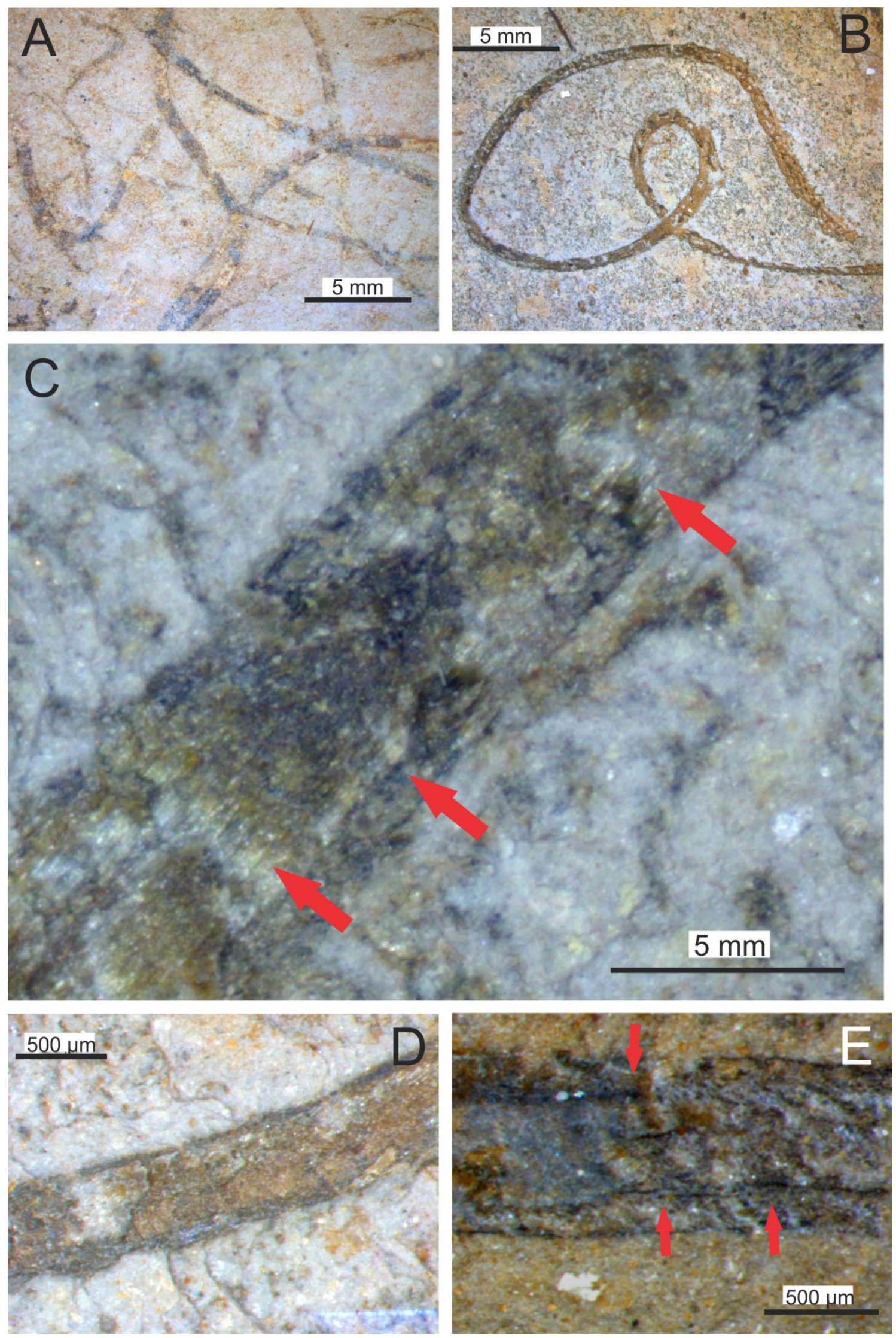

Figura 4.27: Filamentos encontrados na Formação Tamengo. A: Filamentos agrupados, B: Filamento isolado. C: Detalhe do estriamento no filamento (SETA). D: Filamento com película escura E: Filamento com a borda demarcada (SETAS). 

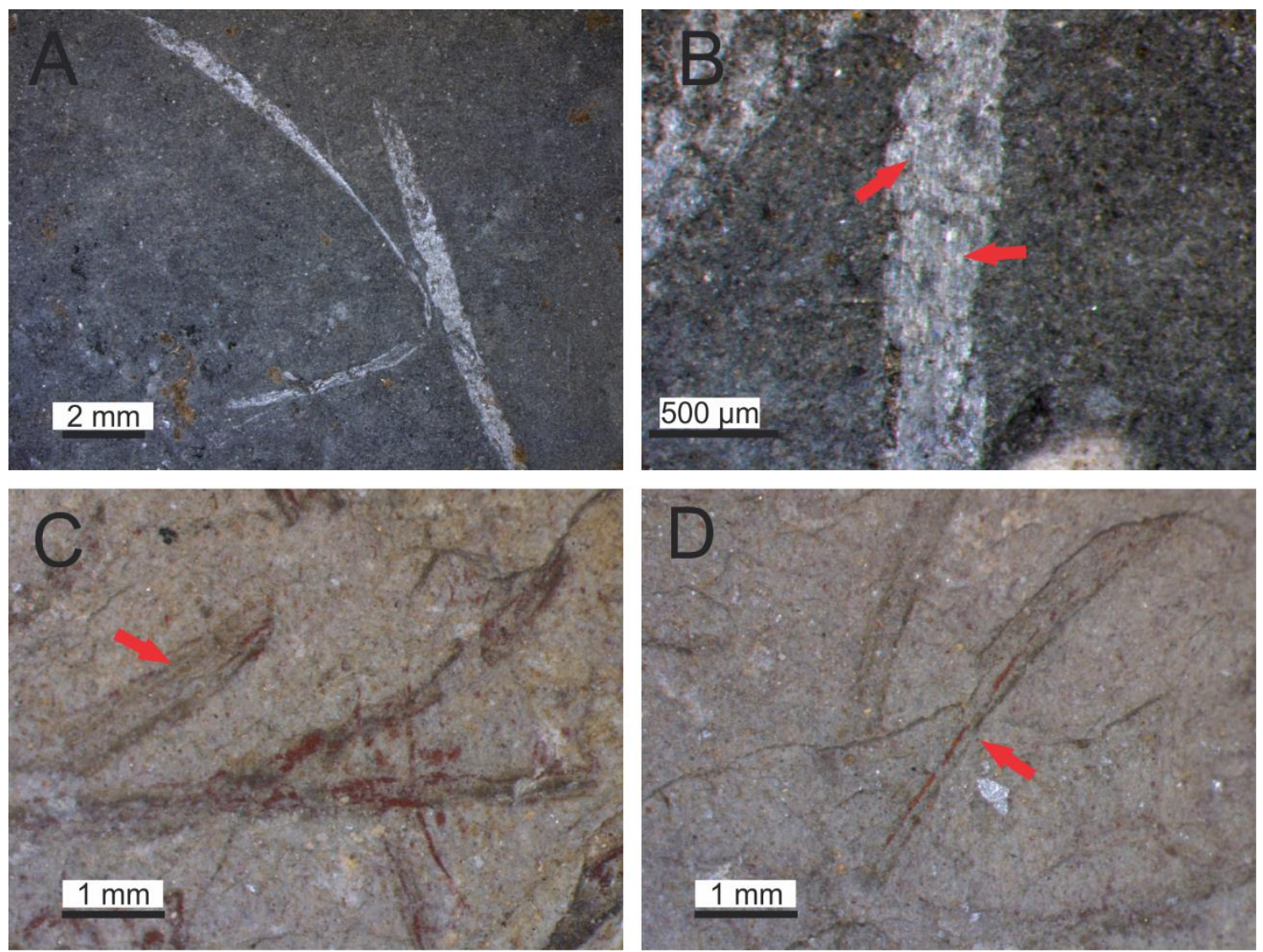

Figura 4.28: Vendotaenídeos descritos por Zaine (1991). A e B: fitas cobertas por mineral (SETAS). C e D: amostras de filamentos com película escura (SETAS).

Foi realizada uma revisão nos fósseis estudados por Zaine (1991) confirmando todas as características observadas. Entretanto, nas novas amostras coletadas e nas amostras estudadas por Zaine (1991) foram encontradas estruturas de superfície estriadas longitudinalmente (Figura 4.27 C), não descritas anteriormente.

A presença dos estriamentos longitudinais, tanto nos fósseis encontrados quanto nos fósseis estudados por Zaine (1991) indicaria que seriam melhor atribuídos a outra espécie de Vendotenídeos, Vendotaenida sp. Esse gênero é caracterizado por possuir talo em forma de fita, multicelular e com multi camadas, raramente ramificado e superfície marcada por estrias longitudinais com presença de esporângios. (Gilovskays 1971, 1979, 1985). Não foi reconhecida a presença de esporângios nas amostras estudadas. 


\subsubsection{Estruturas esféricas}

Molde tridimensional externo de estrutura disforme com área aproximadamente de $5 \mathrm{~cm}^{2}$, constituída por um grupo de estruturas esféricas menores próximas a 100 unidades (Figura 4.29). Tais estruturas, apresentam tamanho uniforme entre $5 \mathrm{~mm}$ a $0,5 \mathrm{~mm}$ e podem se colidir sem haver nenhum espaço entre as duas estruturas ou podem estar encostados com um determinado espaço vago. Não ocorre sobreposição entre uma estrutura e outra e não foi encontrado de forma isolada.

Os fósseis foram encontrados na seção estratigráfica P1 a $80 \mathrm{~cm}$ da base em arenito, em P3 em uma amostra rolada próxima a seção, em P4 a $30 \mathrm{~cm} \mathrm{e}$ $214 \mathrm{~cm}$ da base no siltito, na seção P5S a 170 e $180 \mathrm{~cm}$ da base em ritmito arenito/siltito e na seção P6 a $215 \mathrm{~cm}$ da base no ritmito folhelho/arenito, representando 10 amostras.
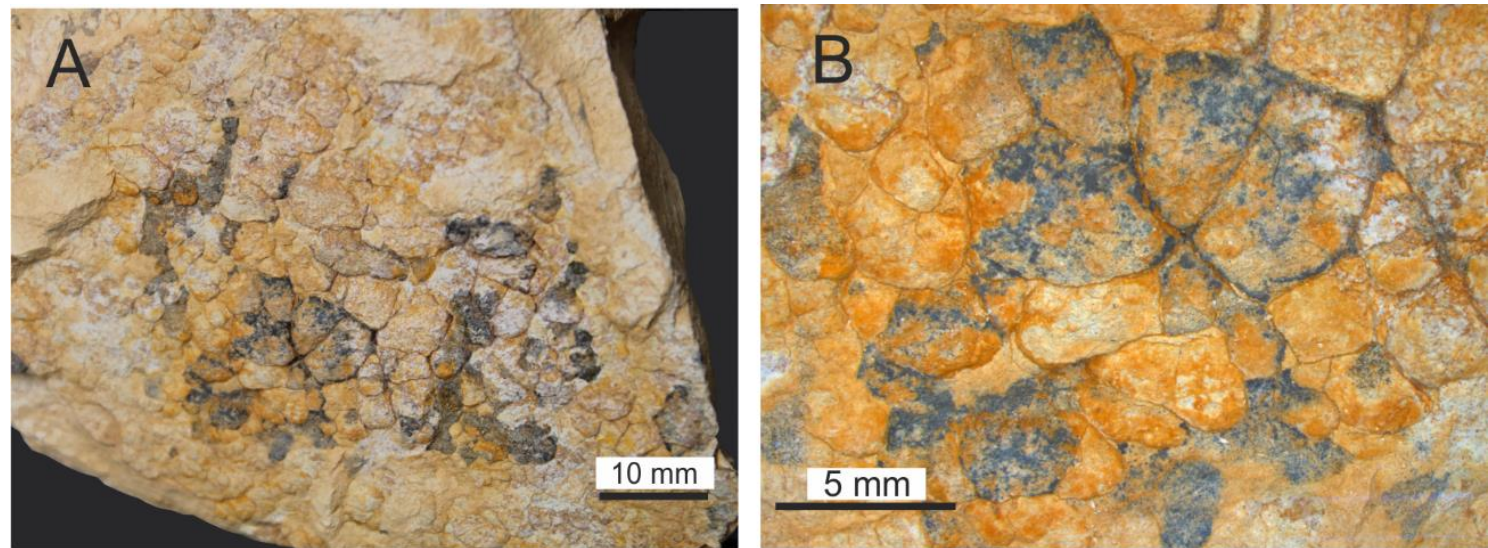

Figura 4.29: Amostra GP/1E - 11197 retirada da seção $P 4$ a $30 \mathrm{~cm}$ da base da seção, representando possível estrutura sedimentar induzida por esteira microbiana (MISS).

As amostras acima descritas foram aqui interpretadas como possíveis estruturas sedimentares induzidas por matéria microbiana (MISS - microbially induced sedimentar structures). Essas estruturas são caracterizadas por serem o resultado de bactérias interagindo com os agentes físicos como erosão, transporte e até mesmo a deposição em ambientes que predominam processos sedimentares físicos (Noffke et al., 1995, 2002).

Podem auxiliar na identificação de fácies e na representação paleoecológica e paleoambiental, pois esteiras microbianas realizadas por bactérias possuem preferências distintas se tratando ao substrato, ambiente e regime 
hidrodinâmico, por exemplo, cianobactérias que prefeririam uma zona fótica para seu crescimento e que poderiam mudar sua posição no sentido em que estaria mais iluminado (Noffke et al., 2001).

Podem estar preservadas de diferentes formas tais como moldes externos em superfície de forma lisa ou aguda ou moldes internos e apresentar diferentes características morfologicas tais como formas ovoóides deformadas, formas geométricas retangulares, formas tubulares entre outras (Gerdes et al., 2000; Gehling and Droser, 2009).

O modo de formação da estrutura é diferenciado de acordo com o sedimento, Noffke et al., (2001) realizou um estudo apresentando 5 tipos distintos de formação dessas estruturas influenciadas pelo sedimento, organismo e ambiente. $O$ tipo Leveling ocorre quando o crescimento orgânico acontece nas partes mais profundas dos sedimentos protegendo os organismos da erosão e nivelando a superfície sedimentar resultando em estruturas rugosas. O tipo Structure imprint ocorre quando os biofilmes irão recobrir estruturas sedimentares que já possuem uma forma e assim preserva-las. O tipo Microbial grain separation, acontece devido ao crescimento contínuo de biofilmes ocorrendo a separação mecânica dos grãos de sedimento formando estruturas sedimentares distintas. O tipo Biostabilization ocorre quando há fixação do sedimento devido a presença de um organismo, seja através da muscilagem, pelo tecido da esteira ou pela vedação do sedimento por ter uma esteira microbiana acima. E o tipo Baffling, Trapping, and Binding significam acúmulo de sedimentos por atividades bacterianas e incorporação dos grãos nos tecidos de esteira por crescimento microbiano.

\subsubsection{Estrutura basal}

Estrutura circular concêntrica lisa com borda externa demarcada com 6,85 $\mathrm{mm}$ de comprimento (Figura $4.30 \mathrm{~B}$ ). Em seu centro apresenta uma estrutura ovalada menor com 2,77 cm de comprimento e 1,79 cm de largura (Figura 4.18). Amostra GP/1E - 9971, encontrada em Corumbá, MS, na Pedreira Sobramil, seção estratigráfica P5. Não possui posição detalhada pois, estava rolada próxima a seção, 

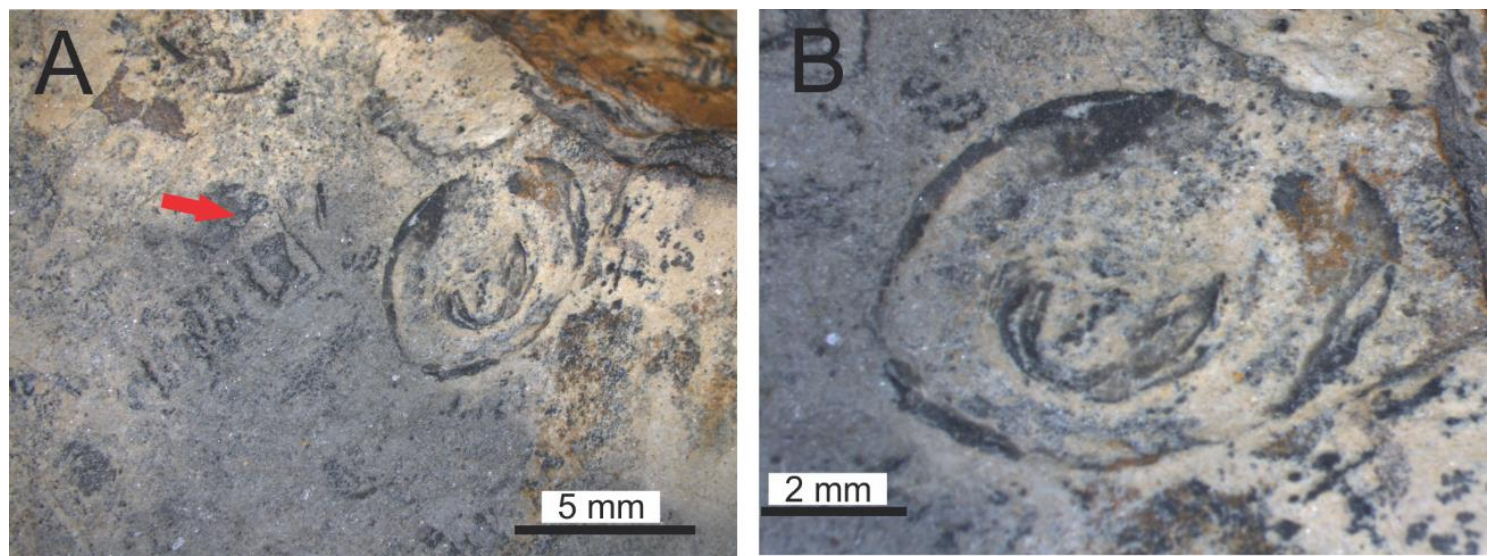

Figura 4.30: Amostra GP/1E - 9971. A: estrutura circular concêntrica, com círculo externo e central. Notar os espécimes incompletos de Corumbella werneri, setas. B: detalhe da estrutura circular.

Alguns organismos apresentavam discos basais para auxiliar em sua fixação como, por exemplo, o fóssil Ediacarano Charnia sp. (Ford, 1958). Esse gênero possuía um disco basal, descrito como Charniodiscus sp. de 5 a $30 \mathrm{~cm}$ (Figura 4.31 A), que se espalharia na superfície do substrato mantendo a fronde que se conecta através de uma área central do disco estabilizada (Ivantsov, 2016). Outra espécie de cnidário chamada Sphenotallus sp. Hall 1847, um cnidário com possível afinidade com os conuláridios, que surgiu no Cambriano, utilizava também uma estrutura de fixação similar a um disco basal de aproximadamente $0,1 \mathrm{~mm}$ conectada ao tubo em seu centro mantendo-o estabilizado (Figura 4.31 B). (Bodenbender et al., 1989; Van Iten et al., 1992; Li et al., 2004)
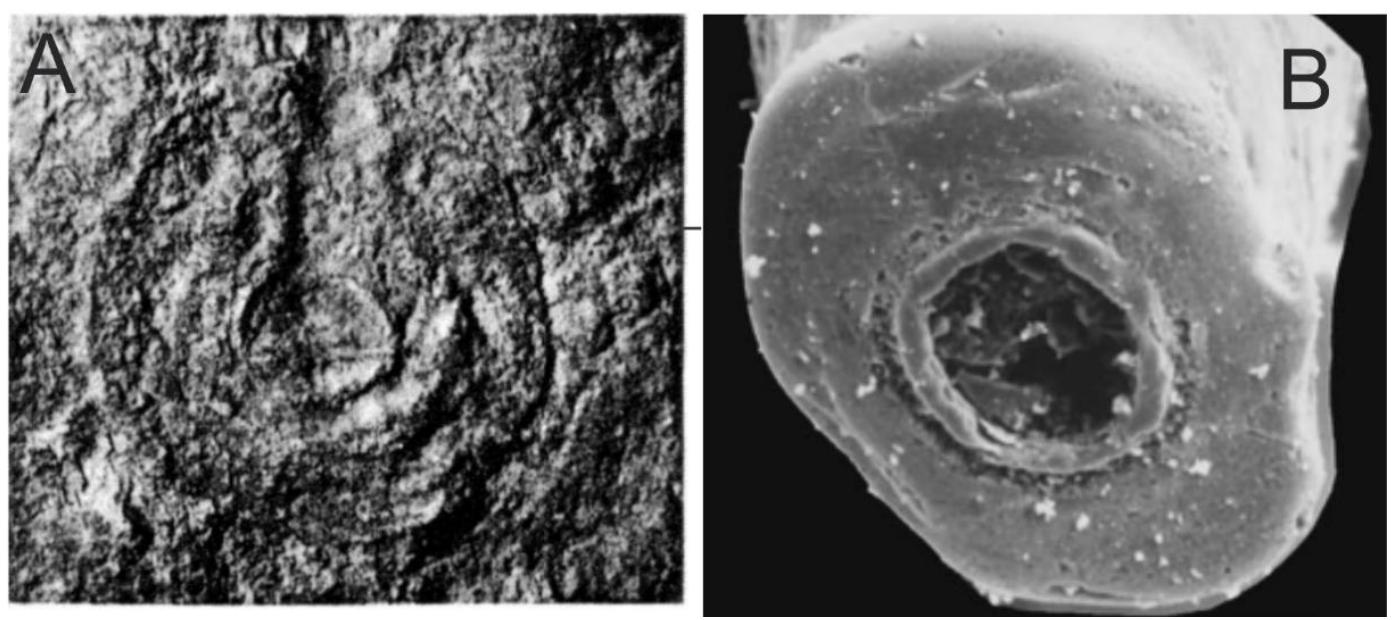

Figura 4.31: A: disco basal Charniodiscus sp. retirado de (Ford, 1958). B: Parte basal de Sphenotallus sp. na qual se conectaria ao disco retirado de ( $L i$ et al., 2004).

Em relação à $C$. werneri, ainda não foram descritas estruturas de fixação, Babcock (2005) interpretou exemplares entrelaçados próximas a $C$. werneri a possíveis massas orgânicas que auxiliariam em sua fixação. Na mesma amostra, 
próximo à estrutura circular descrita, ocorrem exemplares incompletos de Corumbella werneri com $1,87 \mathrm{~mm}$ de largura com a carapaça parcialmente preservada (Figura 4.30 A). Devido às semelhanças morfológicas e de tamanho, essa estrutura foi aqui interpretada como possível disco basal de Corumbella werneri.

\subsubsection{Estruturas fragmentadas}

Foram ecnontradas duas amostras com moldes externos de estruturas fragmentadas associadas a sedimento ferruginoso de tamanhos variados. A primeira amostra, GP/1E - 11124, (Figura 4.32 A e B) retirada em Ladário, MS na seção estratigráfica $\mathrm{P} 3$, a $90 \mathrm{~cm}$ da base as seção, no ritmito folhelho/siltito apresenta fragmentos alongados, aparentemente lisos, que podem ter entre 0,20 $\mathrm{mm}$ a $0,50 \mathrm{~mm}$ de largura e entre $1 \mathrm{~mm}$ e $2 \mathrm{~mm}$ de comprimento. Alguns fragmentos, se ramificam e podem se conectar a outros por suas extremidades. Entretanto, também podem ser encontrados isolados (Figura 4.32 B).

A segunda amostra, GP/1E - 11125 (Figura 4.32 C e D), coletada em Ladário, MS na seção estratigráfica $\mathrm{P} 3$, a $95 \mathrm{~cm}$ da base da seção no ritmito folhelho/siltito apresenta estruturas disformes, com a parte externa irregular. Largura média de $1,5 \mathrm{~mm}$ e comprimento médio de $5 \mathrm{~mm}$. Ligam-se a outras estruturas através de ramos mais finos, também podem ser encontradas isoladas (Figura 4.32 D). 

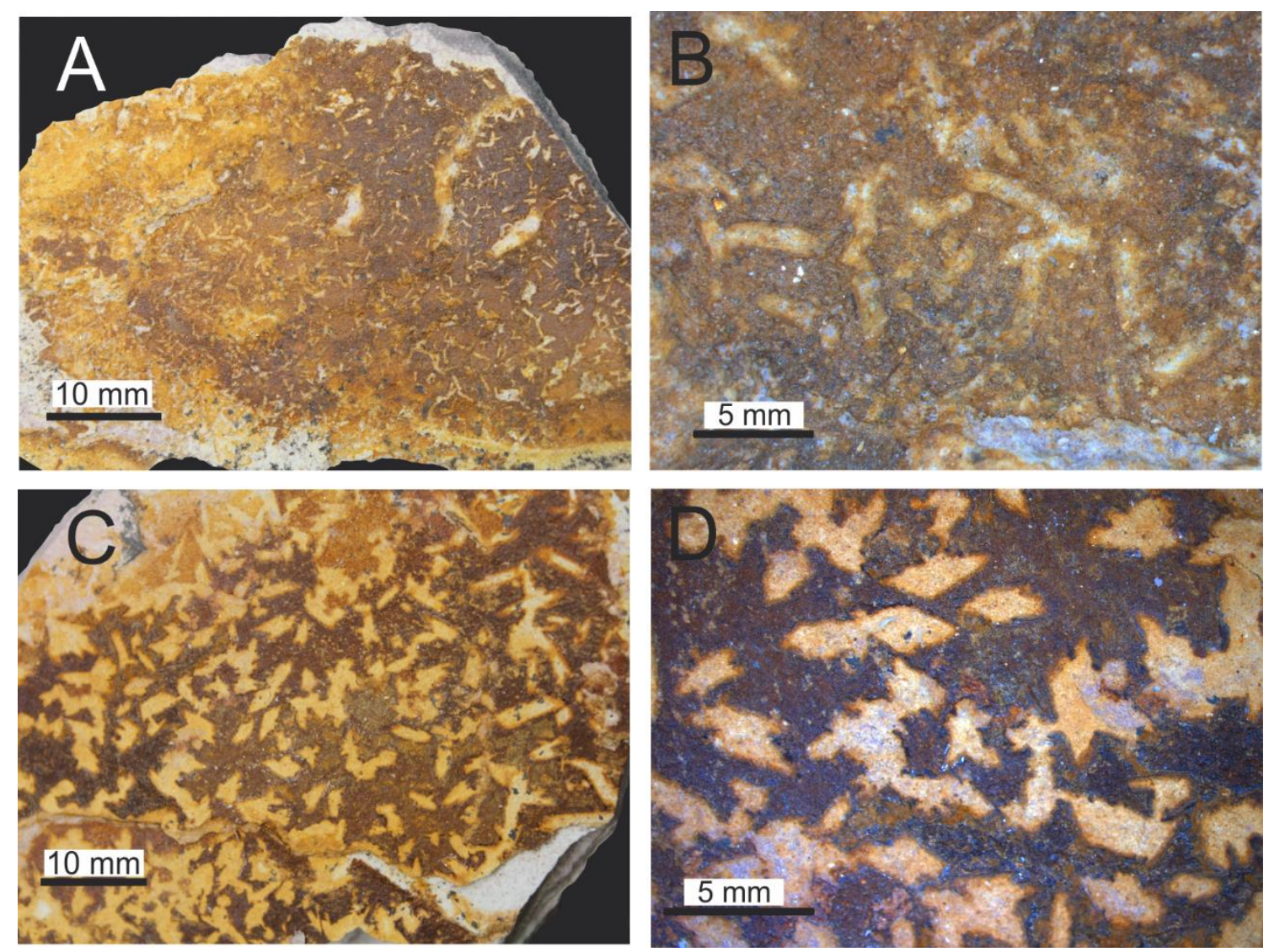

Figura 4.32: Imagens de possível fragmentos . A e $B$ amostra GP/1E - 11124, representando fragmentos ramificados e uniformes. . C e $D$ amostra $G P / 1 E$ - 11125, representado fragmentos de estruturas disformes. 


\section{DISCUSSÃO}

\subsection{Distribuição Estratigráfica de Corumbella werneri e relações paleoecológicas}

A partir dos dados obtidos foi possível identificar que Corumbella werneri não aparece de forma aleatória ao longo da seção, ocorrendo em níveis estratigráficos distintos, onde são mais abundantes. Foi observado que, são mais concentradas na base da Formação Tamengo, em especial nas seções P1, P2 e P3. Embora ocorram em níveis específicos nas seções estudadas, não foi possível determinar uma correlação direta em relação ao litotipo, ou seja, $C$. werneri ocorre em horizontes siliciclásticos, em camadas de ritmito folhelho/arenito, ritmito folhelho/siltito, no folhelho e também no arenito fino. A ocorrência em determinados níveis estratigráficos, onde na maioria dos casos, apresenta uma abundância de carapaças de C.werneri, pode ser provavelmente, explicada por variações ambientais, tais como, a variação na taxa de sedimentação, que eventualmente, proporcionava condições para a preservação das carapaças.

A análise estratigráfica de detalhe também permitiu observar as associações de $C$. werneri com outros organismos e com icnofósseis. Essas associações podem evidenciar correlações paleoecológicas e paleoambientais. A partir de P2 são encontrados na mesma posição estratigráfica que $C$. werneri, os icnofósseis, sugerindo que o substrato onde há ocorrência de $C$. werneri era minimamente oxigenado. Essa associação também é encontrada em P5S e P7S. Em especial na parte intermediária da Formação Tamengo, na seção estratigráfica P4, não são encontrados nenhum registro fossilífero corpóreo, mas ocorre maior abundância de icnofósseis. A abundância de icnofósseis e ausência de fósseis corpóreos nessas seções talvez possa ser explicado pela ação bioturbadora dos icnofósseis no substrato influenciando na preservação dos fósseis corpóreos (Miller \& Smail, 1997).

O motivo de organismos explorarem, revolverem e ocuparem um novo ambiente ou substrato, não está completamente definido, pode ser interpretado como a procura de alimentos (Rogov et al., 2012), ou proteção contra predadores 
(Mcllroy \& Logan, 1999). Entretanto, a atividade mecânica bioturbadora dos organismos, processando o sedimento por ingestão ou escavação levou áreas antes inóspitas possuírem oxigenação. Embora raros, alguns exemplos de icnofósseis no Pré-Cambriano são registrados. Liu et al. (2010) encontraram icnofósseis encontrados no Neoproterozoico, na Formação Mistaken Point, Canadá, em mudstone verde acima de uma área datada com idade máxima de $563 \pm 3 \mathrm{Ma}$. Esses icnofósseis apresentam uma saliência estreita de até $17 \mathrm{~cm}$ de comprimento e $13 \mathrm{~mm}$ de largura, não são ramificados, mas demonstram diferentes orientações. Liu et al. (2010) compara esse registro a actiniários recentes ressaltando as similaridades morfológicas e a capacidade de movimentação da espécie.

Outro registro antigo são icnofósseis na forma de menisco, podendo ser encontrados em seções de calcário laminado na Formação Khatyspyt na Rússia, datadas através de grãos de zircão sugerindo idade máxima de $543.9 \pm 0.3 \mathrm{Ma}$ (Rogov et al., 2012), mas que são interpretados por outros autores como fósseis tubulares semelhantes à cloudinas (Brasier et al., 2013). Esse registro na forma de menisco também pode ser encontrado no Membro Bronnitsy, Formação Yarishev, Ucrânia sendo que subjacente ao membro Bernashevka dessa mesma formação existe um tufo vulcânico datado através de zircão sugerindo sua idade máxima de $553 \mathrm{Ma}$ (Rogov et al., 2013). Rogov et al. (2012) atribuí esse registro ao icnofóssil Nenoxites curvus com idade restrita a $558 \pm 1 \mathrm{Ma}$ (Grazhdankin, 2004). Originalmente, essa icnoespécie foi descrita na região de White Sea como um icnofóssil vertical formado a partir da movimentação peristáltica (Fedonkin, 1976).

A partir de P3 ocorre associação de Corumbella werneri com vendotaenídeos em uma mesma amostra de mão, indicando que poderiam ter vivido e compartilhado o mesmo espaço. A associação de $C$. werneri e vendotaenídeos também foram encontradas em P7S e P7C. Também em P3, foram encontrados na mesma posição que $C$. werneri, mas em amostras diferentes espécies de macroalgas (Diniz \& Leme, 2016) e Paraconularia sp. (Van Iten et al., 2014). Nessa seção estratigráfica ocorre a maior paleobiodiversidade ao longo da Formação Tamengo. Não foram encontrados icnofósseis. A ocorrência de $C$. werneri juntamente com macroalgas, incluindo 
os vendotaenídeos, pode indicar condições de águas mais rasas, ainda em zona fótica, ou seja, numa profundidade que receberia luz solar suficiente para que ocorresse a fotossíntese (Townsend et al., 2008). Outra evidência de que seria provavelmente condições de águas mais rasas é a presença de um exemplar de Paraconularia sp., completamente achatada, incompleta, preservando apenas a região mediana. Segundo (Rodrigues et al., 2003), nas rochas sedimentares da Formação Ponta Grossa (Devoniano), Bacia do Paraná, em geral, nos intervalos mais rasos do Trato de Sistemas Transgressivo, raras são as ocorrências de fósseis de conulários. Quando presentes, as tecas estão achatadas lateralmente e rasgadas, apenas com a região mediana preservada. Essas tecas foram submetidas a algum tipo de transporte, possivelmente curto, antes de sua deposição final.

Em duas seções do topo da Formação Tamengo a P6S e P6C não são encontrados fósseis ou icnofósseis, embora apresentem os mesmos litotipos das outras seções analisadas. Em P6S e P6C, ocorrem muitas alterações como, por exemplo, o intemperismo físico e biológico, que, provavelmente, dificultaram a preservação fossilífera.

No topo da Formação Tamengo, mais especificamente nas seções P5C e P7S, em camadas de grainstones e mudstones foram encontrados exemplares de Cloudina lucianoi. Não foi encontrada associação entre C. lucianoi e $C$. werneri nos pacotes de pelitos analisados.

\subsection{Implicações tafonômicas de Corumbella werneri}

Foram encontrados dois grupos tafonômicos distintos nas amostras estudadas, o grupo 1 representa Corumbella werneri de forma incompleta podendo ou não possuir carapaça preservada e encontradas tanto isoladas como em grupo de maneira fracamente empacotada, com menor comprimento de $2,5 \mathrm{~cm}$ e seu maior comprimento de $10 \mathrm{~cm}$, mas com média de $5 \mathrm{~cm}$. O grupo 2 contém espécimes de Corumbella werneri fragmentadas possuindo entre 1 a 5 anéis preservados variando entre 0,20 e $2 \mathrm{~mm}$ de comprimento, estão de maneira fracamente empacotada podendo ou não possuir carapaça preservada 
com eventual presença de $C$. werneri incompletas. Os diferentes grupos tafonômicos estarem presentes em uma mesma amostra, como encontrado no grupo 2, gera discussão de que o material fóssil possa ter sofrido mistura temporal (time-averaging). A mistura temporal ocorre quando restos orgânicos de indivíduos com diferentes intervalos de tempo estão preservados juntos devido a taxa de sedimentação não ter sido capaz de recobrir um organismo bentônico durante o período de vida, promovendo um mistura de gerações na amostra, sendo impossível eliminar por coleta (Walker \& Bambach, 1971; Kowalewski et al., 1998; Holz \& Simões, 2002; Ritter \& Erthal, 2016).

Kidwell \& Bosence (1991) classificam quatro diferentes escalas de magnitudes de time-averaging para associações de organismos bentônicos que possuem partes mineralizadas de acordo com a taxa de sedimentação. A primeira, denominada "censo ecológico" que consiste em organismos possivelmente preservados articulados e em posição de vida devido ao rápido soterramento dessas comunidades bentônicas. Dessa maneira, teriam a maior semelhança entre o registro fossilífero e comunidades antigas. A segunda, chamada de "mistura intra-habitat" na qual uma comunidade compatível permanece ecologicamente estável durante diversas gerações, e os processos tafonômicos que interferem em restos esqueléticos atuam produzindo diferentes estados de preservação, ocorrendo uma mistura de indivíduos de distintas gerações ao longo do intervalo temporal. A terceira, denominada de "condensação ambiental", na qual organismos não compatíveis ecologicamente de habitats sucessivos alterados a partir de mudanças ambientais rápidas e baixas taxas de sedimentação se acumulam in situ formando um único conjunto fossilífero. A última, chamada de "condensação bioestratigrafica" ocorre devido a baixa taxa de sedimentação e retrabalhamento, fazendo com que duas ou mais espécies que são exclusivas de períodos distintos, ou seja, de diferentes biozonas, apareçam em um mesmo conjunto fossilífero.

Analisando as amostras que apresentam espécimes de $C$. werneri fragmentadas juntamente com espécimes incompletas maiores, a escala de magnitude de mistura temporal que mais explicaria essa ocorrência seria a "mistura intra-habitat", portanto, o grupo tafonômico com $C$. werneri fragmentadas seria uma geração anterior que acumularia indivíduos mortos 
influenciados pela a ação de processos causados pelo ambiente, tais como, baixa taxa de sedimentação, mas estariam próximos aos organismos vivos (Kidwell \& Tomasovych, 2013) aqui atribuídos ao segundo grupo tafonômicos com C. werneri mais completa. Quando houvesse um soterramento rápido preservaria as duas gerações em uma mesma camada, sendo o segundo grupo mais preservado pois, ficou menos tempo na interface água-sedimento (Figura 5.1).

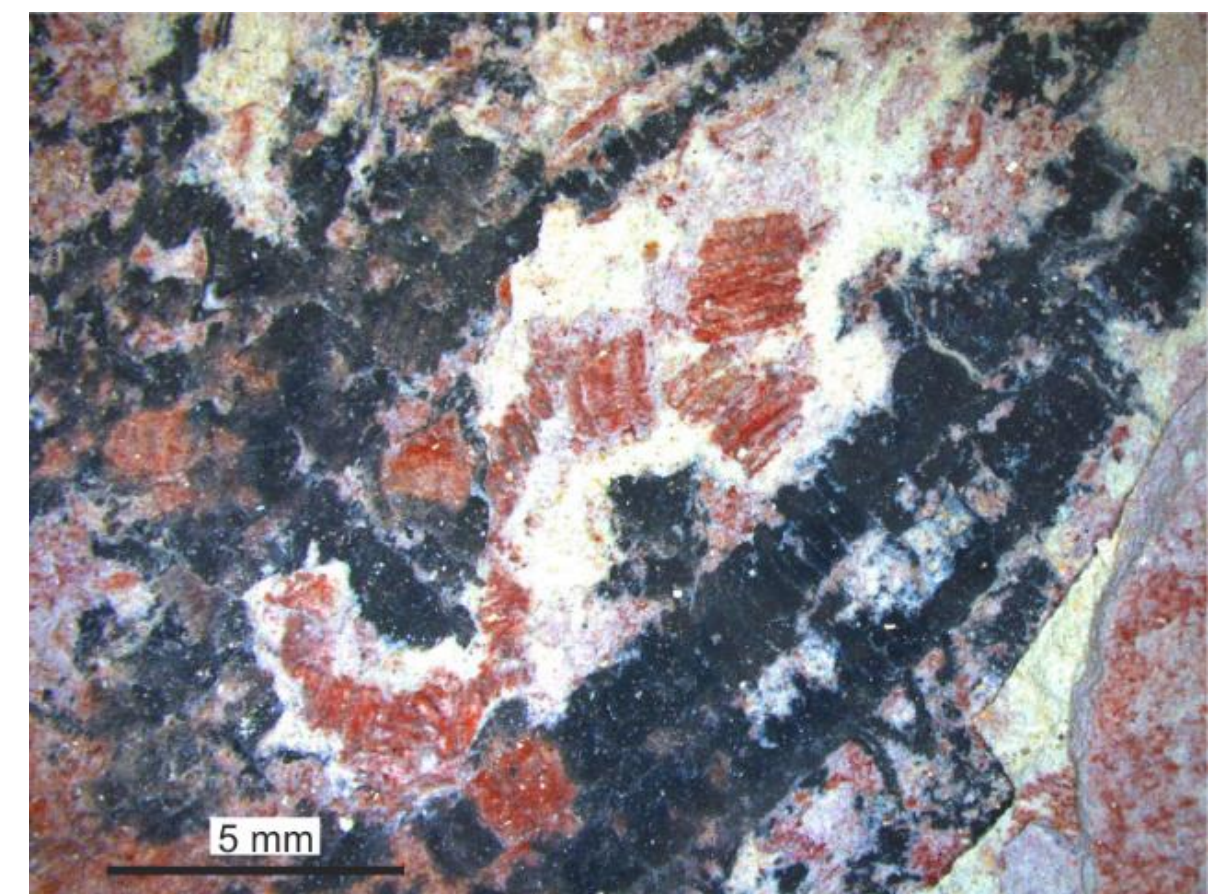

Figura 5.1: Amostra com distintos padrões tafonômicos (espécimes incompletas e fragmentadas) indicando efeito de mistura temporal.

\subsection{Implicações paleoambientais de Corumbella werneri}

Boggiani (1997) dividiu a Formação Tamengo em nove fácies carbonáticas compostas por: fácies de quatzo-arenito sugerindo um retrabalhamento eólico dos grãos. Fácies de brechas intraformacionais originárias da Formação bocaina retrabalhadas e depositadas na formação Tamengo, indicando o limitide da borda do talude. Fácies rudstones com clastos arredondados delimitando o ambiente em talude continental com alta energia. Fácies de mudstones calcíticos pretos, interpretado como um ambiente de deposição com baixa energia rico em matéria orgânica. Fácies de margas carbonosas rica em matéria orgânica indicando uma deposição em zona fótica de baixa energia 
Também foram delimitadas as fácies de ritmitos mudstones/folhelho carbonoso com presença de material fóssil, interpretada como um ambiente de maior profundidade podendo ter condições hemipelágicas. Fácies ooids grainstones com fragmentos de C. lucianoi podendo ser formadas em águas rasas sobre a plataforma durante a transgressão marinha ou podem indicar deposição em águas mais profundas através de processos de ressedimentação. Fácies de oncoids rudstones interpretado como um ambiente com alto nível do mar em águas mais profundas com grande atividade planctônica. Predomina no topo da formação as fácies de rudstones com $C$. lucianoi com laminação estilo hummocky o que indicaria um local de deposição com águas profundas, um ambiente impreciso para o fóssil, o autor sugere então a ocorrência de ressedimentação, associada com tempestitos (Boggiani, 1997).

Oliveira (2010) também estudou as fácies carbonáticas da Formação Tamengo, subdividindo-as em duas associações: A associação shoreface e a associação offshore.

A associação shoreface apresenta barras oolíticas e três fácies, sendo a primeira de grainstone intraclástico maciço formado a partir da ressedimentação por fluxos oscilatórios. A segunda formada por grainstone oolítico maciço lateralmente contínuo, criados a partir da precipitação carbonática em um ambiente com atividade constante de correntes ou ondas, ou seja, um ambiente de alta energia. A terceira caracterizada por ritmito com ocorrência eventual de Cloudina lucianoi em posição de vida formado a partir da alternância da precipitação químicas e deposição de grãos terrígenos em um ambiente de baixa energia. Oliveira (2010) propõe um ambiente de alta energia para essa associação, devido à presença de ooides e intraclastos, mas seria uma região plana com migração de formas de leito em barras a partir da ação de correntes litorâneas. Atribui a presença de ritmitos carbonosos e carapaças de $C$. lucianoi devido a presença das barras ooliticas que serviriam como proteção contra a ação de ondas de tempestade e que auxiliariam a manter um estado de baixa energia no ambiente.

A associação offshore teria sido influenciada por tempestades e composta por quatro fácies: calcário cristalino com estratificação cruzada hummocky com presença de fragmentos de Cloudina lucianoi formada a partir da deposição por 
fluxo combinado dominantemente oscilatório por ondas de tempestades. Calcário cristalino maciço criado a partir da precipitação química de carbonato em ambiente com energia moderada a alta. Pelito carbonático maciço formada a partir da suspensão química. Folhelho rico em matéria orgânica depositado a partir da suspensão em um ambiente de baixa energia.

Segundo (Fazio et al., 2016) a Formação Tamengo teria um possível aporte sedimentar baixo devido a áreas baixas ao seu redor seguido de uma subida no nível do mar (Boggiani, 1997) e por consequência um aumento na taxa de acomodação (Catuneanu, 2006; Catuneanu et al., 2011) criando um ambiente de talude com uma comunicação abrupta de ambientes de água rasa situados a oeste para águas mais profundas e oceânicas a Leste (Boggiani, 1997). As águas mais profundas, abaixo do nível de base de ondas de tempestade, e, de baixa energia, seriam responsáveis pela deposição de materiais finos como pacotes de ritmitos com folhelhos, siltito e argilitos onde viveriam $C$. werneri.

A partir da análise estratigráfica e litológica aqui realizada, foram encontradas camadas de ritmitos apresentando 5 litotipos diferentes como argilito, siltito, folhelho, arenito e calcário que também se apresentam na forma de camadas homogêneas ao longo da seção com presença de registro fossilífero, todos possuem granulometria fina, também são encontrados de forma homogênea calcários grainstones e mudstones podendo ter estratificação cruzada estilo hummocky e em algumas localidades especificamente no topo da Formação podem estar associadas com espécimes de Cloudina lucianoi.

Analisando detalhadamente os pacotes pelíticos, a litologia apresentada indica um ambiente deposicional calmo e de baixa energia capaz de sedimentar materiais finos o que pode ser corroborado por estarem abaixo de grainstones com estratificação cruzada estilo hummocky inferindo estarem abaixo do nível máximo de onda causados por tempestades e a presença de registro fossilífero da espécie de Corumbella werneri, que por possuir uma carapaça mais orgânica e frágil, poderia ser preservada em ambientes mais calmos. Já a presença de $C$. lucianoi em calcários pode inferir que viveriam em ambientes de plataforma rasas que foram retrabalhados para partes mais profundas através de tempestades já que estão associadas a estratificação hummocky ou um ambiente de baixa 
energia onde não são encontradas de forma fragmentada associadas a barreira (Boggiani, 1997; Oliveira, 2010).

Portanto, a ocorrência de Corumbella werneri exclusivamente nos pelitos, enquanto, Cloudina lucianoi apenas nas camadas de calcário, indica que provavelmente habitaram ambientes diferentes, ou pelo menos o modo e a capacidade de preservação das carapaças deveriam ser distintos (Guimarães et al., 2014). De fato, a diferença da composição mineralógica entre as carapaças de $C$. lucianoi composta de $\mathrm{CaCo}_{3}$, e $C$. werneri mais orgânica, composta por uma película escura de carbono, pode ser um fator limitante na preservação desses fósseis.

Entretanto, a ocorrência de C. werneri juntamente com macroalgas, conforme descrito anteriormente, pode indicar condições de águas mais rasas, ainda em zona fótica. Esse novo dado mostra que, talvez, mesmo ocorrendo em pelitos, indicando deposição em águas calmas, seria possível que $C$. werneri tivesse condições paleoecológicas de habitat desde águas mais rasas, acima do nível de base de ondas de tempestades até mesmo, mais profundas. No entanto, conforme os resultados observados, os níveis de ocorrência e de maior abundância de $C$. werneri devem estar associados a momentos de aumento na taxa de sedimentação e deposição de partículas finas, em substrato abaixo do nível de base de ondas de tempestades (Figura 5. 2). 

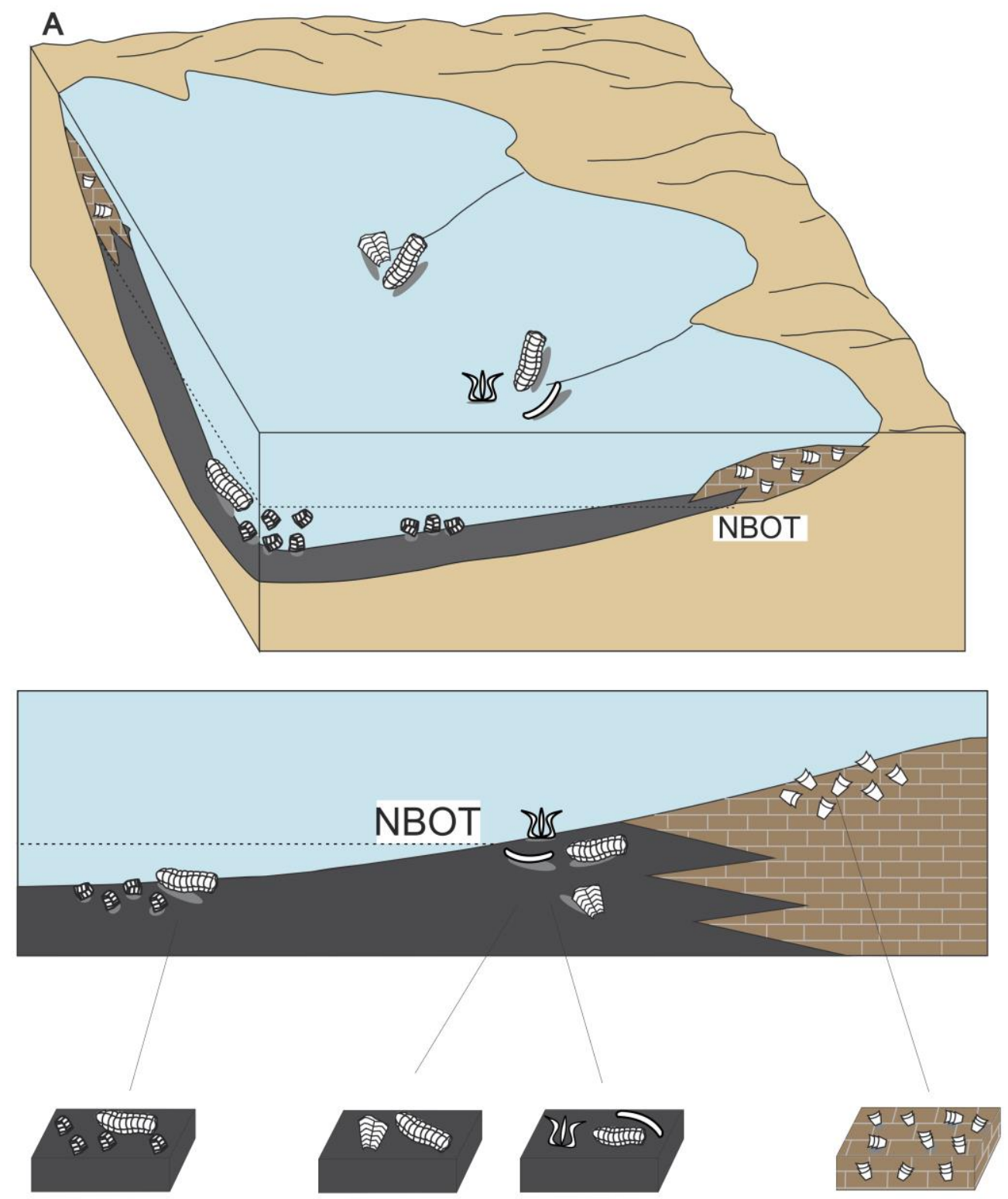

\section{LEGENDA}

\section{Fácies pelíticas \\ Fácies carbonáticas de água rasa Embasamento e terras emersas}

NBOT Nivel de base de onda de Tempestade 2) Alga

$>$ Vendotaenídeo

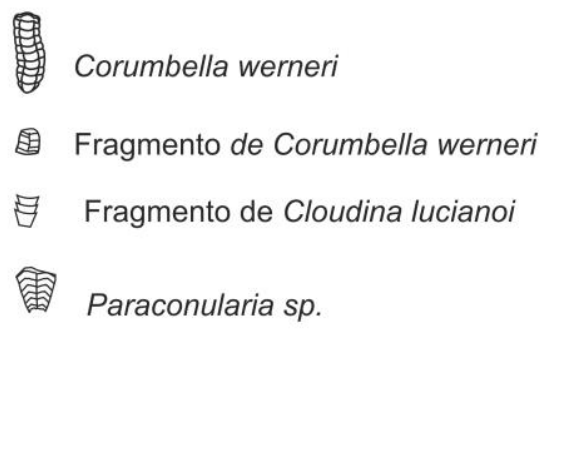

Figura 5. 2: Representação paleoeambiental de Corumbella werneri e outros fósseis da Formação Tamengo. Modificado de Rodrigues et al., (2003) e Matos et al. (2017). 


\section{CONCLUSÕES}

- Os fosseis de Corumbella werneri estão presentes em determinados níveis estratigráficos na parte pelítica da Formação Tamengo em litotipos distintos que pode ser explicada por variações ambientais, tais como, a variação na taxa de sedimentação, que eventualmente, proporcionava condições para a preservação de sua carapaça.

- A análise estratigráfica de detalhe também permitiu observar as associações de Corumbella com outros organismos e com icnofósseis. Essas associações podem evidenciar correlações paleoecológicas e paleoambientais;

- A ocorrência na mesma posição estratigráfica de Corumbella e icnofósseis, pode sugerir que o substrato onde há ocorrência de Corumbella, era minimamente oxigenado;

- A associação entre Corumbella e macroalgas no pacote pelítico-P3, incluindo os vendotaenídeos, pode indicar condições de águas mais rasas, ainda em zona fótica, ou seja, numa profundidade que receberia luz solar suficiente para que ocorresse a fotossíntese, indicando que teria condições paleoecológicas de habitat desde águas mais rasas, acima do nível de base de ondas de tempestades até mesmo, mais profundas.

- A presença de um exemplar de Paraconularia sp., completamente achatada, incompleta, preservando apenas a região mediana, também reforça a hipótese de que o pacote pelítico-P3, deve ter sido depositado em condições de águas mais rasas;

- Foram encontrados outros fósseis na parte pelítica da Formação Tamengo e novas estruturas que podem inferir outros organismos presentes como estruturas sedimentares circulares de provável origem bioinduzida, estruturas fragmentadas, possível estrutura basal, além de macroalgas, vendotaenídeos e icnofósseis. Com esses registros pode-se dizer que a paleodiversidade da Formação Tamengo é maior do que se pensava anteriormente; 
- Foram interpretados dois grupos tafonômicos distintos de Corumbella. $O$ grupo 1 , representado por $C$. werneri incompleta, apresentariam um ambiente deposicional com aumento da taxa de sedimentação. $\mathrm{O}$ grupo 2, caracterizado por $C$. werneri fragmentada, apresentam um ambiente com baixa taxa de sedimentação, resultando em um maior tempo de exposição do organismo no substrato, amostras apresentando os dois grupos tafonômicos podem indicar mistura temporal (time-averaging) resultando em uma registro intra-habitat no qual várias gerações de uma espécie se preservam em uma mesmo registro fossilífero devido à baixa taxa de sedimentação;

- A ocorrência de Corumbella werneri exclusivamente nos pelitos, enquanto, Cloudina apenas nas camadas de calcário, indica que provavelmente habitaram ambientes diferentes, ou pelo menos o modo e a capacidade de preservação das carapaças deveriam ser distintos; 


\section{REFERÊNCIAS BIBLIOGRÁFICAS}

Allman, G. J. (1874). On the structure and systematic position of Stephanoscyphus mirabilis, the type of a new order of Hydrozoa. Trans. Linn. Soc. Land. 2 (1), 61-66.

Almeida, F. F.(1968). Evolução tectônica do centro oeste brasileiro no proterozoico superior. Anais da academia brasileira de ciência, (Suplemento de simpósio de manto superior) 40, 285-296.

Almeida, F. F. M. (1945). Geologia do sudeste mato-grossense. Boletim da divisão de geologia e mineralogia, Departamento nacional de produção mineral, DNPM 116, 1-118.

Almeida, F. F. M. (1965). Geologia da Serra da Bodoquena (mato grosso) Brasil. Boletim da divisão de geologia e mineralogia, Departamento nacional de produção mineral, DNPM 219, 1-96.

Babcock, L. E., Grunow, A. M., Sadowski, G. R. \& Leslie, S. A. (2005). Corumbella, an Ediacaran-grade organism from the Late Neoproterozoic of Brazil. Palaeogeography, Palaeoclimatology, Palaeoecology 220, 7-18.

Babinski, M., Boggiani, P. C., Fanning, M., Simon, C. M. \& Sial, A. N. (2008). U$\mathrm{Pb}$ shrimp geochronology and isotope chemostratigraphy $(\mathrm{C}, \mathrm{O}, \mathrm{Sr})$ of the Tamengo Formation southern Paraguay belt, Brazil. Sounth American Symposium on Isotope Geology, 6, San Carlos de Bariloche, 160.

Bengtson, S. \& Zhao, Y. (1992). Predatorial Borings in Late Precambrian Mineralized Exoskeletons. Science 257, 367-369.

Billings, E. (1872) Fossils in Huroniar rocks. Canadian Naturalist an Quarterly Journal of Science 6, 478.

Bodenbender, B. E., Wilson, M. A. \& Palmer, T. J. (1989). Paleoecology of Sphenothallus on an Upper Ordovician hardground. Lethaia 22, 217-225.

Boggiani, P. C. (1990). Ambientes de Sedimentação do Grupo corumbá na Região Central da Serra da Bodoquena, Mato Grosso do Sul. Universidade de São Paulo.

Boggiani, P. C. (1997). Análise Estratigrafica da Bacia Corumbá (Neoproterozóico) - Mato Grosso do Sul. Universidade de São Paulo.

Boggiani, P. C. \& Alvarenga, C. J. S. (2004). Faixa Paraguai. In: Mantesso-Neto, V., Bartorelli, A., Carneiro, C. D. R. \& Brito-Neves, B. B. (eds) Geologia do Continente Sul-Americano: Evolução da obra de Fernando Flávio Marques de Almeida. São Paulo: Beca, 113-121.

Boggiani, P. C., Fairchild, T. R. \& Coimbra, A. M. (1993). O Grupo Corumbá (Neoproterozóico-Cambriano ) Na Região Central Da Serra Da Bodoquena (Faixa Paraguai), Mato Grosso Do Sul. Revista Brasileira de Geociências 23, 301-305.

Boggiani, P. C., Ferreira, V. P., Sial, A. N., Babinski, M., Trindade, R. I. F., Acenolaza, G., Toselli, A. J. \& Parada, M. A. (2003). The cap carbonate of 
the Puga Hill (Central South America) in the context of the post-Varanger Galciation. IV South American Symposium on Isotope Geology, vol. 1, Short Papers, Salvador, Brasil 324-327.

Boggiani, P. C., Gaucher, C., Sial, A. N., Simon, C. M., Riccomini, C., Ferreira, V. P. \& Fairchild, T. R. (2010). Chemostratigraphy of the Tamengo Formation (Corumbá Group, Brazil): A contribution to the calibration of the Ediacaran carbon-isotope curve. Precambrian Research. Elsevier B.V. 182, 382-401.

Boynton, M. E. \& Ford, T. D. (1995). Ediacaran Fossils from the Precambrian ( Charnian Supergroup) of Charnwood Forest, Leicestershire, England. Mercian Geologist 13, 164-182

Brasier, M. D., Mcllroy, D., Liu, A. G., Antcliffe, J. B. \& Menon, L. R. (2013). The oldest evidence of bioturbation on Earth: COMMENT. Geology 41, e289e289.

Buss, L. W. \& Seilacher, A. (1994). the Phylum Vendobionta - a Sister Group of the Eumetazoa. Paleobiology 20, 1-4.

Butterfield, N.J., Knoll, A.H. \& Swett, K. (1994). Paleobiology of the Neoproterozoic Svanbergfjellet Formation, Spitsbergen. Fossils and Strata, 34, 1-84

Catuneanu, O. (2006). Principles of Sequence Stratigraphy. Changes. Amsterdam: Elsevier B.V.

Catuneanu, O., Galloway, W. E., Kendall, C. G. S. C., Miall, A. D., Posamentier, H. W., Strasser, A. \& Tucker, M. E. (2011). Sequence Stratigraphy: Methodology and Nomenclature. Newsletters on Stratigraphy 44, 173-245.

Clapham, M. E. \& Narbonne, G. M. (2002). Ediacaran epifaunal tiering. Geology 30, 627-630.

Clapham, M. E., Narbonne, G. M. \& Gehling, J. G. (2003). Paleoecology of the oldest known animal communities: Ediacaran assemblages at Mistaken Point, Newfoundland. Paleobiology 29, 527-544.

Corrêa, J. A., Correia-Filho, F. C. ., Scislewski, G., Neto, C., Cavallon, L. A., Cerqueira, N. L. S. \& Nogueira, V. L. (1979). Geologia das regiões Centro e Oeste de Mato Grosso. Projeto Bodoquena. Departamento Nacional de Produção Mineral-DNPM/CPRM. Série Geologia Básica. .

Cortijo, I., Mus, M. M., Jensen, S. \& Palacios, T. (2015). Late Ediacaran skeletal body fossil assemblage from the Navalpino anticline, central Spain. Precambrian Research. Elsevier B.V. 267, 186-195.

Diniz, C. Q. C. \& Leme, J. M. (2016). Macroalgae occurrence in Tamengo Formation, Ediacaran, Brazil. Congreso Latinoamericano Paleontología, 113.

Dunham, R. J. (1962). Classification of carbonate rocks according to depositional texture. In: Ham, W. E. (ed.) Classification of carbonate rocks. American Association of Petroleum Geologist, 108-121.

Eisenack, A. (1958). Tasmanites Newton, 1875 and Leiosphaeridia n. gen. Als 
Gattungen der Hystrichosphäeridea. Paläeontographica A, 110: 1-19.

Fazio, G. ., Guimarães, E. M., Vieira, L. C., Carmo, D. A. \& Walde, D. H. G. (2016). Composição mineral dos pelitos Ediacaranos - Formações Tamengo e Guaicurus (Grupo Corumbá) - E seu Significado deposicional. Congresso Brasileiro de Geologia, 1.

Fedonkin, M. A. (1976). Sledy mnogokletochnykh iz valdaiskoi serii: Izvestiya An SSSR. seriya geologicheskaya 4, 129-132.

Fedonkin, M. A., Gehling, J. G., Grey, K., Narbonne, G. M. \& Vickers-Rich, P. (2007). The rise of Animals: Evolution and diversification of the Kingdom Animalia. Baltimore, Maryland: The Johns HopkinsUniversity Press.

Ford, T. D. B. Y. (1958). PRE-CAMBRIAN FOSSILS FROM CHARNWOOD FOREST. Proceedings of the Yorkshire Geological Society 31, 211-217.

Gaucher, C., Boggiani, P. C., Sprechmann, P., Sial, A. N. \& Fairchild, T. R. (2003). Integrated correlation of the Vendian to Cambrian Arroyo del Soldado and Corumbá Groups (Uruguay and Brazil): palaeogeographic, palaeoclimatic and palaeobiologic implications. Precambrian Research 120, 241-278.

Gehling, J. G. \& Narbonne, M. G. (2007). Spindle-shaped Ediacara fossils from the Mistaken Point assemblage, Avalon Zone, N.ewfoundland. Canadian Journal of Earth Sciences 44, 367-387

Gehling, J. G. \& Droser, M. L. (2009). Textured organic surfaces associated with the Ediacara biota in South Australia. Earth-Science Reviews. Elsevier B.V. 96, 196-206.

Gerdes, G., Klenke, T. \& Noffke, N. (2000). Microbial signatures in peritidal siliciclastic sediments: A catalogue. Sedimentology 47, 279-308.

Germs, G. J. . (1972). New shelly fossil from Nama Group. South West Africa. American Journal of Science 752-761.

Glaessner, M. F. \& Daily, B. (1959). The Geology and Late Precambrian Fauna of the Ediacaran Fossil Reserve. Records of the South Australian Museum 13, 369-407.

Gnilovskaya, M. . (1971). The oldest aquatic plants of the Vendian of the Russian Platform (Late Precambrian). Paleontological Journal 5, 372-378.

Gnilovskaya, M. . (1979). The Vendian Metaphyta. Bulletin Centre Researchs Exploration - Elf-Aquitine 3, 611-618.

Gnilovskaya, M. . (1985). Vendotaenids. In: Sokolov, B. S. \& Ivanovsky, A. B. (eds) Vendian Metaphyta. Vendskaya sistema, 117-125.

Grant, S. W. F. (1990). Shell structure and distribution of Cloudina, a potential index fossil for the terminal Proterozoic. American Journal of Science 290, 261-294.

Grazhdankin, D. (2004). Patterns of distribution in the Ediacaran biotas: Facies versus biogeography and evolution. Paleobiology 30, 203-221. 
Guimarães, E. M., Vieira, L. C., Carmo, D. M., Walde, D. H. G. \& Blois, C. (2014). Mineral composotion of an Ediacaran sequence: Cacimba Escarpment (Tamengo Formation), Corumbá, MS - Brazil. A symposium and field workshop on Ediacaran and Cryogenian Stratigraphy, 23.

Hagadorn, J. W. \& Waggoner, B. (2000). Ediacaran Fossils from the Southwestern great Basin, United States. Journal of Paleontology 74, 349359.

Hahn, G., Hahn, R., Leonardos, O. H. \& Pflug, H. D. (1982). Kfrperlich erhaltene Scyphozoen-reste aus dem Jungprekambrium Brasiliens. Geologica et Paleontologica 16, 1-18.

Hahn, G. \& Pflug, H. D. (1985). Die Cloudinidae n. farm., Kalk-Rfhren aus dem Vendium und Unter-Kambrium. Senckenbergiana Lethaea 65, 413-431.

Hall, C. M. S., Droser, M. L., Gehling, J. G. \& Dzaugis, M. E. (2015). Paleoecology of the enigmatic Tribrachidium: New data from the Ediacaran of South Australia. Precambrian Research. Elsevier B.V. 269, 183-194.

Hall, J. (1847). Palaeontology of New York: containing descriptions of the organic remains of the lower division of the NewYork system, 1.

Hidalgo, R. L. L. (2002). Análise micropaleontologica da Formação Tamengo e Guaicurus, Grupo Corumba e Formação Araras, transição do Neoproterozóico - Fanerozóico. Universidade de São Paulo.

Holz, M. \& Simões, M. G. (2002). Elementos fundamentais de tafonomia. Porto Alegre: Ed. Universidade/UFRGS.

Hua, H., Chen, Z. \& Yuan, X. (2007). The advent of mineralized skeletons in Neoproterozoic Metazoa-new fossil evidence from the Gaojiashan Fauna. Geological Journal 42, 263-279.

Hua, H., Chen, Z., Yuan, X., Zhang, L. \& Xiao, S. (2005). Skeletogenesis and asexual reproduction in the earliest biomineralizing animal Cloudina. Geology 33, 277-280.

Hua, H., Pratt, B. R. \& Zhang, L. Y. (2003). Borings in Cloudina Shells: Complex Predator-Prey Dynamics in the Terminal Neoproterozoic. Palaios 18, 454459.

Ivantsov, A. Y. (1999). A New Dickinsonid from the Upper Vendian of the White Sea Winter Coast (Russia, Arkhangelsk Region). Paleontological Journal 33 (3) 211-221

Ivantsov, A. Y. (2016). Reconstruction of Charniodiscus yorgensis (Macrobiota from the Vendian of the White Sea). Paleontological Journal 50, 1-12.

Jensen, S. (2003). The Proterozoic and Earliest Cambrian Trace Fossil Record; Patterns, Problems and Perspectives. Integr. Comp. Biol 43, 219-228.

Jensen, S., Droser, M. L. \& Gehling, J. G. (2005). Trace fossil preservation and the early evolution of animals. Palaeogeography, Palaeoclimatology, Palaeoecology 220, 19-29. 
Jensen, S., Saylor, B. Z., Gehling, J. G. \& Germs, G. J. . (2000). Complex trace fossils from the terminal Proterozoic of Namibia. Geology 28, 143-146.

Kerber, B. B. (2015). Paleobiologia de Cloudina lucianoi Zaine \& Fairchild, 1985 (Ediacarano, Grupo Corumbá): Implicações Tafonômicas, Taxônomicas e Paleoecológicas. Universidade de São Paulo.

Kidwell, S. M. \& Bosence, D. W. J. (1991). Taphonomy and time-averaging of marine shelly faunas. In: Alisson, P. A. \& Briggs, D. E. G. (eds) Taphonomy: releasing the data locked in the fossil record. Plenum, New York. Plenum Press, 115-209.

Kidwell, S. M. \& Tomasovych, A. (2013). Implications of time-averaged death assemblages for ecology and conservation biology. Annual Review of Ecology, Evolution, and Systematics 44, 539-563.

Knoll, A. H., Sweet, K. \& Mark, J. (1991). Paleobiology of a Neoproterozoic tidal flat/lagoonal complex: the Draken Conglomerate Formation, Spitsbergen. Journal of Paleontology 65 (4), 531 - 570.

Kowalewski, M., Goodfriend, G. A. \& Flessa, K. L. (1998). High resolution estimates of temporal mixing within shell bed: the evils and virtues of timeaveraging. Paleobiology 287-304.

Lacerda-Filho, J. W. et al. (2006). Geologia e Recursos Minerais de Mato Grosso do Sul. Programa Integração, Atualização e Difusão de Dados de Geologia do Brasil. Convênio CPRM/SICME - MS, MME.

Lee, R. E. (1980). Phycology. Cambridge: University Press (Cambridge).

Li, G. X., Zhu, M. Y., Van Iten, H. \& Li, C. W. (2004). Occurrence of the earliest known Sphenothallus Hall in the Lower Cambrian of Southern Shaanxi Province, China. Geobios 37, 229-237.

Lin, S. \& Hommersand, M. H. (2016). Developmental morphology and phylogeny of Paraglossum amsleri sp. nov . (Delesseriaceae, Rhodophyta), a species from Antarctica previously known as Delesseria lancifolia. Phycologia 55, 21-32.

Liu, A. G., Mcllroy, D. \& Brasier, M. D. (2010). First evidence for locomotion in the Ediacara biota from the 565 Ma Mistaken Point Formation, Newfoundland. Geology 38, 123-126.

Matos, S. A., Warren, L. V., Varejão, F. G., Assine, M. L. \& Simões, M. G. (2017). Permian endemic bivalves of the "Irati anoxic event", Paraná Basin, Brazil: Taphonomical, paleogeographical and evolutionary implications. Palaeogeography, Palaeoclimatology, Palaeoecology. Elsevier B.V. 469, 18-33.

Mcllroy, D. \& Logan, G. A. (1999). The impact of bioturbation on infaunal ecology and evolution during the Proterozoic-Cambrian transition. Palaios 14, 58-72.

Miller, M. F. \& Smail, S. E. (1997). A semiquantitative field method for evaluating bioturbation on bedding planes. Palaios 12, 391-396.

Miller, S. A. \& Gurley, W. F. E. (1896). New species of Paleozoic invertebrates 
from Illinois and other states. Illinois State Museum of Natural History, Bulletin, 11, 1-50.

Moraes, L. P. C. (2013). Paleobiologia da Formação Bocaina (Grupo Corumbá), Ediacarano, Mato Grosso do Sul. Universidade de São Paulo.

Narbonne, G. M., Saylor, B. Z. \& Grotzinger, J. P. (1997). The youngest Ediacaran fossils from Southern Africa. Journal of Paleontology 71, 953967.

Narbonne, G. M. \& Gehling, J. G. (2003). Life after snowball: The oldest complex Ediacaran fossils. Geology 31, 27.

Narbonne, G. M. (2004). Modular construction of early Ediacaran complex life forms. Science (New York, N.Y.) 305, 1141-1144.

Narbonne, G. M. (2005). The Ediacara biota: Neoproterozoic Origin of Animals and Their Ecosystems. Annual Review of Earth and Planetary Sciences 33, 421-442.

Noffke, N., Gerdes, G., Klenke, T. \& Krumbein, W. E. (2001). Microbially induced sedimentary structures - a new category within the classification of primary sedimentary structures. Journal of Sedimentary Research 71, 649-656.

Noffke, N., Gerdes, G., Klenke, T. \& W.E., K. (1995). Microbially induced sedimentary structures - Examples from modern sediments of siliciclastic tidal flats. Zentralblatt fuer Geologie und Palaeontologie 1/2, 307-316.

Noffke, N., Knoll, A. H. \& Grotzinger, J. P. (2002). Sedimentary Controls on the Formation and Preservation of Microbial Mats in Siliciclastic Deposits: A Case Study from the Upper Neoproterozoic Nama Group, Namibia. Palaios 17, 533-544.

Oliveira, R. S. (2010). Depósitos de rampa carbonática ediacarana do Grupo Corumbá, região de Corumba, Mato Grosso do Sul. Universidade Federal do Pará.

Pacheco, M. L. A. F. (2012). Reconstituição Morfológica e Análise sistemática de Corumbella werneri Hahn et al. 1982 (Formação Tamengo, Ediacarano, Grupo Corumbá) Mato grosso do Sul, Brasil: Implicações paleoecológicas e tafonômicas. Universidade de São Paulo.

Pacheco, M. L. A. F. et al. (2015). Insights into the skeletonization, lifestyle, and affinity of the unusual ediacaran fossil Corumbella. PLOS ONE 10, 1-19.

Pacheco, M. L. A. F., Leme, J. M. \& Machado, A. (2011). Taphonomic Analysis and Geometric Modelling for the Reconstitution of the Ediacaran Metazoan Corumbella werneri Hahn et al. 1982 (Tamengo Formation, Corumbá Basin, Brazil). Journal of Taphonomy 9, 269-283.

Parry, L., Bogianni P. C., Condon, D., Garwood, R., Leme, J. M., Mcllroy, D., Brasier, M.D., Trindade, R., Campanha, G. A. C., Pacheco, M. L. F, Diniz, C. Q. C., Liu, A. G. (submetido). Ichnological evidence for meiofaunal bilaterians from the terminal Ediacaran and earlist Cambrian of Brazil. 0136. 
Pflug, H.D. (1966). Neue Fossilreste aus den Nama-Schichten in SüdwestAfrika. Paläontologische Zeitschrift 40, 14-25.

Pykhova, N.G. (1973). Dokembriskie akritarhi Moskovskogo graben I Yuzhnogo. Obshchestva ispitateli prirody otdel geologicheskii novaya 48: 91-107.

Reviers, B. (2006). Biologia e Filogenia das algas. Porto Alegre: Artmed.

Ricker, R. W. (1987). Taxonomy and biogeography of Macquarie Island seaweeds. London: British Museum (Natural History).

Ritter, M. N. \& Erthal, F. (2016). Time-averaging e suas implicações para o registro fóssil marinho. Terrae Didatica 12, 81.

Rodrigues, S. C., Simões, M. G. \& Leme, J. M. (2003). Tafonomia comparada dos Connulatae (Cnidaria), Formação Ponta Grossa, Bacia do Paraná, Estado do Paraná. Revista Brasileira de Geociências 33, 1-10.

Rogov, V., Marusin, V., Bykova, N., Goy, Y., Nagovitsin, K., Kochnev, B., Karlova, G. \& Grazhdankin, D. (2012). The oldest evidence of bioturbation on Earth. Geology 40, 395-398.

Rogov, V., Marusin, V., Bykova, N., Goy, Y., Nagovitsin, K., Kochnev, B., Karlova, G. \& Grazhdankin, D. (2013). The oldest evidence of bioturbation on Earth: REPLY. Geology 41, e290-e290.

Seilacher, A. (1956). Der Beginn des Kambrium als biologische Wende. N. Jb. Geol. Palaont 103, 155-180.

Seilacher, A. (1989). Vendozoa: organic construction in the Proterozoic biosphere. Lethaia1 2, 229-239.

Seilacher, A. (1992). Vendobionta and Psammocorallia: lost constructions of Precambrian evolution. Journal of the Geological Society 149, 607-613.

Seilacher, A. (2007). Trace fossil analysis. Berlin, Heidelberg: Springer International Publishing.

Seilacher, A., Grazhdankin, D. \& Legouta, A. (2003). Ediacaran biota: The dawn of animal life in the shadow of giant protists. Paleontological Research 7, 4354.

Shepeleva, E. D. (1962). Plant? Fóssil of unknown taxonomic position from the deposits of the Bvlinskaya Series i the Volga-Urals oil province. Akedemy Nauk SSSR Doklady 142, 170 - 1.

Sour-tovar, F., Hagadorn, J. W. \& Huitrón-Rubio, T. (2007). Ediacaran and Cambrian index fossils from Sonora, Mexico. Palaeontology 50, 169-175.

Sprigg, R. C. (1947). Early Cambrian (?) Jellyfishes from the Flinders Ranges, South Australia. Transactions of The Royal Society of South Australia 71, 212-224.

Sprigg, R. C. (1949). Early Cambrian Jellyfishes of Ediacara, South Australia and Mount John, Kimberley District, Western Australia. Transactions of The Royal Society of South Australia 73, 72-99. 
Tobias, T. C. (2014). Micropaleontologia da formação Tamengo, Eco Parque Cacimba da saúde, Ediacarano, Grupo Corumbá, Estado de Mato Grosso do Sul, Brasil. Universidade de Brasília.

Townsend, C. R., Begon, M. \& Harper, J. L. (2008). Fundamentos em Ecologia. Blackwell Publishing [S I].

Trainor, F. R. (1978). Introductory Phycology. Nova Yorke: John Wiloy \& Sons.

Uchman, A. (2001). Eocene flysch trace fossils from the Hecho Group of the Pyrenees, northen Spain. Beringeria 28:3-41.

van Iten, H., Cox, R. S. \& Mapes, R. H. (1992). New data on the morphology of Sphenothallus Hall: implications for its affinities. Lethaia 25, 135-144.

Van iten, H., Leme, J. M., Pacheco, M. L. A. F., Simões, M. G., Fairchild, T. R., Rodrigues, F., Galante, D., Boggiani, P. C. \& Marques, A. C. (2016). Origin and Early diversification of Phylum Cnidaria: Key Macrofossils from the Ediacaran System of North and South America. In: Goffredo, S. \& Dubinsky, Z. (eds) The Cnidaria, Past, Present and Future. Cham: Springer International Publishing, 31-40.

Van Iten, H., Marques, A. C., Leme, J. M., Pacheco, M. L. A. F. \& Simões, M. G. (2014). Origin and early diversification of the phylum Cnidaria Verrill: Major developments in the analysis of the taxon's proterozoic-cambrian history. Palaeontology 57, 677-690.

Vidal, G. (1976b). Late Precambrian achritarcs from the Eleonore Bay Group and Tillite Group in East Greenland. A preliminary report. Grönlads Geol. Unders. Bull. 362, 53.

Waggoner, B. (2003). The Ediacaran Biotas in Space and Time. Integrative and Comparative Biology 43, 104-113.

Walde, D. H. G., Carmo, D. A., Guimarães, E. M., Vieira, L. C., Erdtmann, B. D., Sanchez, E. A. M., Adorno, R. R. \& Tobias, T. C. (2015). New aspects of Neoproterozoic-Cambrian transition in the Corumbá region (state of Mato Grosso do Sul, Brazil). Annales de Paléontologie. Elsevier Masson SAS 101, 213-224.

Walde, D. H. G., Erdtmann, B. D., Steiner, M., Weber, B., Carmo, D. \& Antonietto, L. (2016). Revision of the taphonomy of Corumbella werneri from the Tamengo Formation ( Corumbá-MS ). , 1.

Walker, K. R. \& Bambach, R. K. (1971). The significance of fossil assemblages from fine-grain sediments: time-averaged. Geological Society of America Abstracts with Programs 783-784.

Warren, L. V., Fairchild, T. R., Gaucher, C., Boggiani, P. C., Poiré, D. G., Anelli, L. E. \& Inchausti, J. C. G. (2011). Corumbella and in situ Cloudina in association with thrombolites in the Ediacaran Itapucumi Group, Paraguay. Terra Nova 23, 382-389.

Warren, L. V., Pacheco, M. L. A. F., Fairchild, T. R., Simões, M. G., Riccomini, C., Boggiani, P. C. \& Cáceres, A. A. (2012). The dawn of animal skeletogenesis: Ultrastructural analysis of the Ediacaran metazoan 
Corumbella werneri. Geology 40, 691-694.

Wu, M., Tong, J., Fu, X. \& Zhao, Y. (2010). Doushantuophyton Chen et Xiao (Algae) from Kaili Biota, Guizhou Province, China. Geological Journal of China Universities 16, 317-326.

Xiao, S. ., Yuan, X., Ssteiner, M. \& Knoll, A. H. (2002). MACROSCOPIC CARBONACEOUS COMPRESSIONS IN A TERMINAL PROTEROZOIC SHALE: A SYSTEMATIC REASSESSMENT OF THE MIAOHE BIOTA, SOUTH CHINA. Journal of Paleontology 76, 347-376.

Xiao, S. \& Knoll, A. H. (2007). Fossil preservation in the Neoproterozoic Doushantuo phosphorite Lagerstätte, South China. Lethaia 32, 219-238.

Xiao, S., Knoll, A. H. \& Yuan, X. (1998a). Morphological Reconstruction of Miaohephyton Bifurcatum a possible brown alga from the neoproterozoic doushantuo formation, South China. Journal of Paleontology 72, 1072-1086.

Xiao, S., Knoll, A. H., Yuan, X. \& Pueschel, C. M. (2004). Phosphatized multicellular algae in the Neoproterozoic Doushantuo Formation, China, and the early evolution of florideophyte red algae. American Journal of Botany 91, 214-227.

Xiao, S. \& Laflamme, M. (2009). On the eve of animal radiation: phylogeny, ecology and evolution of the Ediacara biota. Trends in Ecology \& Evolution 24, 31-40.

Xiao, S., Zhang, Y. \& Knoll, A. H. (1998b). Tree-dimensional preservation of algae and animal embryos in a Neoproterozoic phosporite. Nature 391, 553-558.

Yoon, H. S., Muller, K. M., Sheath, R. G., Ott, F. D. \& Bhattacharya, D. (2006). DEFINING THE MAJOR LINEAGES OF RED ALGAE (RHODOPHYTA)1. Journal of Phycology 42, 482-492.

Yuan, X., Chen, Z., Xiao, S. H., Wan, B., Guan, C. G., Wang, W., Zhou, C. M. \& Hua, H. (2013). The Lantian biota: A new window onto the origin and early evolution of multicellular organisms. Chinese Science Bulletin 58, 701-707.

Yuan, X., Chen, Z., Xiao, S., Zhou, C. \& Hua, H. (2011). An early Ediacaran assemblage of macroscopic and morphologically differentiated eukaryotes. Nature. Nature Publishing Group 470, 390-393.

Zaine, M. F. (1991). Análise dos Fósseis de parte da Faixa Paraguai (MS,MT) e seu contexto temporal e paleoambiental. Universidade de São Paulo.

Zaine, M. F. \& Fairchild, T. R. (1985). Comparison of Aulophycus lucianoi Beurlen \& Sommer from Ladário (MS) and the genus Cloudina Germs, Ediacaran Namibia. Anais academia Brasileira de Ciências 57, 130.

Zaine, M. F. \& Fairchild, T. R. (1987). Novas considerações sobre os fósseis da Formação Tamengo, Grupo corumbá, SW do Brasil. Congresso Brasileiro de Paleontologia 10. Rio de Janeiro: Anais, 797-806. 